\title{
Physicochemical and biochemical properties of the Keplerate-type nanocluster polyoxomolybdates as promising components for biomedical use
}

\author{
A. A. Ostroushko ${ }^{1}$, K. V. Grzhegorzhevskii ${ }^{1}$, S. Yu. Medvedeva $^{1,2}$, I. F. Gette ${ }^{2}$, \\ M. O. Tonkushina ${ }^{1}$, I. D. Gagarin ${ }^{1}$, I. G. Danilova ${ }^{1,2}$ \\ ${ }^{1}$ Ural Federal University named after the first President of Russia B. N. Yeltsin, \\ Ekaterinburg, Russia \\ ${ }^{2}$ Institute of Immunology and Physiology of the Ural Branch of the Russian Academy of Sciences, \\ Ekaterinburg, Russia \\ alexander.ostroushko@urfu.ru
}

DOI 10.17586/2220-8054-2021-12-1-81-112

\begin{abstract}
The paper discusses the results of a research on physicochemical and biochemical properties of the Keplerate-type molybdenum-based nanocluster polyoxometalates (POMs), which show promise in the field of biomedicine as a means of targeted drug delivery, including the transport to immune privileged organs. POMs can be considered as components of releasing systems, including the long-acting ones with feedback (for controlling the drug active component release rate). POMs are promising drugs for the treatment of anemia. Also, the paper deals with the results of studies of POM effect on living systems at the molecular and cellular levels, at that of individual organs, and on the organism as a whole. The mechanism and kinetics of POM destruction and possibilities of stabilization, the oscillatory phenomena manifestation, the formation of POM conjugates with bioactive substances which can be released during the destruction of POM, with polymer components, and with indicator fluorescent dyes, as well as forecasts for further research, are considered.
\end{abstract}

Keywords: Keplerate-type nanocluster polyoxomolybdates, physicochemical and biochemical properties, impact on living systems, means of targeted delivery, releasing systems, prolonged action.

Received: 27 March 2020

Revised: 14 July 2020, 19 January 2021

\section{Contents}

1. Introduction

1.1. Nanoscale components of targeted drug delivery systems.

1.2. Nanocluster polyoxometalates (POMs).

2. Investigation of the effect of Keplerate-type POMs on living systems at the level of the organism, of individual organs, and at the molecular-cellular level.

2.1. Study of POMs accumulation characteristics and toxicity.

2.2. POMs impact at the cellular-molecular level.

3. Association of POMs with bioactive substances and polymers.

4. POMs destruction processes and their stabilization.

5. Prospects for the creation of POM-based releasing systems with feedback.

6. Conclusion

References

\section{Introduction}

\subsection{Nanoscale components of targeted drug delivery systems}

The targeted delivery of drugs can employ nanostructured systems that differ in terms of the nature of components and design, to which, for instance, liposomal systems belong [1-13]. Some natural aspects can impede the use of liposomal agents. These aspects include the active capturing of liposomes by macrophages, which results in the limited possibility of drug delivery to some organs and tissues. The capturing also significantly reduces the time of drugs circulation in the organism, thus leading to the liposome membrane degradation under the influence of lipoproteins. In addition, the manufacturing of liposomal products employs rather sophisticated technologies. Various inorganic nanoscale objects are considered as components of targeted drug delivery systems; these include metal, oxide or complex oxide objects, and some other types of nanoparticles [14-25], as well as carbon clusters (fullerenes, nanotubes, graphene, and nanodiamonds) [26-59]. These objects can be used, for instance, as shells or cores of nanocapsules, providing the release of drugs, for example, under local electromagnetic influence. They can play the 
role of carriers of bioactive substances in surface functionalization [44-46, 48, 49, 51-56], or when the porous structure of nanoparticles and clusters is used, including non-magnetic and magnetic systems for delivery, therapy [57-83] and diagnostics [60-68]. The use of carbon clusters and inorganic nanoparticles is associated with the problem of removing such materials from the body after they have performed their function, in order to reduce the xenobiotics load.

Nanocluster polyoxometalates (POMs) can be produced and characterized in terms of composition and structure using fairly simple and proven techniques. Representatives of this class of compounds, in particular molybdenumcontaining ones, do not pose a danger to a living organism and are practically non-toxic. They do not accumulate in the body for long, because, for instance, they are capable of gradual decomposition into decay products, which are assimilated as microelements and further evacuated in the course of natural metabolism. For these reasons, POMs are considered as promising materials for targeted delivery of drugs, of long-acting therapeutic agents, including those with feedback for controlling the drug release rate. Also, the advantages of POMs include their solubility in aqueous media and the charge of polyanions, which provides the possibility of iontophoretic delivery. The present review briefly discusses the biochemical properties of the most promising POMs, their ability to associate with biologically active substances, as well as issues related to the processes of POM destruction and stabilization as a key aspects in terms of biomedical application.

\subsection{Nanocluster polyoxometalates (POMs)}

Variously composed and structured POMs, which include both hetero- and isopoly compounds, have found a wide application as catalytic systems, components of hybrid structures, supramolecular assemblies, etc. [84-87]. New types of molybdenum-containing nanocluster polyoxometalates with toroidal [88-91] and fullerene-like structures (Keplerates) containing subnanometer-sized windows and pores [92,93] (Fig. 1) became known at the turn of the past and present centuries due to studies carried out at the Bielefeld University (Bielefeld, Germany) under the guidance of Prof. A. Müller, whose laboratory synthesized these compounds and confirmed their structure. In comparison with other nanosized particles, such water-soluble clusters have a high ionic charge and are capable of gradual degradation. The discovery of such POMs was, apparently, one of those cases, which are far from rare in the history of science, when such POMs had been most likely obtained in earlier experiments, but the researchers were unaware of their unique structure, which was later deciphered and purposefully reproduced. The POM structure was primarily characterized by single crystal X-ray structure analysis. The everyday scientific practice employs for this purpose reliable and more rapid spectroscopic methods (e.g., IR, Raman, NMR spectroscopy) [94]. The obtaining of giant POM clusters was also confirmed by mass spectrometry (MALDI method) [95]. Among the merits of Prof. Müller's group is the creation of fairly simple and reproducible methods for obtaining POM [93] with a specified structure and composition. In addition to the above-mentioned, basket-like molybdenum-containing POMs [96], with a structure derived from Keplerates, as well as giant clusters named by their creators "nano hedgehog", "blue lemon" [97,98] were also obtained.

The structure of these POMs is based on such structural blocks (coordination oxygen polyhedra surrounding multicharged metal cations) such as octahedra, pentagonal bipyramids, which are connected to each other by vertices or edges. In particular, $\mathrm{Mo}_{2}$ dimolybdenum bridges, $\mathrm{Mo}_{6}$ and $\mathrm{Mo}_{11}$ blocks should be attributed to basic structural elements. The symmetry of the latter $\left(\mathrm{C}_{5}\right.$ or $\mathrm{C}_{s}$ point group) determines the shape of the resulting nanocluster (Keplerate or toroid, respectively). The structure of a POM is stabilized, as a rule, by the organic or inorganic acid residues and water molecules. POMs contain a significant number of molecules of both constitutional and intracluster water. The latter also occupy the internal cavity of Keplerates in the normal state and can exchange with molecules of other substances through the pores. POM synthesis proceeds in the self-assembly mode under conditions of a specified medium acidity and in the presence of a reducing agent, since, for instance, the basic structure of $\mathrm{Mo}_{132}$ Keplerate (Fig. 1) includes both hexavalent molybdenum and $\mathrm{Mo}(\mathrm{V})$ :

$\left(\mathrm{NH}_{4}\right)_{42}\left[\mathrm{Mo}_{72}^{V I} \mathrm{Mo}_{60}^{V} \mathrm{O}_{372} \cdot\left(\mathrm{CH}_{3} \mathrm{COO}\right)_{30}\left(\mathrm{H}_{2} \mathrm{O}\right)_{72}\right] \cdot 300 \mathrm{H}_{2} \mathrm{O} \cdot\left(\sim 10 \mathrm{CH}_{3} \mathrm{COONH}_{4}\right)$.

There is a possibility to use the basic structure of a POM and substitute ions in it. For instance, the isostructural substitution of $\mathrm{Mo}(\mathrm{V})$ with ferric ions leads to the formation of a $\mathrm{Mo}_{72} \mathrm{Fe}_{30}$ Keplerate [99] (Fig. 2):

$\left[\mathrm{Mo}_{72} \mathrm{Fe}_{30} \mathrm{O}_{252}\left(\mathrm{CH}_{3} \mathrm{COO}\right)_{12}\left\{\mathrm{Mo}_{2} \mathrm{O}_{7}\left(\mathrm{H}_{2} \mathrm{O}\right)\right\}_{2}\left\{\mathrm{H}_{2} \mathrm{Mo}_{2} \mathrm{O}_{8}\left(\mathrm{H}_{2} \mathrm{O}\right)\right\}\left(\mathrm{H}_{2} \mathrm{O}\right)_{91}\right] \sim 150 \mathrm{H}_{2} \mathrm{O}$.

The POMs isolated from the concentrated stock solution are mainly crystalline substances, which may include a fraction of the material in an amorphous state [94]. Upon subsequent dissolution in water, POMs dissociate into Keplerate polyanions and cations (ammonium, sodium and potassium), or do it as a weak acid $\left(\mathrm{Mo}_{72} \mathrm{Fe}_{30}\right)$. The crystallographic size of a $\mathrm{Mo}_{132}$ ion is $2.9 \mathrm{~nm}\left(\mathrm{Mo}_{72} \mathrm{Fe}_{30}\right.$ is $\left.2.5 \mathrm{~nm}\right)$, while the hydrated $\mathrm{Mo}_{132}$ ion in a solution has a size of $3.2 \mathrm{~nm}$. The charge of polyanions depends on the acidity and environment, and can reach -42 and $-22[93,100]$ for $\mathrm{Mo}_{132}$ and $\mathrm{Mo}_{72} \mathrm{Fe}_{30}$, respectively.

The POMs capable, in principle, of changing the energy state of molecules included in their cavity, are considered promising catalytic materials in reactions of fine organic synthesis, membrane technologies, and sensorics [101-113]. 


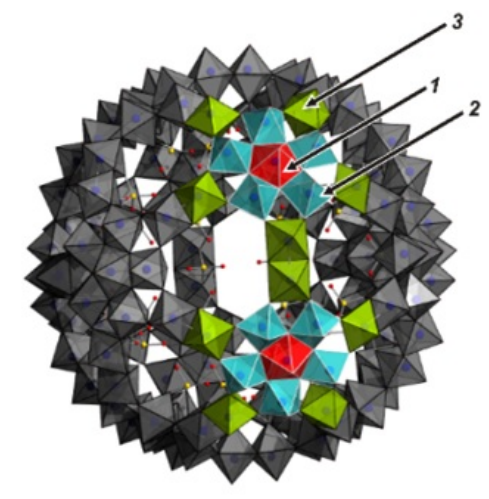

FIG. 1. Structure of $\mathrm{Mo}_{132}$ polyoxometalate. The red polyhedron (No. 1) marks the pentagonal $\mathrm{MoO}_{7}$ bipyramid, linked by common edges with five $\mathrm{MoO}_{6}$ octahedra (blue, No. 2) - this is the so-called $\mathrm{Mo}_{6}$ structural unit; Highlighted in green (No. 3) are $\mathrm{Mo}^{V} \mathrm{O}_{6}$ polyhedra, which are part of $\mathrm{Mo}_{2}$ dimolybdenum bridges

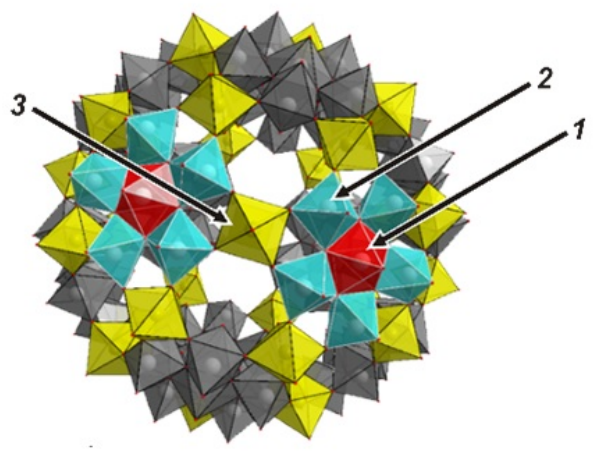

FIG. 2. Structure of $\mathrm{Mo}_{72} \mathrm{Fe}_{30}$ polyoxometalate. Iron-coordinated oxygen polyhedra are marked in yellow (No. 1 is $\mathrm{MoO}_{7} ; 2$ is $\mathrm{MoO}_{6} ; 3$ is $\mathrm{FeO}_{6}$ )

At the same time, such compounds are also of interest for the biomedical industry (Scheme 1). On the one hand, they can be interesting as individual drugs, because molybdenum and iron are widely known to be used in vitamin and mineral supplements as microelements involved in a number of enzymatic processes of importance for the organism [114]. In addition, it was shown that simpler molybdenum-containing POMs can be used in chemotherapy [115, 116]. On the other hand, the initially predicted possibility of the formation of POM conjugates with bioactive substances, drugs, and metal cations using intra- and extrasphere interactions, the possibility of their transport (including iontophoretic) in the body, adds relevance to the studies of POM in the field of targeted drug delivery and diagnostics [117-131]. These prospects may relate, inter alia, to immunomodulatory and antiviral agents. Important aspects of iontophoretic transport include the potential ability to deliver drugs to lesion areas and body tissues with low degree of vascularization. The very first experimental results showed that these ideas are promising. The low toxicity of Keplerate POMs for the warm-blooded animals, in particular of the iron-containing compounds, has been established on the basis of a set of data [132-137]. When studying the acute and subacute effects of $\mathrm{Mo}_{72} \mathrm{Fe}_{30}$ on rats, no significant negative changes in internal organs were revealed. The animal organism is able to adapt to the action of the named POM, which is confirmed by the absence of a pronounced autoimmune reaction of lymphocytes to hepatocytes during the intramuscular administration of a $\mathrm{Mo}_{72} \mathrm{Fe}_{30}$ preparation in the form of an aqueous solution. There is no long-term and substantial accumulation of POMs and their components in the body (various organs and tissues), as they are excreted by metabolism. This occurs, inter alia, due to the POM degradation into simpler components [106, 137]. The issues of POM toxicity are discussed in more detail below. At the same time, in the case of iontophoretic administration, it is possible to create a temporary $\mathrm{Mo}_{72} \mathrm{Fe}_{30}$ depot localized, for example, in the skin and partly in the subcutaneous fatty tissue, which ensures a prolonged action of POM and its conjugates. In general, the present review is devoted to the 
consideration of specific properties and behavior of POMs, as well as to generalization of the results obtained by its authors.

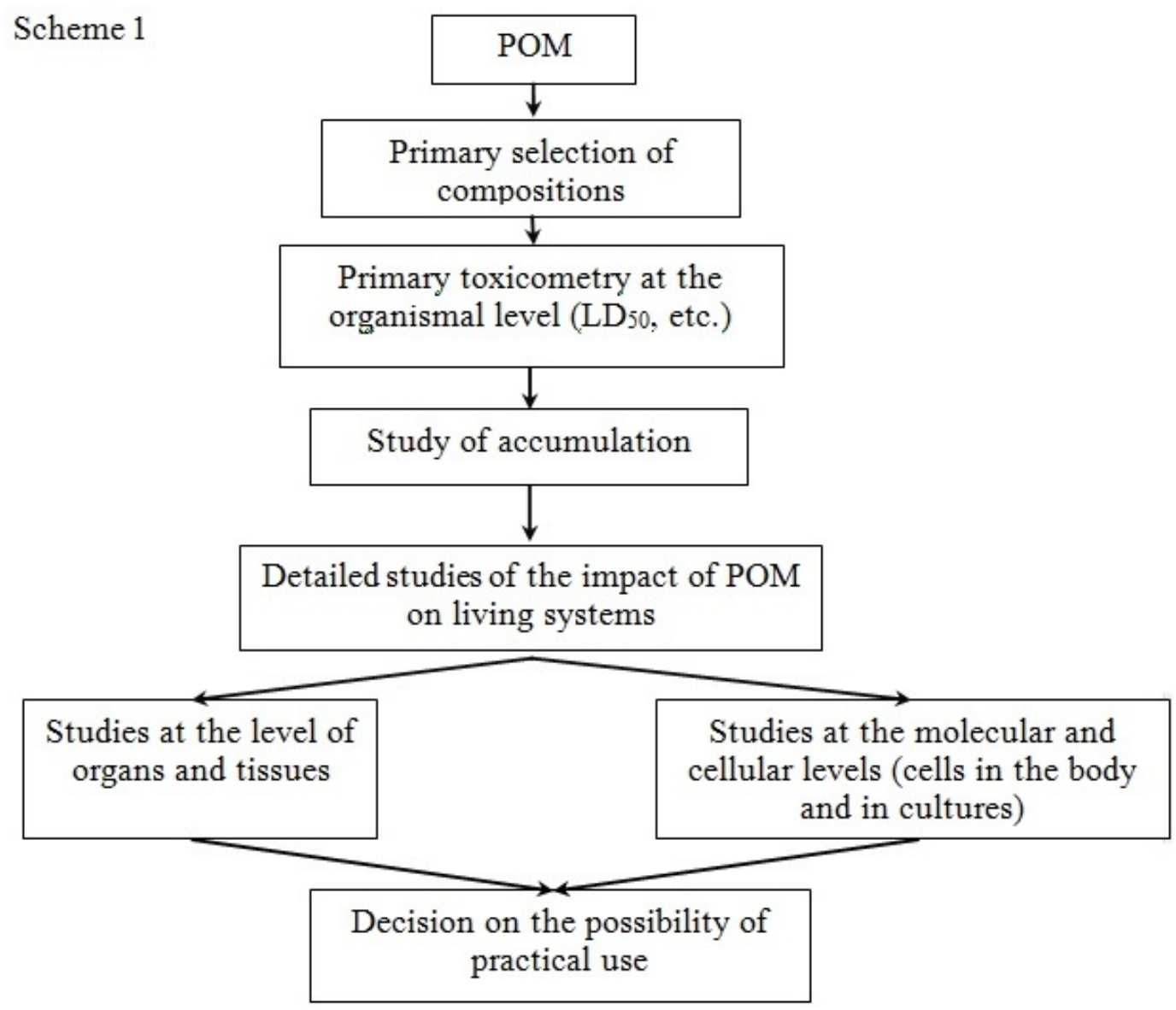

\section{Investigation of the effect of Keplerate-type POMs on living systems at the level of the organism, of individual organs, and at the molecular-cellular level}

\subsection{Study of POMs accumulation characteristics and toxicity}

The chosen and studied ${ }^{1} \mathrm{POMs} \mathrm{Mo}_{132}$ and $\mathrm{Mo}_{72} \mathrm{Fe}_{30}$ exhibited both similar and different behavior due to their different composition. While the first of them contains $\mathrm{Mo}(\mathrm{V})$ in addition to $\mathrm{Mo}(\mathrm{VI})$, the second one includes both molybdenum and iron in the highest oxidation states, which makes it promising in terms of low toxicity (no lethality found in animals). The accumulation of $\mathrm{Mo}_{132}$ [136] was studied by injecting it into the gastrocnemius muscle of rats at a concentration of $1.5 \cdot 10^{-4} \mathrm{~mol} / \mathrm{L}$ daily for a month. A single dose of POM amounting to $0.15 \mathrm{mg} / 100 \mathrm{~g}$ of the body weight, corresponded to the upper limit of the normal daily intake of molybdenum and to the supposed therapeutic dose. Intact animals served as the control. The absence of the drug and its components accumulation in the liver and bones was established. A sharp decrease in the content of molybdenum in the kidneys was found, the cause of which is, apparently, the excretion of the excessive amount of this element via the urinary tract. Experiments with the $\mathrm{Mo}_{72} \mathrm{Fe}_{30}$ polyoxometalate $[132,133,137]$ administered at the same dosage, made it possible to establish for this POM the absence of accumulation of molybdenum in the liver, kidneys, bones, and skin of animals, including its hairy part and subcutaneous fatty tissue, since the average values of molybdenum content in the experimental samples after the termination of the procedures did not differ significantly from those in the intact animals.

\footnotetext{
${ }^{1}$ The results of studies of the effect of Keplerate POMs on the animal subject, in particular, the data on transport, accumulation characteristics and toxicity were obtained on outbred rats of both sexes, weighing 200-230 g, kept on the usual diet of the vivarium. The keeping conditions and handling of the animals used in the experiment were in accordance with the principles formulated in Directive 2010/63/EU of the European Parliament and of the European Council of 22 September 2010 on the protection of animals used for scientific purposes (Official Journal of the European Union, 2010). European Parliament, Council, Directive 2010/63/EU of the European Parliament and of the Council of 22 September 2010 on the Protection of Animals Used for Scientific Purposes. Off. J. Eur. Union., 2010, 53, P. 33-79. doi:10.3000/17252555.L_2010.276.eng.
} 
The histological analysis [132,137] of animal organs [138] and the results of hematologic studies [134] indicated a relatively higher toxicity of $\mathrm{Mo}_{132}$ as compared to $\mathrm{Mo}_{72} \mathrm{Fe}_{30}$. Signs of hepatocyte damage were observed for $\mathrm{Mo}_{132}$. However, the characteristic signs of intensified liver regeneration processes were obviously observed. The histologic analysis of kidney sections from the experimental group of animals after administration of $\mathrm{Mo}_{72} \mathrm{Fe}_{30}$ showed that the structural changes in the organ were minimal. It should be stressed that a weaker toxic effect of iron-molybdenum POMs [133, 139] was confirmed by the analysis of such biochemical parameters [140] characterizing the state of various organs, as aspartate aminotransferase (AST), alanine aminotransferase (ALT), alkaline phosphatase, alpha amylase, urea, and the total protein.

An analysis of peripheral blood parameters $[138,140]$ of animals allowed one to draw the conclusion that there was no anemia [141] in the group of animals that got $\mathrm{Mo}_{132}$ injections, since no significant difference was found in the number of erythrocytes, concentration of hemoglobin, the content and concentration of hemoglobin in erythrocytes in the experimental and intact rats. The total leukocytes in animals that got $\mathbf{M o}_{132}$ injections also did not increase, which indicates the absence of a systemic inflammatory process. The total leukocytes did not significantly increase in the animals within 30 days after $\mathrm{Mo}_{72} \mathrm{Fe}_{30}$ injections, and the leukocyte formula remained almost unchanged, which indicates the absence of inflammation at the organismal level.

An analysis of red blood parameters in rats injected with $\mathrm{Mo}_{72} \mathrm{Fe}_{30}$ yielded a conclusion that there was no anemia - a sign characteristic of many chronic intoxications, since the content of hemoglobin in erythrocytes of experimental rats did not decrease, but increased, on the contrary [108, 139, 142]. Moreover, the experimentally revealed effect of rapid recovery of the hemoglobin level in animals after modeling the post-hemorrhagic anemia [141] is interesting from the point of view of the possible use of POMs in treatment and prevention of iron deficiency anemia, which is confirmed by a patent [142]. The presence of molybdenum in the preparation does not prevent an increase in its effectiveness; besides, molybdenum is effectively removed from the body. Given its lower toxicity, $\mathrm{Mo}_{72} \mathrm{Fe}_{30}$ was subjected to additional studies, in particular, of acute and subacute toxicity [133]. In order to further study the pathways of possible toxic action of POM [133], three methods of Keplerate administration were chosen, that is, the intramuscular, intraperitoneal, and intragastric. The intragastric (1 day) method of administration allowed a significant increase in the POM dose by using not only a POM solution, as in other methods, but also a suspension (concentration of $60 \mathrm{mg} / \mathrm{ml}$ ). The introduction of the maximum possible dose of POM by the intragastric method was not accompanied by lethality, therefore, the conclusion about low toxicity of the tested compound was confirmed, especially since the amount of POM was 200 times higher than the estimated therapeutic dose of $0.15 \mathrm{mg} / 100 \mathrm{~g}$.

The blood plasma of rats in all experimental groups [133] showed no increase in the activity of alkaline phosphatase, which is one of the indicators of cholestasis(impaired bile secretion). This fact indicated that the bileproducing function of hepatocytes was preserved after both short and long-term administration of POM. Alkaline phosphatase is also a specific enzyme of osteoblasts, it is involved in mineralization, and the activity of this enzyme is an indicator of changes in the rate of mineral components remodeling in the bone tissue. Molybdates are known of being able to be capable of reducing the activity of phosphatases, probably through the interaction of molybdenum with the cysteine thiol groups and histidine imidazole groups located in the active sites of enzymes [138, 140]. The groups of animals with single intramuscular, intraperitoneal, and intragastric administration of $\mathrm{Mo}_{72} \mathrm{Fe}_{30}$ have shown a relatively small (within 20-25\%), but significant decrease in alkaline phosphatase activity [133], possibly due to the inhibitory effect of molybdenum. Just a short-term, 1 day-long, decrease in the activity of alkaline phosphatase eliminates the risk of osteoporosis development after a single administration of Keplerates.

When comparing the average values of other indicators in groups of animals with acute administration of POM (alpha-amylase activity, total protein and creatinine content in blood plasma), no significant differences with those of intact rats were found, which evidences the absence of pronounced changes in the kidneys, liver, and pancreas of animals in these groups [133]. The group with subacute POM administration showed no significant deviations of all the studied biochemical indicators from the norm, which suggested the absence of cytolysis and damage to the liver, kidneys, myocardium, pancreas, and bone tissue after a long (30 days) daily POM administration.

It is important to note that after POM administration by all the studied methods, a significant increase in the content of molybdenum in the blood was recorded [133] after a single POM load. The amount of molybdenum found in the blood 1 day after the administration of Keplerate POMs was proportional to the amount of the injected nanomaterial. A significant decrease in the level of molybdenum in the blood after 1 day compared to the content of the microelement one hour after intramuscular injection, as well as the normalization of the indicator after daily injections of POM within 30 days, was consistent with previously obtained data on the absence of molybdenum accumulation [132, 137, 141]. The absence of molybdenum accumulation [133] in the liver, kidneys, skin, and bone tissue [138] is probably associated with the decomposition and accelerated excretion of the elements constituting POM, which contributes to the normalization of the studied parameters (glucose, aminotransferase, and alkaline phosphatase values) [138] by day 30, a change of which was recorded upon a single injection of POM. 


\subsection{POMs impact at the cellular-molecular level}

Further investigations of $\mathrm{Mo}_{72} \mathrm{Fe}_{30}$ were aimed at studying its effect at the cellular and molecular level, since the use of $\mathrm{Mo}_{72} \mathrm{Fe}_{30}$ as a means of targeted delivery requires knowledge of potential risks and side effects that manifest themselves not only at the macrolevel (in organs and tissues) [138, 140]. For instance, the effect of POM on the content of histone and heat shock proteins in the blood and liver of rats was investigated upon intramuscular injection of this compound into the body [143], since the changes, undetectable by means of assessing traditional indicators, can be identified using other methods. One of the possible mechanisms of the damaging effect of nanoparticles at the molecular level can be their effect on the tertiary structure of proteins. It may be accompanied by immune reactions towards denatured proteins that acquire the properties of antigens alien to the body, by increased proteolysis, apoptosis, necrosis, inflammation, and membrane permeability $[144,145]$. Fractions of histone proteins and heat-shock proteins are informative indicators of changes in cells at an early stage of nanoparticles influence before the appearance of the "macrotoxicity" signs. The synthesis of inflammatory factors by lymphocytes depends on the modifications and the amount of histone proteins, the release of which from DNA is essential for the expression of proinflammatory factor genes [146-148]. The disruption of the structure of various body proteins is counteracted by heat shock proteins (Hsp), a class of conservative proteins, whose expression increases with the increasing temperature, the action of toxic substances [150], or under other conditions stressing the cell [149]. Heat shock proteins can act as chaperones, restoring native conformation in other proteins. They can enhance proteolysis, reduce apoptosis, and participate in the transport of other proteins and gene expression [149-152]. The liver is the main organ of detoxication, it is saturated with a large number of specific cells presenting antigens, and it normally deposits iron. Therefore, this organ was chosen as the object of experimental research. The action of most toxicants leads to liver infiltration by lymphocytes coming from the blood. The toxic effect of $\mathrm{Mo}_{72} \mathrm{Fe}_{30}$ in cases of single and repeated administration at the cellular, subcellular and organismal levels was studied as regards the content of histone proteins, heat shock proteins and cytolytic enzymes. The experiment showed no expression of heat shock proteins Hsp70 in the liver cells of intact animals [153], and the expression of Hsp60 was detected on average in about $30 \pm 7$ cells per unit area. When determining the content of histone proteins in blood lymphocytes [143], during all periods of POM load, no significant changes were found in the fractions of histone proteins, which, according to the literature, regulate the expression of genes of proinflammatory factors $[148,154]$. A study of heat shock proteins [143] has detected no Hsp70 in the liver in the groups of both intact and control animals, while Hsp60 were recorded. It indicated the inducible nature of Hsp70 and the constitutive of Hsp60. The normalization of biochemical parameters (characterizing the state of the liver) within 30 days of POM administration [132,143], gives evidence for the activation of defense systems in the organism. Heat shock proteins restore the native conformation of denatured proteins, which can also segregate proteases, and new proteins are synthesized instead of the segregated ones.

Thus, the single and multiple administration of iron-molybdenum POMs manifested itself at the molecular level only in changes in the content of heat shock proteins [143] involved in the adaptation and maintenance of homeostasis. The studies carried out by a number of authors yielded a suggestion that the absence of an increase in heat shock proteins in response to the action of a stress factor is a violation of adaptation [155, 156]. The action of POM (single and multiple) did not cause a decrease in the amount of histone proteins in blood lymphocytes, which allows an assumption about the absence of autoimmune aggression of these cells against liver tissue. An increase in the amount of Hsp60 and Hsp70 heat shock proteins in rat liver after single and multiple administration of POM can be considered as a way of adaptation, which is confirmed by a study of indicators of cytolysis and synthetic liver function [157, 158].

The content of heat shock proteins in the thymus and spleen was also studied, and it was shown that POM administration is accompanied by an increase in the number of cells containing Hsp60 and Hsp70 heat shock proteins in both organs [108, 132, 159]. The increased expression of heat shock proteins in the thymus [160], despite the presence of a hematothymic barrier, gives reasons to suppose the ability of POM to overcome the histo-hematic barriers of immune privileged organs [161]. Taking into account the results of the ongoing studies [161], it has been shown that POM can also exert a similar effect on other organs with special histo-hematic barriers, in particular, hematoencephalic, hematoophthalmic, hemato-testicular, etc. According to the results of histological studies, the effect of POM on immune privileged organs did not lead to a change in their morphology and structure. There are prospects concerning the transport of medicinal substances with the help of POM across the histo-hematic barriers.

In the course of further investigation of the action of POMs at the cellular level, the effect of $\mathrm{Mo}_{72} \mathrm{Fe}_{30}$ and $\mathrm{Mo}_{132}$ on normal and transformed fibroblasts was assessed [162]. The effect of polyoxometalates on cell survival in culture and their cytotoxic action have been studied [163]. Human dermal fibroblasts (HDF) are more resistant to $\mathrm{Mo}_{72} \mathrm{Fe}_{30}$. On the contrary, $\mathrm{Mo}_{132}$ causes extensive destruction of the membrane organelles of dermal fibroblasts in the first hours after exposure. Thus, it can be concluded that $\mathrm{Mo}_{72} \mathrm{Fe}_{30}$ is not toxic for normal fibroblasts (it causes only weak changes in cells), while $\mathrm{Mo}_{132}$ is toxic for both normal and transformed fibroblasts, and its damaging effect 
is more pronounced on transformed fibroblasts. A decrease in the proliferative activity of cells (cell multiplication by division) was recorded. An assessment of the nanocluster toxicity using the MTT test demonstrated a change in the mitochondrial activity after the impact of $\mathrm{Mo}_{132}$. Probably, this type of nanocluster inhibits cellular respiration and causes disruption of energy metabolism in cells. According to the obtained data, the effect of polyoxometalates on cells is selective. The transformed cells accumulated inorganic elements included in the composition of $\mathrm{Mo}_{72} \mathrm{Fe}_{30}$ polyoxometalate (e.g., molybdenum) more intensively than of $\mathrm{Mo}_{132}$. At the same time, iron and molybdenum were absorbed from simpler compounds (iron and molybdenum salts) in smaller amounts, which confirms the selectivity of the action. For instance, 24 hours after the exposure to $\mathrm{Mo}_{72} \mathrm{Fe}_{30}$, the number of transformed cells decreased, and cells with an uncontoured cell membrane (indicated by an arrow in Fig. 3) and an increased number of microvilli appeared. This increases the membrane surface, as was recorded by means of optical, electron, and scanning probe microscopy (a comparison of images obtained by different methods is of interest), and can lead, in turn, to an additional increase in its ability to interact with drugs. The obtained results confirm the prospects for the application of POMs in the field of biomedicine, including the use of $\mathrm{Mo}_{132}$ in oncological practice [163].
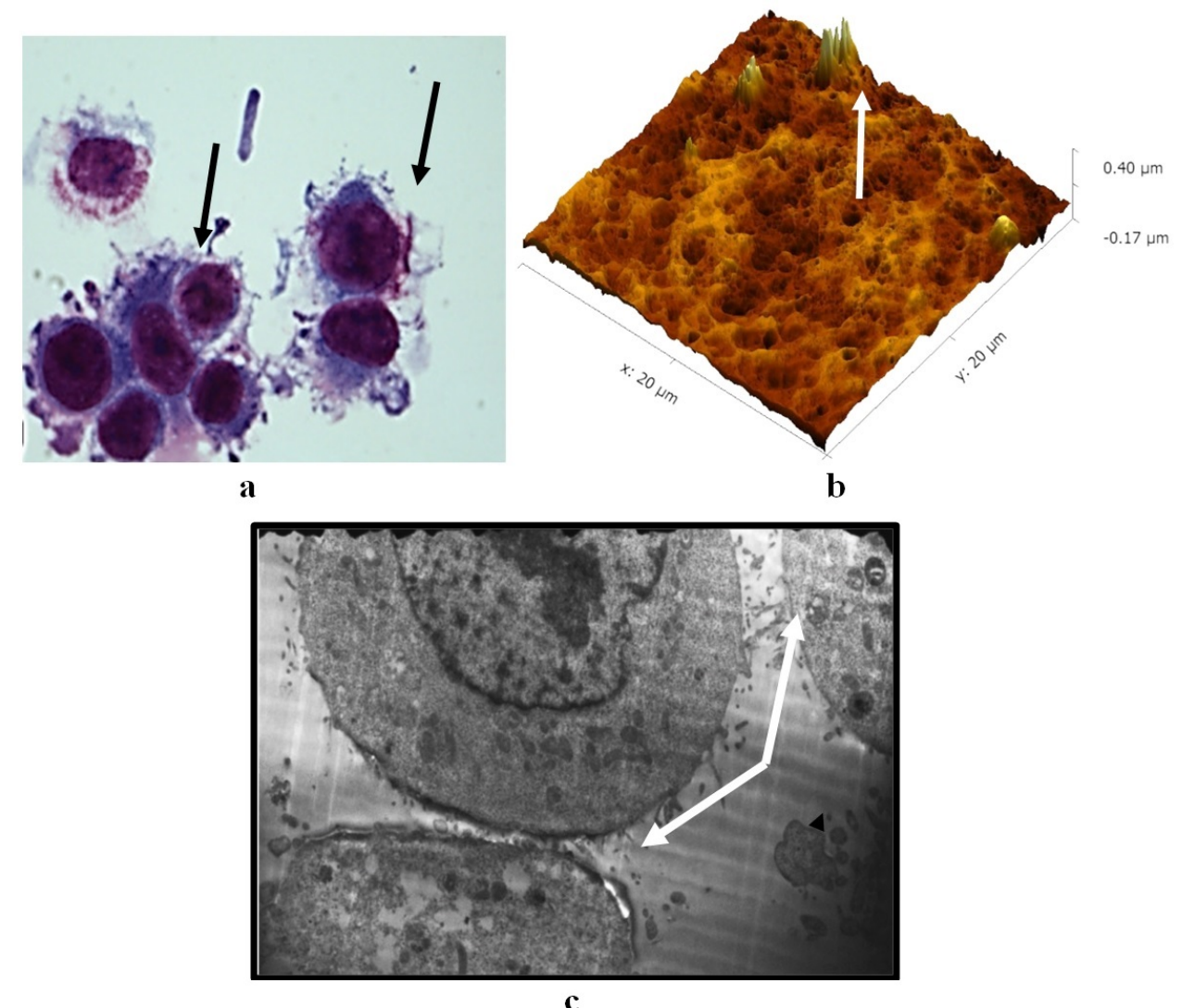

FIG. 3. Transformed fibroblasts after exposure to $\mathrm{Mo}_{72} \mathrm{Fe}_{30}$ POM: a - optical microscopy $(\times 1000$ magnification); $b-$ atomic force microscopy; $c-$ scanning electron microscopy $(\times 15550$ magnification) (equipment of the Ural Center of Shared Use "Modern Nanotechnologies" of the Ural Federal University). The increase in the number of microvilli is indicated by arrows

\section{Association of POMs with bioactive substances and polymers}

Polyoxometalates that have been selected in the course of research (Scheme 1) as having characteristics that make their practical use in biomedicine promising, are studied for the compliance of their properties to requirements to the materials for targeted drug delivery systems (Scheme 2).

The Keplerate-type POMs and alike, being hydrophilic particles, are able to associate (form conjugates) in their external sphere with diverse substances, which include surfactants (SAs) of various nature [164-171], dyes, photosensitizers [109, 110,172-174], and polymers [174-179], mainly water-soluble ones. POMs functionalization makes it possible to selectively influence their hydrophilic and hydrophobic properties [110], create catalytic and photocatalytic 


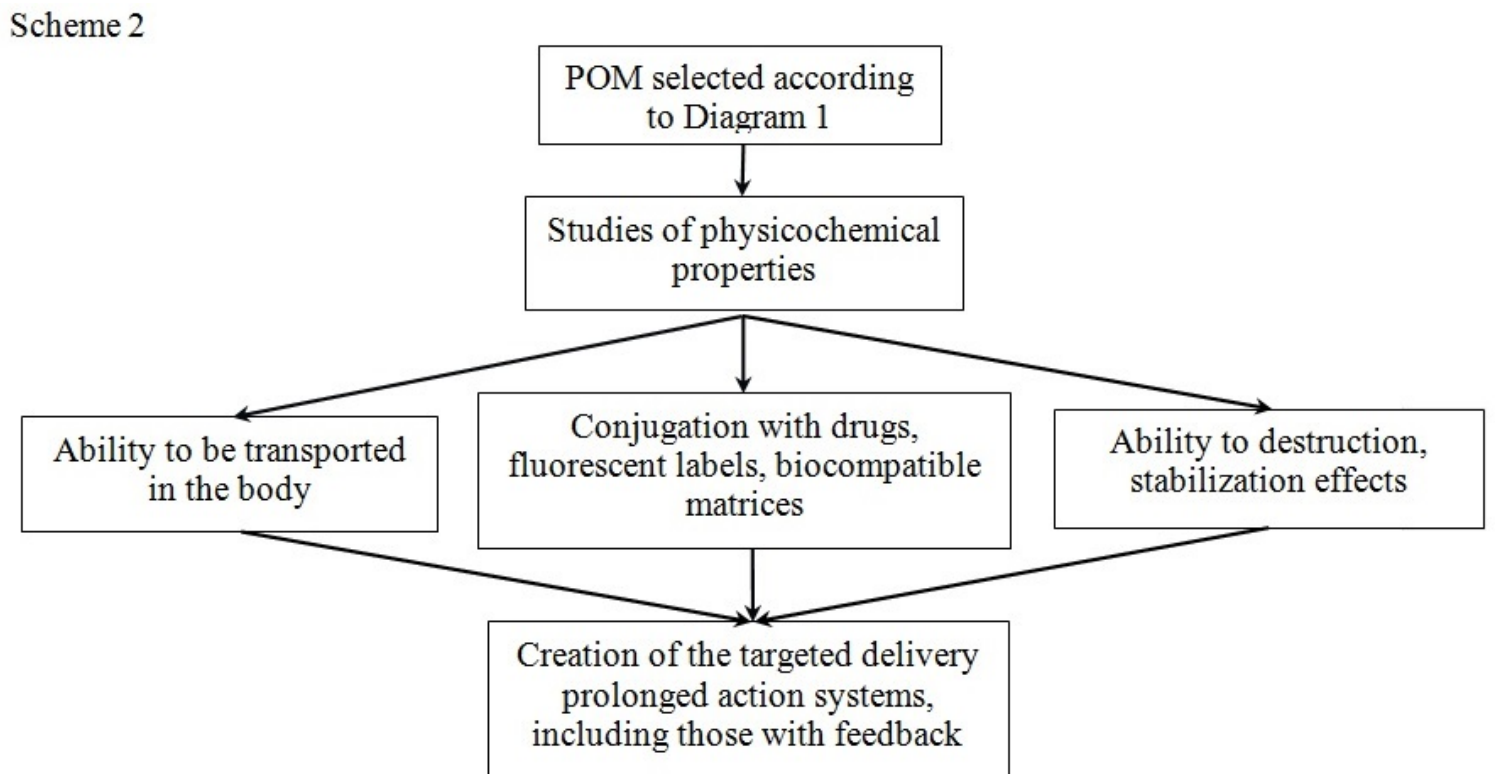

systems with adjustable characteristics, as well as compositions for targeted delivery in biomedicine, controlled by an electric [179] or magnetic field [180,181]. The hydrophobized POMs acquire an ability to more actively interact with molecules of nonpolar substances and adsorb them [110]. There appears a possibility of formation of ionic associates based on POM and cations of metals (alkaline earths, rare earths, transition metals, including luminescent labels and magnetic resonance imaging (MRI) tags [19,121-123]), and of cationic surfactants. Weaker, e.g., hydrogen, bonds also actively participate in the interaction of organic compounds with POMs [182]. The formation of POM associates with water-soluble nonionic polymers [174-179, 183-185], including the biocompatible ones, makes it possible to create protective shells on the POM surface, similar to polyethylene glycol (PEG) layers, or to diblock copolymers on nanocapsules [186-194]. In a number of cases, the energy factor (interaction enthalpy) contributes to the formation of these associates. For instance, the enthalpy of POM and polymer interaction is negative over the entire concentration range of the components in the $\mathrm{Mo}_{72} \mathrm{Fe}_{30}$ - polyvinylpyrrolidone (PVP) system [177]. Similar local concentration regions were found for the systems containing polyethylene glycol (PEG) and polyvinyl alcohol (PVA) [183]. In some of the studied systems, the formation of associates is facilitated by the entropy factor [183].

As is noted above, the use of ionic associates of POMs with rare earths as components of diagnostic systems in biomedicine has been proposed $[19,121-123,195,196]$. In such associates, POM recharging occurs, so the resulting complex can be positively charged [197], unlike the initial POM, and be transferred in an electric field by iontophoresis to the cathode instead of the anode. The structure of a POM is retained in associates [197], which was shown by IR and Raman spectroscopy. A number of drugs, including antibiotics, form bioactive anions in solutions, the association of which directly with POM is prevented by the Coulomb repulsion. The competitive interaction of drug cations with the existing complexing anions also complicates the formation of the cation-POM complexes [197]. On the other hand, there is a way to obtain transportable associates of anionic bioactive substances with POM, for example, through the bridging calcium cations $[119,198]$. The discovered POM stabilization in associates with calcium will be discussed below. It is important to note the ability of the Keplerate and compositionally similar toroidal [88-91,110] POMs to self-association in solutions, i.e., to self-assembly into hollow single-walled globules (Fig. 4) [91,199], the diameter of which can vary from tens to hundreds of nanometers, depending on concentration, acidity, and dielectric permittivity of the medium [199]. These formations can also be considered as transport units for the targeted delivery of medicinal substances, and the formation of associates, e.g., with surfactants, makes it possible to control the properties of POMs not only at the level of single molecules, but also at the level of globules and aggregates [111,180,181].

In the course of investigations, the ratio of components in the formed POM-polymer associates (Fig. 5) was established, which in some cases, is close to the calculated value of the monomolecular coating of POM with polymer chains $[175,178,184]$. Such systems include, for example, associates based on polyvinyl alcohol, PVP with $\mathrm{Mo}_{132}$, and on PVP with $\mathrm{Mo}_{72} \mathrm{Fe}_{30}$. As mentioned above, spontaneous energetically favorable formation of associates occurs in some systems, e.g., of PVP with $\mathrm{Mo}_{72} \mathrm{Fe}_{30}$ (in the entire concentration range of components), as well as in certain concentration ranges - of polyvinyl alcohol and PEG with $\mathrm{Mo}_{72} \mathrm{Fe}_{30}$ [177,183]. The interaction of POM with polymer macromolecules has specific features, and one of the main ones is the nonlinearity of the associates physicochemical properties dependence on concentration [175,176,200,201]. The oscillating concentration dependencies (Fig. 6-8) are 


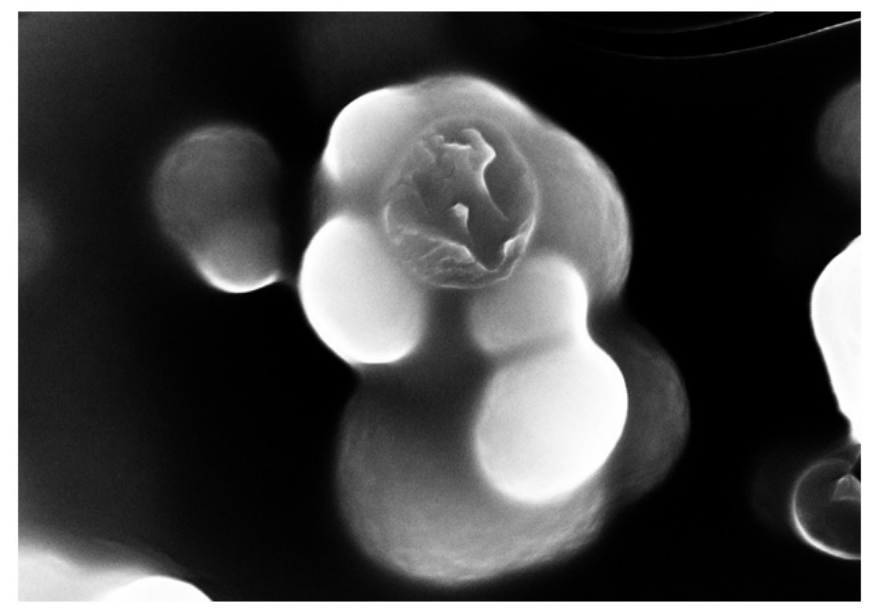

FIG. 4. POM globules, 20000-time magnification. (The electron micrograph was obtained using the equipment of the Ural Center of Shared Use "Modern Nanotechnologies" of the Ural Federal University)

associated with the non-statistical nature of the mutual distribution of the interacting nanoscale components [200,201]. They are observed for such independent characteristics as optical density, solution viscosity, electrical properties, particle size, etc. Obviously, this fact should be taken into account when choosing the ratio of components in associates used for the targeted drug delivery.

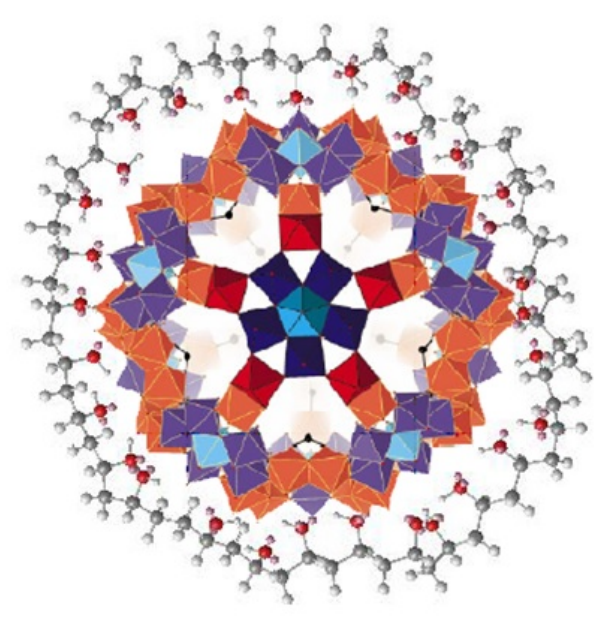

FIG. 5. Diagram of a polymer-salt complex structure [178]

It has been established that $\mathrm{Mo}_{72} \mathrm{Fe}_{30} \mathrm{POM}$ forms associates with the drugs that are most promising in terms of targeted delivery. Thiamine chloride (vitamin B1) was considered as a model substance [161, 197]. Thiamine is present in a solution in the form of cations, which get associated with the POM polyanion. It was confirmed by UV/Vis spectroscopy, by measuring the $\mathrm{pH}$ of solutions, zeta potential, and the size of the particles in them. In concentrated solutions, colloidal particles get formed along with the solid phase of the resulting conjugates, in which the preservation of the original POM structure and the presence of thiamine are confirmed. To this end, IR and Raman spectroscopy were used. The thiamine-POM ratio in the associates was estimated as $4: 1$, with the retention of the total negative charge of the conjugate. $\mathrm{Mo}_{72} \mathrm{Fe}_{30}$ associates with substances belonging to the class of immunomodulators, e.g., with 2-morpholino-5-phenyl-6H-1,3,4-thiadiazine bromide [197-202].

$\mathrm{Mo}_{72} \mathrm{Fe}_{30}$ forms conjugates with such an antibiotic as kanamycin sulfate, without reducing the activity of this drug when affecting colibacilli cultures [197]. Also, it was possible to establish that $\mathrm{Mo}_{72} \mathrm{Fe}_{30}$ can associate with insulin in aqueous solutions [197], as well as with amphiphilic protein molecules, such as albumins [161, 197]. This result is of great importance in terms of the possibility of obtaining complexes with POM and with homing peptides for the implementation of bioactive substances targeted delivery to specific cells. Protein molecules, the so-called protein 


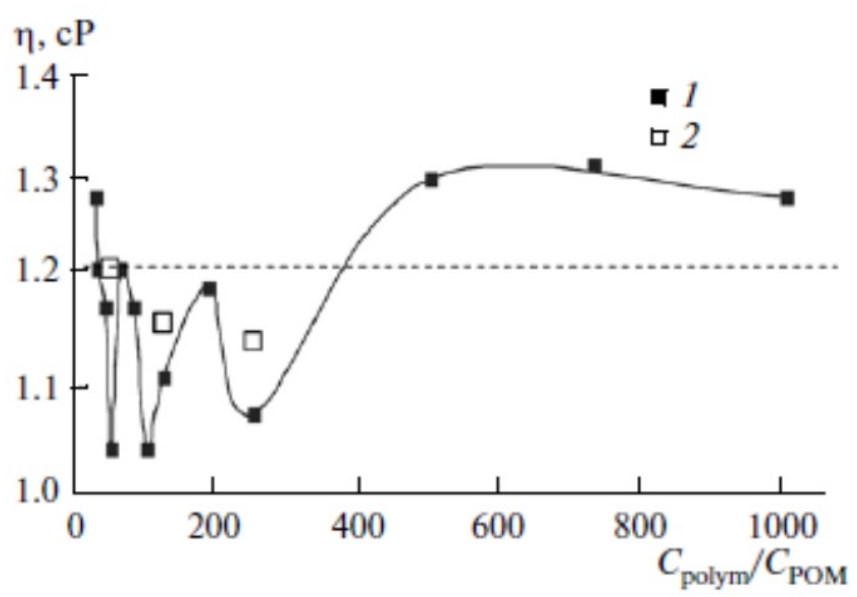

FIG. 6. Dependence of the solutions dynamic viscosity $(\eta)$ [201] on the ratio of the polyvinylpyrrolidone macromolecular units number per 1 ion of $\mathrm{Mo}_{132}$ polyoxometalate (1); 2 viscosity of the specified POM aqueous solution; the dotted line indicates the viscosity of a $1 \%$ pure polymer aqueous solution. CPleiades Publishing, Ltd. 2015
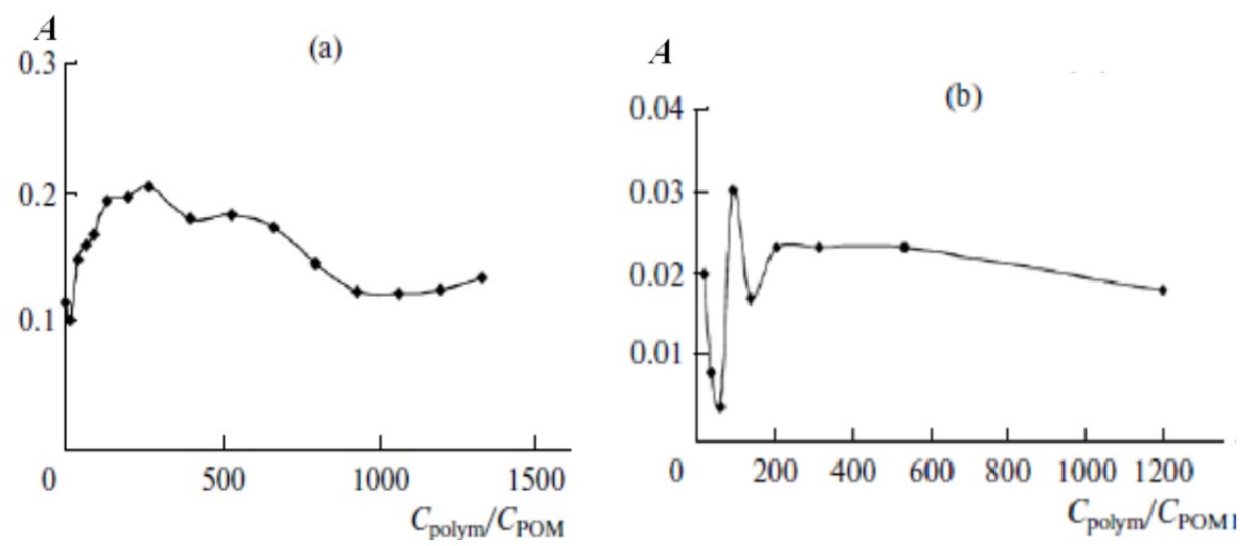

FIG. 7. Optical density (A) $(\lambda=450 \mathrm{~nm})$ [201] of $\mathrm{Mo}_{132}$ POM and polymer solutions, depending on the molar ratios of the components: $\mathrm{a}-$ of polyvinylpyrrolidone $\left(\mathrm{C}_{P O M}=1.5 \cdot 10^{-6} \mathrm{~mol} / \mathrm{L}\right) ; \mathrm{b}-$ of polyvinyl alcohol $\left(\mathrm{C}_{P O M}=1.5 \cdot 10^{-7} \mathrm{~mol} / \mathrm{L}\right)$. CPleiades Publishing, Ltd. 2015

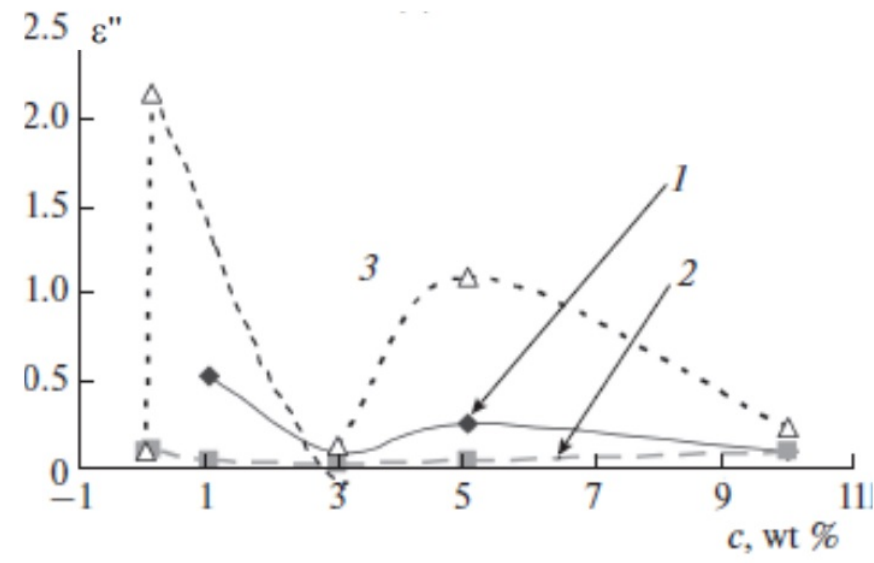

FIG. 8. Concentration dependencies of the dielectric loss factor [175] at the $25 \mathrm{~Hz}$ frequency for the PVA-based composites, including (1) $\mathrm{Mo}_{132}$, (2) $\mathrm{Mo}_{138}$, and (3) $\mathrm{Mo}_{72} \mathrm{Fe}_{30}$. C is the POM content (wt \%). CPleiades Publishing, Ltd. 2016 
corona, significantly influence the biological properties of nanoparticles [203-207]. It should be noted that the blood serum proteins stabilize $\mathrm{Mo}_{72} \mathrm{Fe}_{30}[161,177]$, in spite of the fact that the serum is an alkaline medium, where the POM is unstable, in principle, which is illustrated by its rapid decomposition in buffer solutions. Stabilization by the natural protein corona opens up prospects for the prolonged action of the POM-based drugs. While in buffer solutions with the corresponding $\mathrm{pH} 8 \mathrm{Mo}_{72} \mathrm{Fe}_{30}$ decomposes rapidly, and the effective constant of the POM destruction rate has a value of $2.6 \cdot 10^{-2} \mathrm{~h}^{-1}$ even for the self-aggregated ones, its value is only $1.8 \cdot 10^{-3} \mathrm{~h}^{-1}$ in the composition of conjugates with proteins [96]. The initial experiments aimed at establishing the possibility of obtaining conjugates of $\mathrm{Mo}_{72} \mathrm{Fe}_{30}$ with doxorubicine yielded positive results. Doxorubicin is an anthracycline antitumor antibiotic [208-212] that is actively used in medicine in the treatment of various types of solid tumors. Two main mechanisms of doxorubicin's antitumor activity are proposed in the literature, namely DNA intercalation and disruption of the viral DNA repair, and the generation of free radicals that damage the cell membrane, DNA, and proteins [213]. Along with high efficiency, doxorubicin has high toxicity associated with low selectivity for its action. In addition to high cardiotoxicity, a decrease in bone marrow activity (myelosuppression) is often observed in the course of doxorubicin administration [214]. To date, a significant amount of research has been conducted with the purpose of reducing the toxic effect of doxorubicin on healthy cells by creating means of its targeted delivery. Various types of different systems for the targeted delivery have been considered, in particular, based on liposomes [215-222] (similar forms have already found application in medical practice [223-227]); proteins [228-233]; polymers [234-243]; fullerenes and CNT [35, 244-251]; metal and oxide nanoparticles [52,76] (gold [250-255], silver [255], and iron oxide [256-260]). The further study of the properties of POM-doxorubicin conjugates should be recognized as promising, given the corresponding properties of POM.

An important aspect of the possible use of POM in the field of biomedicine is the possibility of iontophoretic, including percutaneous, transport of Keplerates and their conjugates into the body. These processes were considered in our previous work [179]. As is noted above, these processes are important, in particular, for the delivery of drugs, e.g., of doxorubicin, to the regions with a low degree of vascularization.

Additional opportunities for the use of $\mathrm{Mo}_{72} \mathrm{Fe}_{30}$ in biomedicine are opened by the preparation of its new coordination compound [261] that can serve as a transportable donor of nitric oxide - a mediator of some important processes in the body [262-267], which include the activation of antiviral and antimicrobial activity, and the cardiotropic action. It is important that the compound [POM- $\left.\left(\mathrm{NO}_{2}\right)_{x}\right]\left(\mathrm{NO}_{2}\right)_{y}$ (where $x=6, y=14 \pm 3$ ), obtained by the interaction of nitrogen oxides with POM and characterized by a complex of methods, belongs to the group of water-soluble compounds. Iron compounds are used as nitric oxide donor and transport vehicles for its delivery [268-275]. Examples of obtaining other POMs containing nitric oxide can be found in the literature [276-278].

\section{POMs desrtuction process and their stabilization}

One of the main above-mentioned properties of POMs is their ability to degrade in diluted solutions [279], which depends on both the POM initial concentration and the $\mathrm{pH}$ of the medium. This property can be useful for POM removal from the body after the function of bioactive substances delivery has been performed. The results of studies of thermal stability and destruction of the Keplerate and toroidal type POMs in the solid state using spectroscopic methods are given in [280-286]. At the same time, it was shown that a thorough spectroscopic analysis and a comprehensive interpretation of the results are necessary [280,286] in order to avoid unreliable conclusions [284] about the POMs' thermal stability. The features of the processes of POMs destruction in solutions have been considered in the earlier performed works $[135,198]$. For each of the considered POM, there is a region of stable state in aqueous solutions in terms of POM concentration and medium $\mathrm{pH}$. For $\mathrm{Mo}_{132}$, this region can be clearly illustrated by a diagram (Fig. 9). The region of $\mathrm{Mo}_{72} \mathrm{Fe}_{30}$ stability in sufficiently concentrated solutions is also limited by $\mathrm{pH}$ within the 3.7-5.9 range $[100,106]$. Under the conditions that exist beyond the range of POM stability, they undergo gradual destruction into simpler components.

UV/Vis spectroscopy was used for studying the kinetics of POM degradation in solution. The time dependencies $(\tau)$ of the optical density $A$ (directly proportional to the current POM concentration) obtained [135] for different initial concentrations of $\mathrm{Mo}_{72} \mathrm{Fe}_{30}$ POM were approximated by equations describing reactions of different orders, in order to establish which of them the experimental data obey. A satisfactory agreement with the linear dependence was observed in the $\ln \left(\frac{A_{0}}{A_{\tau}}\right)=f(\tau)$ coordinates for $\mathrm{Mo}_{72} \mathrm{Fe}_{30}$ solutions in the domain of relatively low concentrations. The experimental data correlated best with the first order reaction equation. For relatively high $\mathrm{Mo}_{72} \mathrm{Fe}_{30}$ concentrations, the experimental data were approximated by two lines with different slopes (for different time periods). Each of them was linearized in the $\ln \left(\frac{A_{0}}{A_{\tau}}\right)=f(\tau)$ coordinates. In this case, the constant of POM decomposition rate in the 


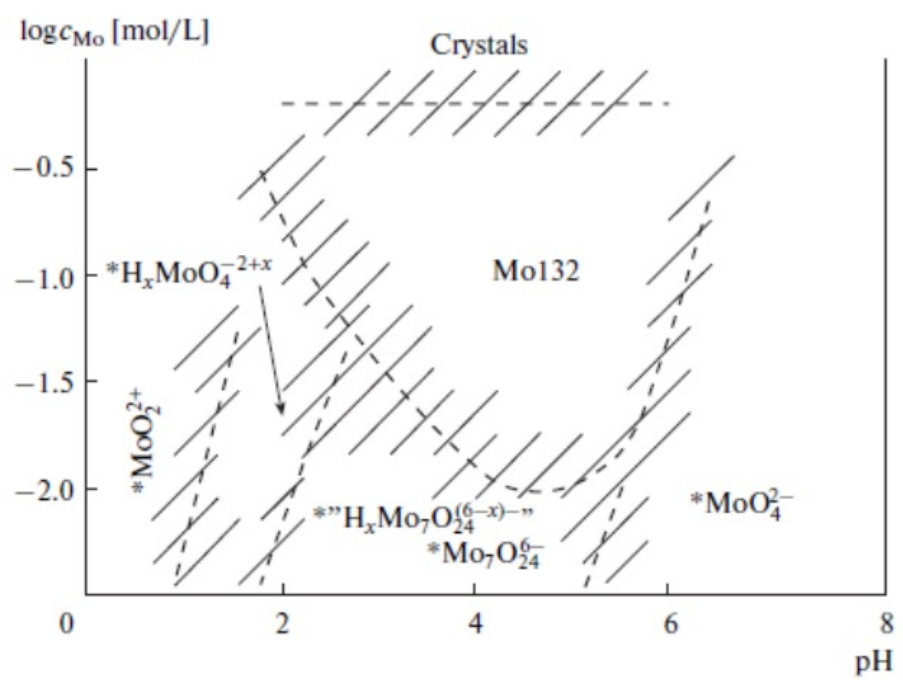

FIG. 9. Hypothetical diagram of $\mathrm{Mo}_{132}$ POM stability [184]. CPleiades Publishing, Ltd. 2010

first time interval coincided with the constant of $\mathrm{Mo}_{72} \mathrm{Fe}_{30}$ destruction rate in low concentration solutions. Such a situation can be explained by a change in the mechanism of the destruction process depending on the concentration and a change in the limiting stage of the general process where inflection between two lines was observed. An example of the experimental data processing is shown in Fig. 10. For comparison, the table also shows the data on the destruction kinetics for a toroid-structured $\mathrm{Mo}_{138} \mathrm{POM}$, for which the one-step destruction process in a solution with a relatively high $\left(2.4 \cdot 10^{-6} \mathrm{~mol} / \mathrm{L}\right)$ initial POM concentration was satisfactorily described by the first-order reaction equation.

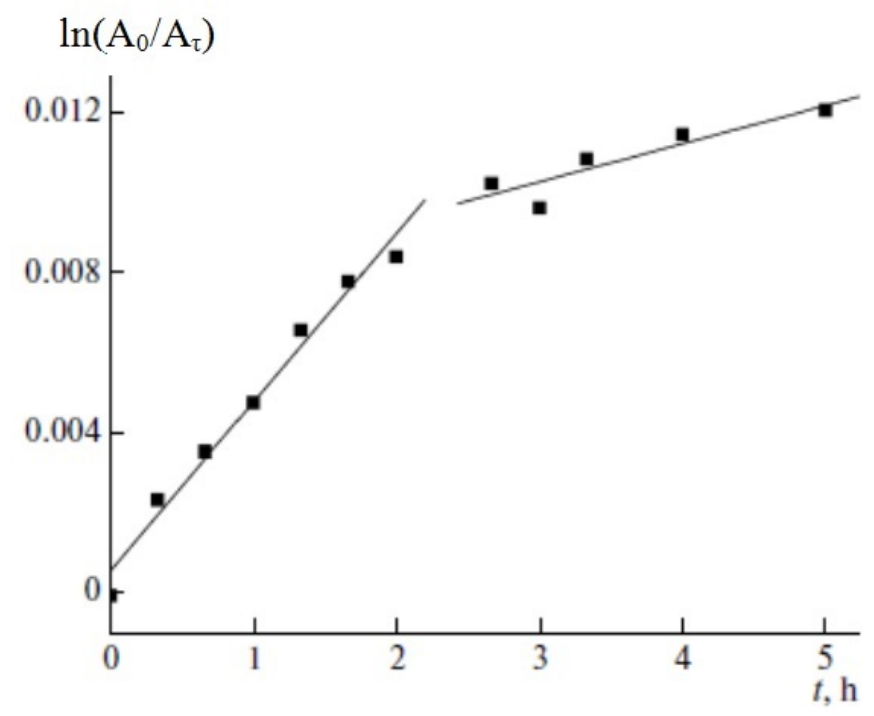

FIG. 10. Kinetics of the $\mathrm{Mo}_{72} \mathrm{Fe}_{30}$ Keplerate decomposition [135] in a solution with the initial concentration of $5 \cdot 10^{-6}$ M. CPleiades Publishing, Ltd. 2015

In [135], a supposition was made concerning the possible differences in the process of $\mathrm{Mo}_{72} \mathrm{Fe}_{30} \mathrm{POM}$ destruction at different concentrations. The mentioned POMs tend to form aggregates or hollow globules in solutions [89,199,286292]. In solutions with high concentrations, aggregation proceeds in such a way that a significant part of the available POM molecules (ions) happens to be bound into aggregates within a relatively short time. In diluted solutions, the relative amount of free POM molecules is more noticeable. Therefore, it can be assumed that the free POM destruction rate constant is higher than that of those bound into globules, in which they are protected due to the presence of bonds between molecules (ions) and a lesser contact with the environment. When the experimental dependencies demonstrate 
TABLE 1. Polyoxometalates $\left(k_{i}\right)$ destruction rate constants at the naturally formed acidity of solutions, $\mathrm{h}^{-1}[135]$

\begin{tabular}{|c|c|c|}
\hline \multirow{2}{*}{ Solution concentration, mol/L } & \multicolumn{2}{|c|}{ Polyoxometalate composition } \\
\cline { 2 - 3 } & $\mathrm{Mo}_{72} \mathrm{Fe}_{30}$ & $\mathrm{Mo}_{138}$ \\
\hline $1 \cdot 10^{-7}-6 \cdot 10^{-7}$ & $k_{1}=0.02$ & \\
$1 \cdot 10^{-6}-1 \cdot 10^{-5}$ & $k_{1}=0.02$ & $k=0.05$ \\
& $k_{2}=0.002$ & \\
\hline
\end{tabular}

an inflection within the same initial concentration, a change in the limiting stage occurs, apparently, after the majority of the available free POM molecules have been spent.

The proposed hypothesis is supported by the fact that the constant of the aggregates formation rate [289] (calculated also for the first-order reaction) is lower than the POM decomposition rate constant, and equals $5.4-7 \cdot 10^{-5} \mathrm{~h}^{-1}$ for $\mathrm{Mo}_{72} \mathrm{Fe}_{30}$, in particular. Therefore, the initially obtained solution should contain at the first stage a sufficiently large number of unbound POM molecules, which decompose faster than the aggregated ones. A relatively faster process of decomposition of free $\mathrm{Mo}_{72} \mathrm{Fe}_{30}$ molecules, which are initially present in a significant amount, can also explain a steeper initial section in the kinetic dependencies of aggregate formation [289]. The rate constant in this section can be estimated as $2.5-3.9 \cdot 10^{-4} \mathrm{~h}^{-1}$. In this case, it can be assumed that the appearance of iron ions due to the POM destruction leads to acceleration of the aggregation process. The literature indicates a similar effect of cations on the formation of aggregates [291]. At the same time, the existence of singlet POMs in a solution is not typical for the toroid-like $\mathrm{Mo}_{138}$ [286]; therefore, its destruction is a one-step process in a certain time interval.

In [289], the ratio between the number of aggregates and singlet nanoclusters was determined, from which the degree of aggregation was calculated. The authors apparently did not take into account a possibility of this ratio increase due to a higher rate of $\mathrm{Mo}_{72} \mathrm{Fe}_{30}$ POM free ions destruction, as well as the change of the total concentration of POM, which could lead to an overestimation of the globule formation rate constant.

Another question that arises is about the mechanism of POM decomposition s included in the aggregates. Do the POM molecules get destroyed directly in the globules, and then the latter disintegrate, or does the preliminary disintegration of the globules occur when the concentration of free POM ions decreases? The destruction of POM in globules could have possibly led to a change in their size; however, according to the data from [289], the size of the existing globules remains practically unchanged. Therefore, it can be assumed that the destruction of POM molecules (ions) into simpler compounds occurs after the preliminary destruction of these globules, which goes along with the decreasing concentration of the studied POM in the course of its decomposition in the solution. Some previously found differences in the kinetics of $\mathrm{Mo}_{138} \mathrm{POM}$ and $\mathrm{Mo}_{72} \mathrm{Fe}_{30}$ destruction can be associated with both the globules destruction rate, and with the stability of the polyoxometalates themselves. Thus, it was shown in [135] that, depending on the concentration of $\mathrm{Mo}_{72} \mathrm{Fe}_{30}$ POM solutions, the disintegration of single nanoclusters, or the "dissolution" of the existing globules consisting of nanoclusters, can be the limiting stage of the overall destruction process.

The destruction of $\mathrm{Mo}_{132}$ has also been investigated [198]. An analysis of the spectrophotometric data from experiments on the destruction of $\mathrm{Mo}_{132}$ POM showed that the time dependencies of the optical density and, accordingly, of the POM concentration, have an induction period when the concentration decreases rather slowly. Then the decomposition accelerates, and after passing the interval with the maximum rate, it noticeably slows down again. For this reason, the standard linearization of the data using kinetic reaction equations of various orders (including those at the stages after the induction period) was a failure. Considering the shape of the obtained dependences, it was logical to assume that the destruction proceeds in the autocatalytic reaction mode. A typical picture of the kinetic dependence is shown in Fig. 11a.

The experimental kinetic data obtained at the initial concentration of the studied POM of $10^{-5}$ mol/L, were processed using an equation that describes the autocatalytic process [293-295]:

$$
\mathrm{C}=\mathrm{C}_{0}\left(\mathrm{~K}_{0}+\mathrm{K}_{c} \mathrm{C}_{0}\right) /\left(\mathrm{K}_{c} \mathrm{C}_{0}+\mathrm{K}_{0} \exp \left(\left(\mathrm{K}_{0}+\mathrm{K}_{c} \mathrm{C}_{0}\right) \mathrm{t}\right),\right.
$$

where $\mathrm{C}_{0}$ is the nanocluster initial concentration, $\mathrm{K}_{0}$ is the non-catalytic process rate constant, $\mathrm{K}_{c}$ is the catalytic process rate constant, $\mathrm{C}$ is the nanocluster current concentration, and $\mathrm{t}$ is the time. The values of $\mathrm{K}_{0}$ were estimated from the slope of the dependence during the induction period, and it was assumed that the catalytic process rate is negligible during this period (of the non-catalytic reaction), which is a standard assumption in such cases. The experimental data for the interval, corresponding to the rapid course of the catalytic process with further deceleration 

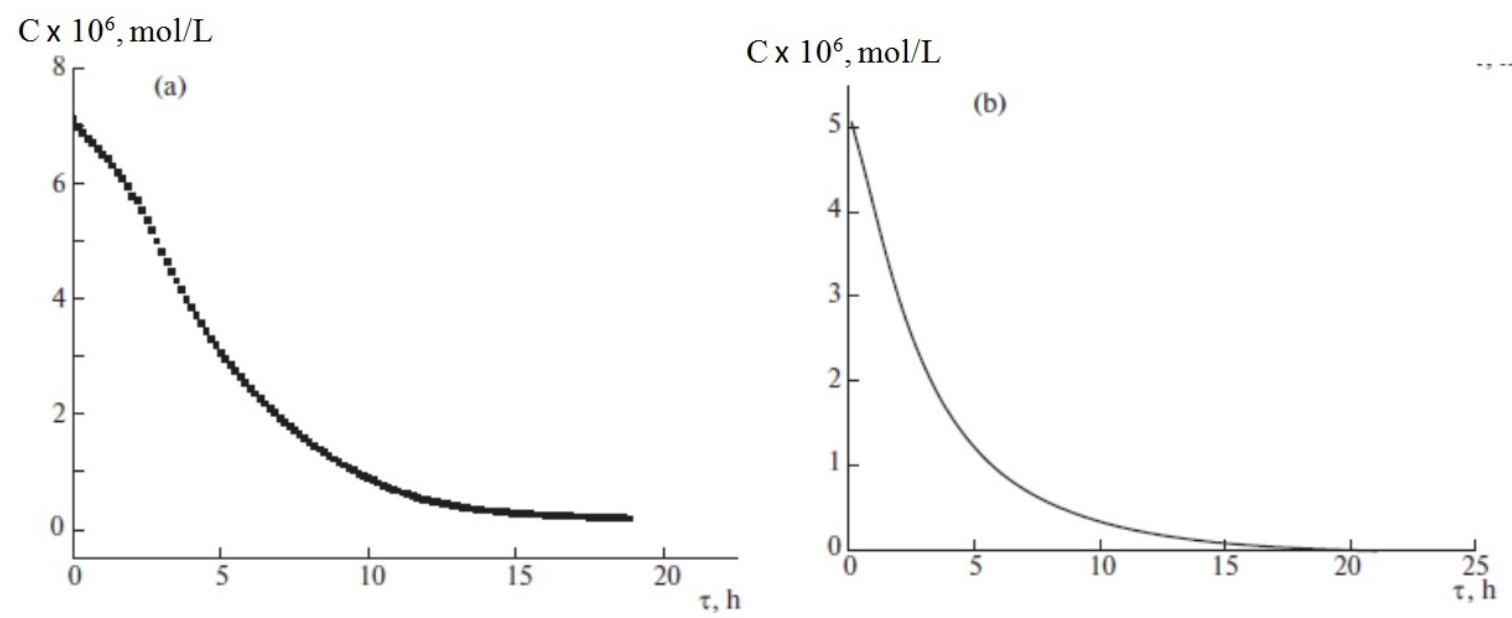

FIG. 11. Typical kinetic dependencies (concentration - time) of the $\mathrm{Mo}_{132}$ destruction process [198] at an initial concentration of $7 \cdot 10^{-6} \mathrm{~mol} / \mathrm{L}$ (a) with an induction period; shape of dependence with no induction period (b) at the introduction of sodium molybdate (the initial $\mathrm{Mo}_{132}$ concentration: $\left.5 \cdot 10^{-6} \mathrm{~mol} / \mathrm{L}\right)$. (Pleiades Publishing, Ltd. 2016

due to the consumption of autocatalytic particles, were used for determining $\mathrm{K}_{c}$ values for each experimental point, and then plotting the time dependence of this parameter.

It is impossible to deduce the $\mathrm{K}_{c}$ value from the above equation by using the analytical method, therefore a special algorithm was developed for determining this value. It consists in the following:

1. Since the equation is transcendental, it was rewritten as:

$\mathrm{C}\left(\mathrm{K}_{c} \mathrm{C}_{0}+\mathrm{K}_{0} \exp \left(\left(\mathrm{K}_{0}+\mathrm{K}_{c} \mathrm{C}_{0}\right) \mathrm{t}\right)-\mathrm{C}_{0}\left(\mathrm{~K}_{0}+\mathrm{K}_{c} \mathrm{C}_{0}\right)=0\right.$ or $\mathrm{F}\left(\mathrm{C}, \mathrm{t}, \mathrm{K}_{c}\right)=0$.

2. The available data array $\mathrm{C}=\mathrm{C}(\mathrm{t})$ was used to construct the function $\mathrm{F}=\mathrm{F}\left(\mathrm{C}, \mathrm{t}, \mathrm{K}_{c}\right)$, according to which, the time-dependent $\mathrm{K}_{c}$ values were reconstructed.

The performed calculations showed that the value of the catalytic process rate constant practically did not change in the corresponding interval in time and averaged about $4.8 \cdot 10^{2} \mathrm{~L} / \mathrm{mol} / \mathrm{min}$ at the initial POM concentration of $10^{-5} \mathrm{~mol} / \mathrm{L}$, and $6 \cdot 10^{2} \mathrm{~L} / \mathrm{mol} / \mathrm{min}$ at $5 \cdot 10^{-6} \mathrm{~mol} / \mathrm{L}$, respectively. The half-transformation time estimated on the basis of such rate constant values, correlates well with the experimental data (about 4-5 hours). Thus, it can be considered that the destruction process proceeds as an autocatalytic reaction, and the used assumptions are correct, since the shape of kinetic dependence could be approximated successfully by a corresponding equation. The possible reasons for the differences in the obtained Kc values at different initial concentrations will be discussed below. The value of $\mathrm{K}_{0}$ in this case was about $1.8 \cdot 10^{-3} \mathrm{~min}^{-1}$, regardless of the initial POM concentration in the range of 1-10 $\mu \mathrm{M}$.

The features of $\mathrm{Mo}_{132}$ destruction in the presence of calcium ions, associated with the POM polyanion, are also considered. The hydrated calcium ions are capable of forming differently configured associates with POMs [119]. Calcium can stabilize POM in solutions, thus increasing the effective value of its lifetime in solutions. In this case, as in that of POM association with polymers, the non-additive properties are observed, for instance, the nonlinear concentration-dependent ability of calcium to stabilize POM. In the processes of calcium cations and POM interaction, apparently, 20 pores in the Keplerate structure are involved as active centers, i.e., the places where the association of the hydrated ions of divalent metals occurs [296]. It cannot be excluded that the filling of these positions leads to the associate's stabilization. In addition, the next level of interactions is realized along with the increase in the associated ions concentration. Naturally, ion associates are found in dynamic equilibrium with free ions in a solution, and a certain excess of associated ions is required to ensure the filling of active positions. The change in time of the solutions optical density at the POM characteristic wavelength indicated that the almost completely destroyed pure $\mathrm{Mo}_{132}$ persisted for several days in the presence of calcium, especially at the Ca-POM ratios of 8:1, 24:1, and 60:1. The presence of POM with the original structure was confirmed by Raman spectroscopy.

This is another case when the POM destruction process is described as an autocatalytic reaction. Such parameters as the induction period duration, and the rate constants in this interval and during the catalytic process were determined for the destruction reaction. When the Ca content increases, the induction period lengthens, and the rate constant of the noncatalytic stage decreases (Fig. 12), but nonmonotonically depends on the Ca content in solutions, and has minima for some compositions. The autocatalytic process rate constant increased along with an increase in the Ca content. It 

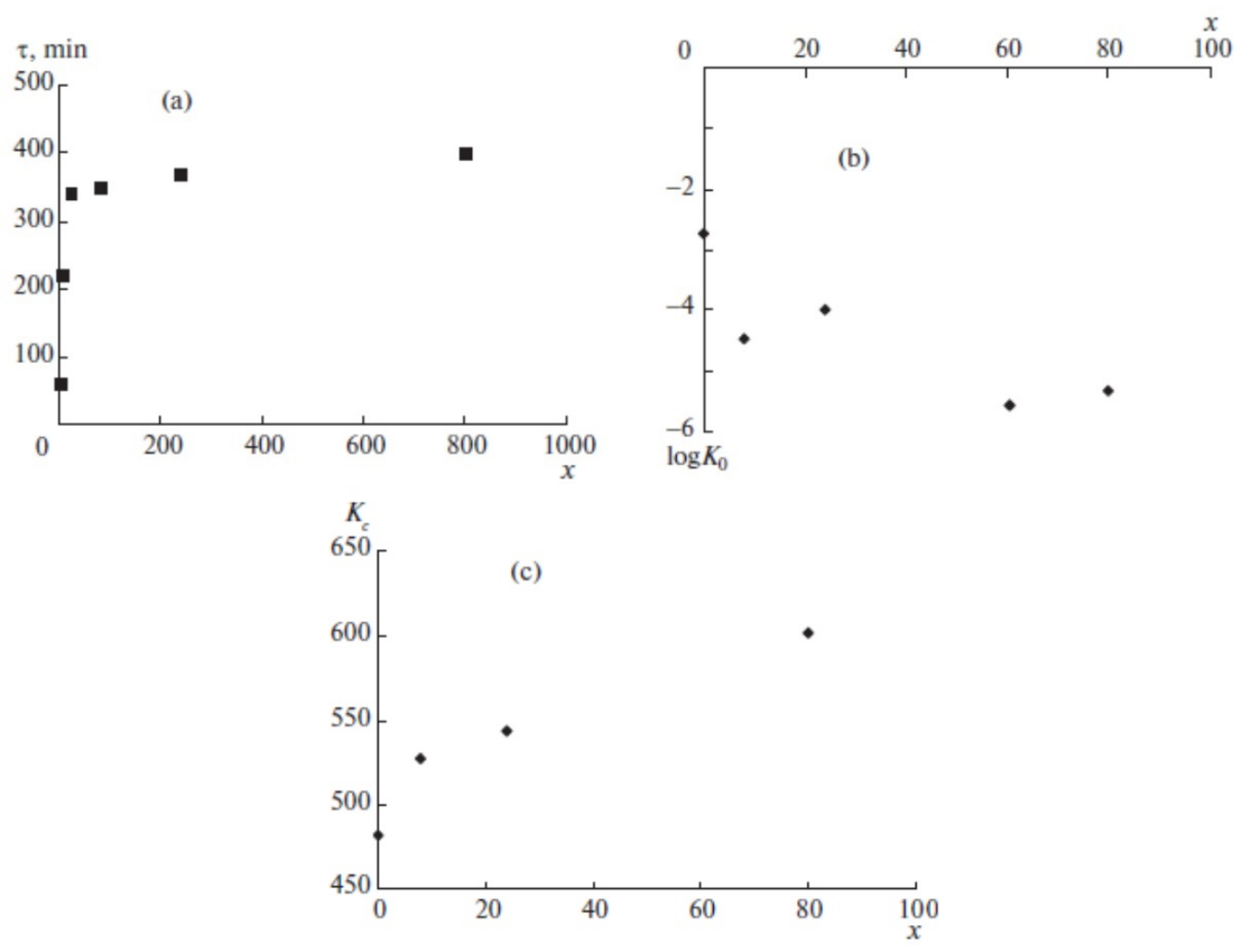

FIG. 12. Dependencies of the induction period duration (a), $\mathrm{K}_{0}(\mathrm{~b})$, and $\mathrm{K}_{c}$ (c) on the $\mathrm{Ca}^{2+}{ }_{-} \mathrm{POM}$ ratio for solutions with the initial $\mathrm{Mo}_{132}$ concentration of $10^{-5} \mathrm{~mol} / \mathrm{L}$ [198]. CPleiades Publishing, Ltd. 2016

should be noted that since the formation of variously structured POM-Ca associates is possible, the rate constants can really differ, as the mechanism of POM destruction is determined by its structure.

It was noted during the research that the $\mathrm{pH}$ of freshly prepared POM solutions decreased depending on the amount of $\mathrm{Ca}$ (Fig. 13) at POM concentrations of 1 and $10 \mu \mathrm{M}$, and the nature of the kinetic parameters dependence (in absolute value) on the $\mathrm{Ca}$ concentration was generally similar to the $\mathrm{pH}$ concentration curve, although the pure $\mathrm{Mo}_{132}$ solution did not fit this series. On the one hand, this shows that the destruction mechanism and rate are determined not only by the solution $\mathrm{pH}$. Along with that, it can be stated that the maximum stability of some compositions is determined by a combination of a sufficiently long induction period and a relatively low non-catalytic stage rate constant.

When considering the pure $\mathrm{Mo}_{132}$ destruction process again, a monotonic decrease in the $\mathrm{pH}$ of solutions was observed at a concentration of $10 \mu \mathrm{M}$. Notable is that this decrease was more rapid during the induction period. From the point of view of the direction of change in acidity, this regularity is quite logical taking into account the possible simultaneous process of the available pentavalent molybdenum oxidation with atmospheric oxygen, which can be conventionally described as follows:

$$
7 \mathrm{Mo}_{72}^{V I} \mathrm{Mo}_{60}^{V} \mathrm{O}_{372}^{12-}+105 \mathrm{O}_{2}+354 \mathrm{H}_{2} \mathrm{O} \rightarrow 132 \mathrm{Mo}_{7} \mathrm{O}_{24}^{6-}+708 \mathrm{H}^{+} \text {. }
$$

Due to the presence of the above-described change in acidity, the hydroxonium ions $\mathrm{H}_{3} \mathrm{O}^{+}$were considered as autocatalytic particles, which is often the case. However, it was taken into account that along with the decreasing $\mathrm{pH}$ of calcium-containing solutions and increasing amount of $\mathrm{Ca}^{2+}$ in them, the rate constant of the non-catalytic stage of the process decreases, and its duration increases. Therefore, non-condensed molybdate (or dimolybdate) ions that appear during the destruction of $\mathrm{Mo}_{132}$, can act as the autocatalytic particles. Further onIn addition, the diagram from [184] (Fig. 9) was taken into account, as it showed the regions of stability of various molybdate forms (including $\mathrm{Mo}_{132}$ ions) depending on the total molybdenum in solutions, and on the $\mathrm{pH}$ of the medium. The point corresponding to a POM solution with initial concentration of $10 \mu \mathrm{M}$ in a more detailed fragment of the diagram (Fig. 14), is found in the region of heptamolybdate ions stable existence. It should be noted that the earlier studies of POM decomposition by photon correlation spectroscopy [184] discovered the appearance of POM particles with an effective size of about $1.3 \mathrm{~nm}$, which is close to the estimated size of the heptamolybdate ion. If, in addition, fragments containing less than 7 molybdenum atoms also appear during the POM destruction, then they must be completed up to a heptamolybdate 


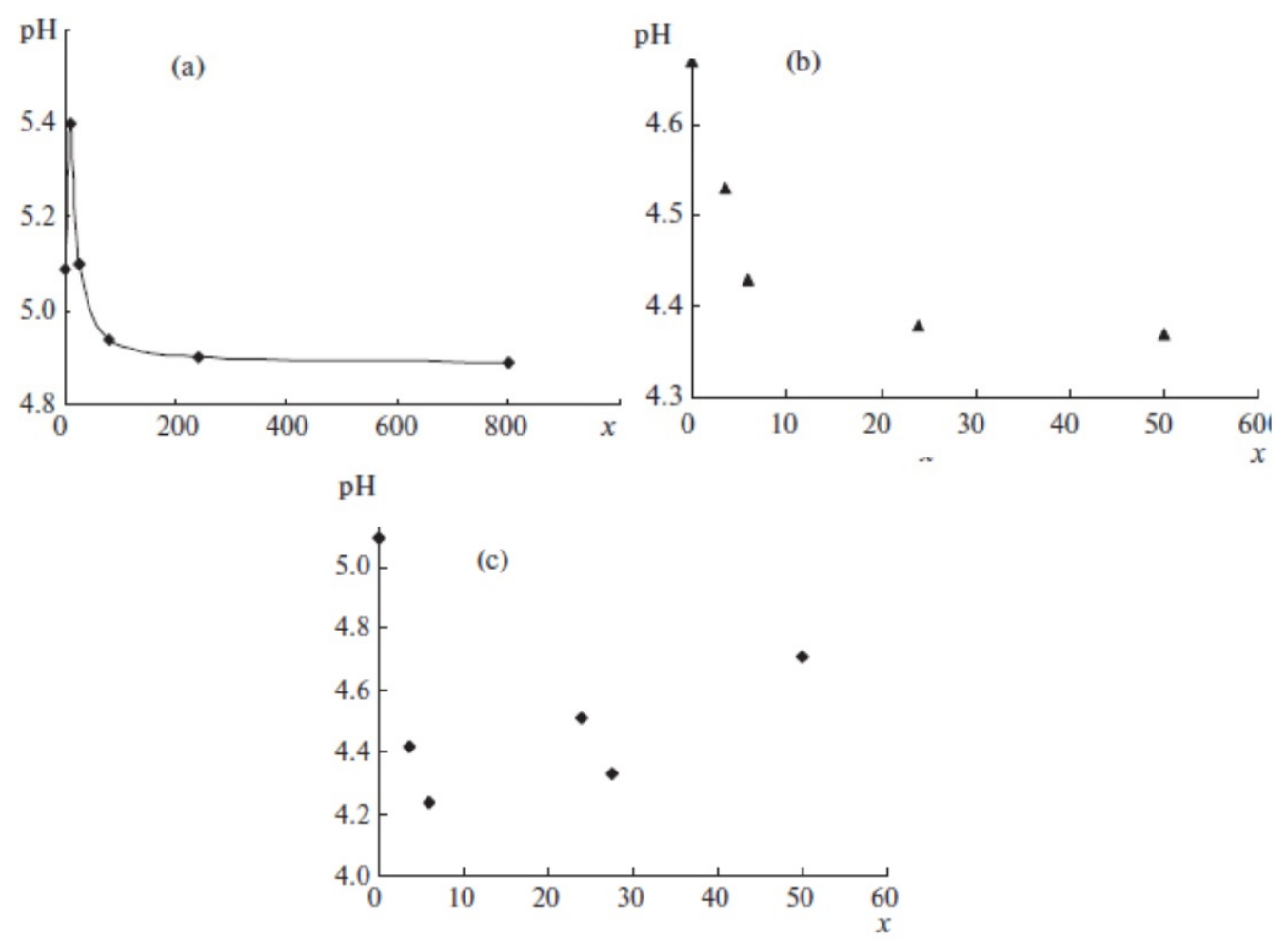

FIG. 13. Dependencies of the $\mathrm{Mo}_{132}$ solutions $\mathrm{pH}$ on the calcium-POM ratio (a) at the concentration of $10^{-6} \mathrm{~mol} / \mathrm{L}$, as well as on the experimental time at concentrations of $10^{-5}$ (b) and $10^{-6} \mathrm{~mol} / \mathrm{L}$ (c) [198]. CPleiades Publishing, Ltd. 2016

form that is stable in this region. Then, it cannot be ruled out that these particles "attack" a POM to obtain the required material. An accelerated destruction in this case is achieved when weakly condensed compounds or monomolybdate forms get accumulated in the solution. The slowing down of the destruction process corresponds to the consumption of the mentioned autocatalytic particles. At the initial $\mathrm{Mo}_{132}$ concentration of $1 \mu \mathrm{M}$, the resulting monomolybdate particles do not need to build up to heptamolybdate.

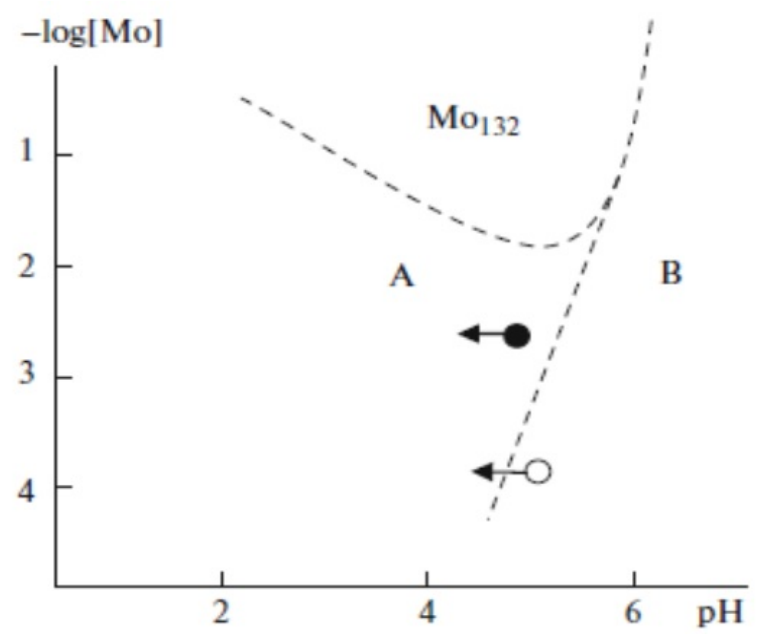

FIG. 14. Fragment of the phase diagram of forms of ions in a solution: A - heptamolybdate ions stability region; B - monomolybdate existence region. The arrows indicate the direction of change in the acidity of the solution during the $\mathrm{Mo}_{132}$ destruction [198]. CPleiades Publishing, Ltd. 2016 
The conclusions made above about the nature of autocatalytic particles are consistent with the data on increase in POMs stability in acidic buffer solutions [279]. These data indirectly indicate that hydronium ions do not catalyze destruction. The catalytic action of monomolybdate ions can be confirmed by a direct experiment. The addition of sodium molybdate into the $\mathrm{Mo}_{132}$ solution (with the initial concentration of $5 \mu \mathrm{M}$ ) practically did not affect the $\mathrm{pH}$ of the solution, and led to the exclusion of the induction stage from the destruction process (Fig. 11b). In this case, the molar content of molybdenum in the form of monomolybdate was set equal to the molar content of molybdenum contained in the form of $\mathrm{Mo}_{132}$. Changes in the solutions acidity during the destruction of more diluted (e.g., $\left.\mu \mathrm{M}\right)$ $\mathrm{Mo}_{132}$ solutions without additives did not have a monotonic character (Fig. 11). It is also related to the thermodynamic factor (diagram in Fig. 14). The point corresponding to the indicated concentration is found in another region of the diagram, where simpler ions are stable. However, the $\mathrm{pH}$ decreases in the course of destruction, and the composition transits across the boundary between two regions (Fig. 14). At the initial $\mathrm{Mo}_{132}$ concentration of $\mu \mathrm{M}$, the appearing monomolybdate particles do not need to build up to heptamolybdate before crossing the boundary of the indicated regions. Such a flow of processes is even more complicated than in the first case, so it becomes difficult to unambiguously interpret the kinetics and describe it by the used autocatalytic equation. The course of reaction can be additionally complicated by the fact that products of destruction, including pentavalent molybdenum, have different degree of stability in different regions of phase diagram. They have a higher stability [200] in the condensed forms in region A (Fig. 14). As for the Keplerate structures destruction, it was noted that the Keplerate decomposition stage (with the solution turning blue) [104] can be followed by the Mo(V) compounds oxidation, accompanied by discoloration. The change in the medium acidity during POM destruction in the presence of $\mathrm{Ca}^{2+}$ is also not monotonic in all cases. However, the above-noted general trend of an increase in the induction period duration along with an increase in the amount of $\mathrm{Ca}^{2+}$ in the solution, may be associated with the fact that calcium ions are able to form sufficiently stable associates with molybdate, which leads to at least partial binding of autocatalytic particles. However, calcium molybdate $\left(\mathrm{CaMoO}_{4}\right)$ solubility product was not obtained at the studied concentrations of solutions, and no precipitation in noticeable amounts was observed. To summarize, let us note once again that POM destruction is a process, the rate of which is determined by both POM concentration and medium acidity. The destruction mechanism can vary depending on these conditions. There are possibilities for temporal stabilization of POMs and a decrease in the value of the process rate constant - by regulating either the acidity of the medium and POM self-aggregation, or POM interaction with stabilizing agents, including those of natural origin.

The effect of light on POM solutions increases the rate of their destruction [297,298] and can change the mechanism of this process (to be discussed in more detail in the next section). Mutual stabilization of POMs and watersoluble nonionic polymers (including biocompatible ones) during the formation of their associates, which manifested itself under sufficiently severe photothermal effect on systems, was studied in [198,297-299]. This aspect is important not only in itself, but also when using POM as, e.g., part of ointment compositions, or sterilized materials. The stabilization effect was studied by means of the EPR spectroscopy for determining the number of paramagnetic centers (spins) as an indicator of the composition components destruction processes. Quite interesting are the results of studies, which indicate the above-noted significant stabilization of $\mathrm{Mo}_{72} \mathrm{Fe}_{30} \mathrm{POM}$ due to the interaction with proteins of the blood serum [161,300], which has an alkaline $\mathrm{pH}$. In buffer solutions with a similar $\mathrm{pH}$, POM destruction proceeded at a very high rate, while in the serum they persisted for up to dozens of hours. The destruction rate constant of POM in the resulting conjugates with serum proteins was at least an order of magnitude lower than in aqueous solutions of the POM itself. Thus, there exists a possibility to regulate POMs stability, their lifetime, and the period of the conjugated drugs release. Preliminary stabilization of POM in solutions can be carried out outside the body.

\section{Prospects for the creation of POM-based releasing systems with feedback}

An integrated approach to the study of the physicochemical properties of the $\mathrm{Mo}_{132}$ and $\mathrm{Mo}_{72} \mathrm{Fe}_{30} \mathrm{Keplerate}$ POMs $[138,161,301]$, as well as the possibility of their association with bioactive molecules and fluorescent dyes, made it possible to formulate the concepts [302-304] of creating long-time-drug-releasing systems (LDRS) with a function LDRS will be based on the release of molecules of bioactive (medicinal) substances, initially bound with POM, and the intensification of fluorescent labels luminescence. The release occurs at the normal pH (7.2-7.4) of the body environment, due to the POM destruction. The main principle LDRS are based on is the discovered effect [302-304] of a fluorescent label (xanthene dye rhodamine-B, RhB) inactivation on the POM surface due to charge transfer processes. This makes it possible to monitor the drugs release due to the intensification of the signal from the fluorescent labels [305, 306] incorported in the applied LDRS. In [307], it was found that RhB, chosen from a number of xanthene dyes, is characterized by the concentration quenching of luminescence due to a static mechanism, i.e., formation of non-luminescent H-aggregates. It was shown in [304] that the reason for the RhB fluorescence quenching in an associate with POM is the photoinduced charge transfer from the level of the lowest unoccupied molecular orbital (LUMO) of the donor (RhB) to the LUMO level of the acceptor (POM). According to the cyclic 
voltammetry data [308,309], the LUMO level of RhB is $0.65 \mathrm{eV}$ higher than the LUMO level of POM, which leads to the spontaneous electron transfer from $\mathrm{RhB}$ to $\mathrm{POM}$ in an excited state and formation of the $\mathrm{RhB}+/ \mathrm{Mo}_{132}^{n-}$ ionic pair.

It should be noted that the transfer of electrons between the HOMO/LUMO levels of dye molecules and POM (Fig. 15) also underlies the promising use of such photosensitized systems in catalysis [310]. The experiments performed to date have yielded such components of the above systems (Fig. 16) as the NHS ester of rhodamine-B - a potential fluorescent label [302,303], which can be covalently fixed on the macromolecular backbone of biocompatible polymers (chitosan, polyallylamine) by an amide bond. It was shown that the $\mathrm{Mo}_{132}$ nanocluster, which had been chosen as a model POM, can be connected with matrix macromolecules of biocompatible polymers, such as polyallylamines, aminopropyltrimethoxysilane, and chitosan, resulting in microgels based on similar matrices. In principle, the proposed LDRS can be used as a subcutaneous implant with the function of on-line pharmacokinetic monitoring. Such nanoscale systems can, in principle, be created on the basis of hybrid supramolecular assemblies that act autonomously, like liposomes with highly specific ligands on their surface [311]. Such systems can also be components of a microscopic implant [312] or of a biocompatible polymer matrix capable of carrying a large number of bioactive molecules (BAM) for the long-time release [313,314]. As regards the future, the further steps under consideration relate to both realization of the target properties of the proposed LDRS systems [302], and to optimization of their chemical design, and in vitro and in vivo study of their biological properties. Such a task can be solved, for instance, by studying a possibility of pairwise assembly of components of a composition that includes a polymer, a POM, a xanthene dye (rhodamine) covalently bound in the form of NHS-ester, and a drug.

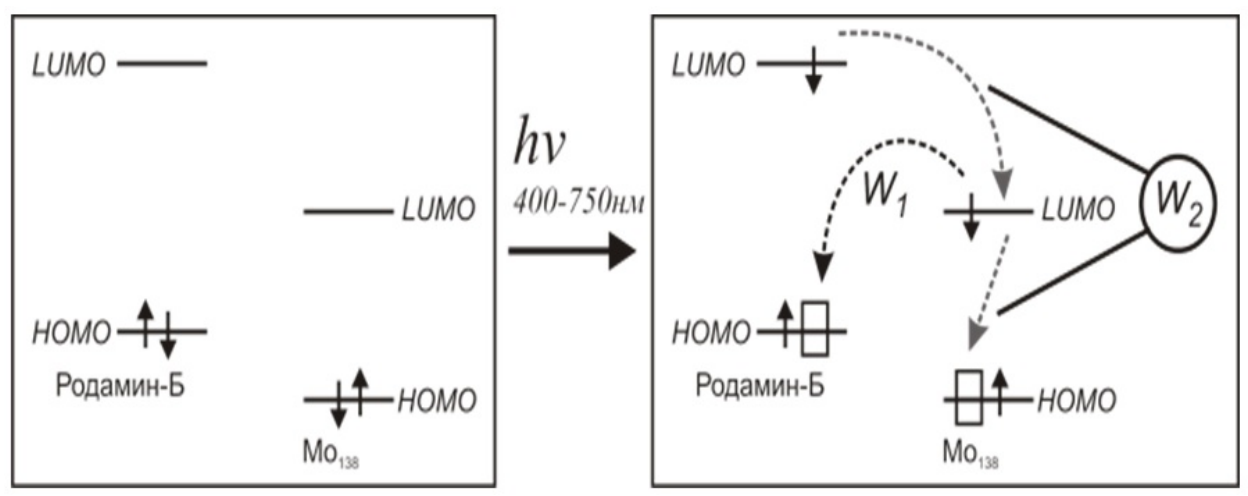

FIG. 15. Photochemical processes in a POM-dye system on the example of a toroidal compound $\mathrm{Mo}_{138}$

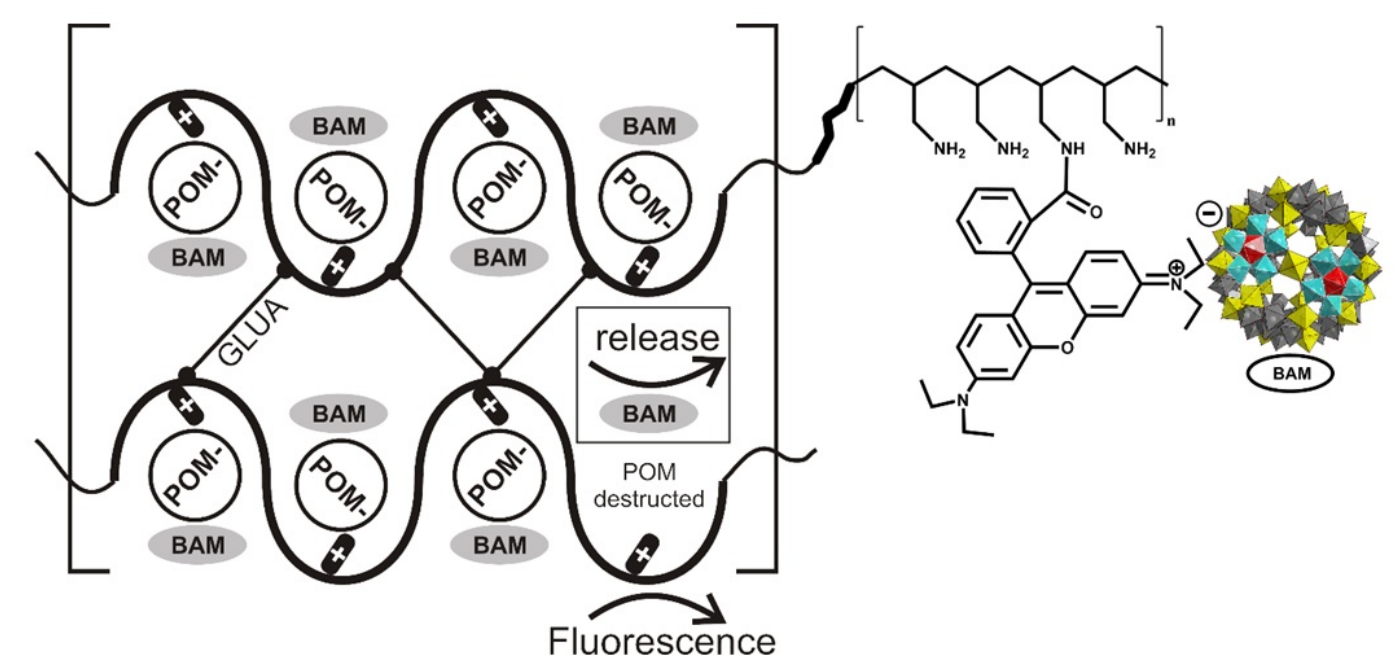

FIG. 16. Diagram of a promising POM-based releasing system. BAM - bioactive molecules; GLUA - glutaric dialdehyde

The oscillatory nature of the dependence of the physicochemical characteristics of POM-based associates (Section 3) and the possibility of influencing the compositions by ultraviolet radiation have been pointed out above. It 
is important to understand the light-influenced behavior of nanostructured objects when developing photoinduced controlled-release systems (Section 1.1) and feedback systems (Section 5). It is impossible to miss the fact that in some cases, oscillatory phenomena are observed during the impact on the systems that contain gradually destructing POMs, [297,303]. In this case, fluctuations depend not only on the composition; temporal oscillations of fundamental physical and chemical properties, such as optical density, photovoltaic potential, etc. also occur. Oscillations of physical properties are most often characteristic of the systems containing macromolecular components, e.g., polymers or POMs [175, 201,315]. For POMs, the oscillatory phenomena prerequisites include the large size of polyanions, as well as the nonlinearity of characteristics, including the optical properties [316] of molybdenum-containing complexes (associates) with organic substances, e.g., with citric acid [317]. Due to the reversibility of redox reactions of d-metal ions (electron transfer in associates [297]), POMs are able to participate in oscillatory processes. The oscillatory phenomena mechanism can have significant differences in the differently composed systems and in varying conditions in which these phenomena are observed. Each case requires a detailed consideration, which we did below for the above-described systems containing $\mathrm{Mo}_{132}$, rhodamine-B, and also showing signs of properties oscillation.

The experiments aimed at studying $\mathrm{Mo}_{132}$ destruction in aqueous solutions with a concentration of $5.4 \mu \mathrm{M}$ and in contact with argon showed that this process is stimulated by the influence of light [303]. For irradiation, two LEDs were used together, the first of which emitted light mainly at 630 and $570 \mathrm{~nm}$ wavelengths, and the second at $466 \mathrm{~nm}$. This combination made it possible to reproduce the main spectral components of daylight. Before irradiation of the solutions, they were preliminarily purged with argon. In the course of the experiments (Fig. 17), there was a general decrease in the optical density (A) at $455 \mathrm{~nm}$ wavelength, associated with POM destruction, and the measured value A was found to fluctuate exceeding the measurement error. The previously performed experiments [318] demonstrated similar oscillations related to the potential difference $\mathrm{U}$ between the frontally $\mathrm{UV}$-irradiated $\mathrm{Mo}_{132}$ solution, which also contained polyvinyl alcohol (PVA), and a likewise solution, though light-protected (Fig. 18). The potential difference had a negative value and increased with time. It occurred due to a decrease in the $\mathrm{Mo}(\mathrm{V})$ concentration in the irradiated solution during the photochemical destruction of POM, and the oxidation to Mo(VI) during $\mathrm{Mo}_{132}$ destruction despite the presence of PVA. On the contrary, when other POMs were present in solutions instead of $\mathrm{Mo}_{132}$, partial reduction of molybdenum ions occurred during the interaction with PVA and was accompanied by an increase in positive values of the potential difference. The presence of a photoinduced potential difference accompanying the photochromic effect manifestation in molybdenum-containing systems, as well as signs of nonlinear and oscillatory processes, are also described in $[317,319]$. Oscillatory processes could occur in this case due to the partial reversibility of photochemical processes.

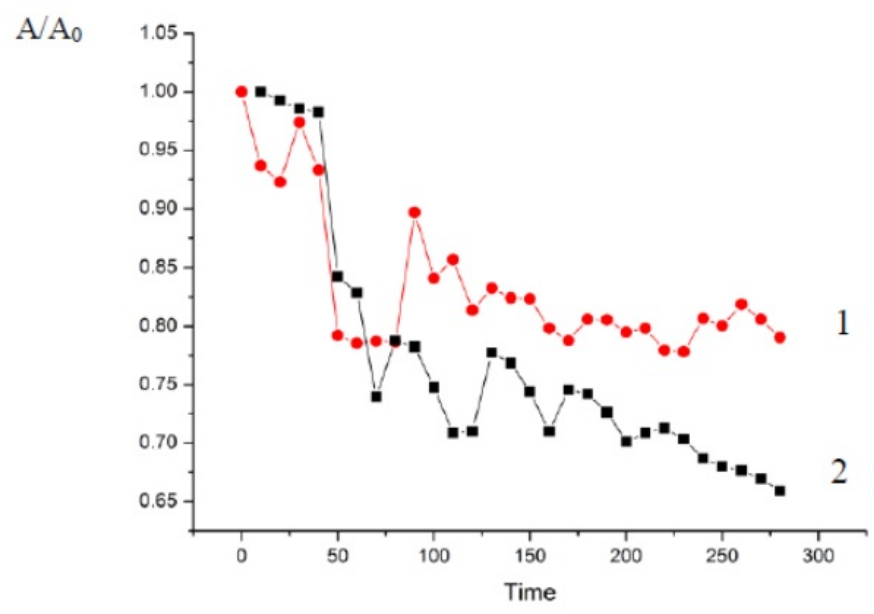

FIG. 17. Relative optical density of $\mathrm{Mo}_{132}$ solutions as a function of the irradiation time (min) in contact with argon (1) and air (2). The initial optical density is designated as 1

It should be noted that, in contrast to the systems containing, e.g., ammonium heptamolybdate, where redox reactions are reversible [297] and the occurrence of fluctuations in the potential difference is generally understandable, $\mathrm{Mo}_{132}$ destruction proceeds irreversibly [198]. The products of destruction do not absorb light intensely at the $455 \mathrm{~nm}$ wavelength characteristic of $\mathrm{Mo}_{132}$. In this relation, there arises a question about the causes of the fluctuating optical density of $\mathrm{Mo}_{132}$ solutions and of the concentration-induced potential difference. If the value of U could fluctuate due to a reversible change in the content of $\mathrm{Mo}(\mathrm{V})$, including its non-Keplerate forms, upon their interaction with PVA, then why did the optical density fluctuate? Note that the LEDs irradiated the studied solutions from above [303], i.e., 


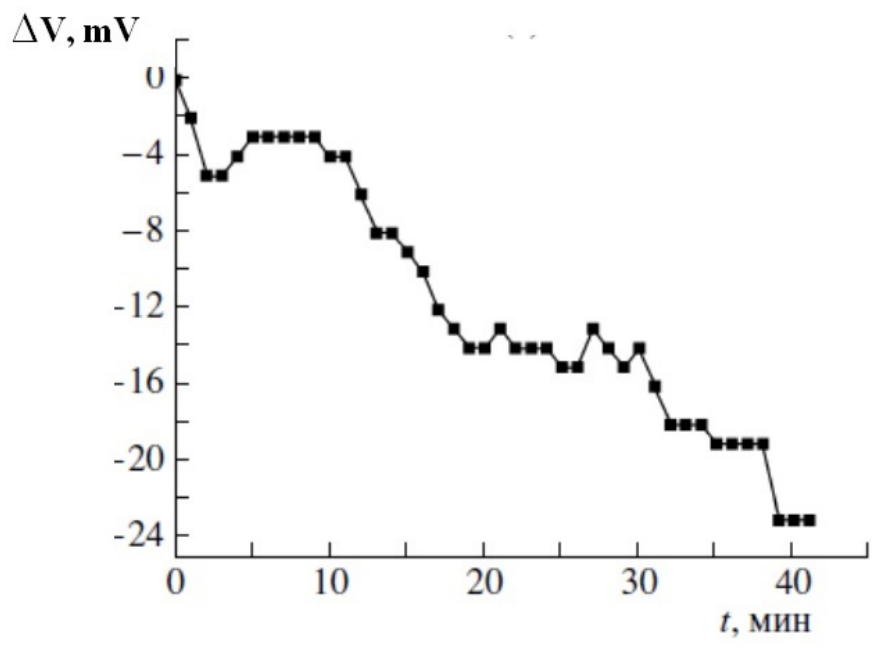

FIG. 18. Potential difference $(\Delta \mathrm{V})$ between the illuminated and light-protected $\mathrm{Mo}_{132}$ solution (0.015 wt. \%) - PVA (10 wt. \%) [318]. CPleiades Publishing, Ltd. 2009

from where the gaseous medium was in contact with the solutions. In this case, the harder part of the LEDs radiation at $466 \mathrm{~nm}$ was absorbed by the solution itself, the characteristic wavelength of which is in the near region. Therefore, it can be assumed that the photoinitiated reaction of $\mathrm{Mo}_{132}$ destruction, accompanied by the oxidation of molybdenum to Mo(VI), was localized precisely at the solution surface in a relatively thin layer, the thickness of which did not exceed $0.5 \mathrm{~mm}$ [320]. In this case, the described above potential difference appeared between the liquid-gas interface and bulk solution. So, the solution surface can be considered formally as a positive electrode (cathode). The reaction of POM oxidative destruction, which occurs due to the interaction with residual oxygen in argon (no more than 1 vol.\%), can be written for this case, in principle, as the sum of two half-reactions, e.g., the following ones:

$7 \mathrm{Mo}_{72}^{V I} \mathrm{Mo}_{60}^{V} \mathrm{O}_{372}^{12-}+564 \mathrm{H}_{2} \mathrm{O}-252 \mathrm{e} \Rightarrow 132 \mathrm{Mo}_{7} \mathrm{O}_{24}^{6-}+1128 \mathrm{H}^{+}$

$\mathrm{O}_{2}+4 \mathrm{H}^{+}+4 \mathrm{e} \Rightarrow 2 \mathrm{H}_{2} \mathrm{O}$.

In total: $7 \mathrm{Mo}_{72}^{V I} \mathrm{Mo}_{60}^{V} \mathrm{O}_{372}^{12-}+438 \mathrm{H}_{2} \mathrm{O}+63 \mathrm{O}_{2}=132 \mathrm{Mo}_{7} \mathrm{O}_{24}^{6-}+876 \mathrm{H}^{+}$.

The oxidation-reduction potentials of the components of the considered system make the above reaction feasible. At least for the second half-reaction, the standard potential is $+1.229 \mathrm{~V}$.

During $\mathrm{Mo}_{132}$ decomposition in accordance with the proposed reaction scheme, the acidity of the medium is supposed to increase, which was confirmed experimentally [198]. The potential difference between the solution surface layer and its lower part should accelerate the migration of protons (hydronium ions $\mathrm{H}_{3} \mathrm{O}^{+}$) deeper into the solution and the supply of anions to the cathode. Taking into account the circumstance that the spectrophotometer beam aperture did not cover the entire measuring cell and the beam was passing through its middle part, it can be assumed that the relative increase in optical density in the observed oscillations was associated with an increase in the Mo $\mathrm{M}_{132}$ concentration in the aperture due to the accelerated diffusion from the lower part of the cell. The diffusion coefficients of hydronium ions and polyanions are sufficiently different; therefore, an oppositely directed diffusion potential could occur in the system under study, which, on the contrary, slowed down the flow of ions, thus leading to a stepwise decrease in the value of A (Fig. 17), since POM destruction continued. The interaction of these factors could lead to the observed fluctuations.

Another factor that could potentially lead to a temporary partial blocking of the reaction of POM destruction is the oxygen deficiency in the solution, because the rate of oxygen dissolution in a liquid medium is limited. The value of $\mathrm{D}$, the coefficient of oxygen diffusion in an aqueous medium given in [320], is around $2 \cdot 10^{-5} \mathrm{~cm}^{2} / \mathrm{s}$. A comparison of this value with the effective $\mathrm{D}$ value of $\mathrm{Mo}_{132}$ polyanions under electrodiffusion conditions $\left(1.8 \cdot 10^{-7} \mathrm{~cm}^{2} / \mathrm{s}\right)$ [107] (POM concentration of $4 \cdot 10^{-4} \mathrm{~mol} / \mathrm{L}$ ), shows that the latter are much less mobile. For this reason, the supply of polyanions to the solution surface is more likely the limiting stage of the oxidative photodecomposition process. In this case, the diffusion restrictions, as well as fluctuations of A values, can at least be partially removed due to intensive vertical mixing of the solution. However, this is difficult to implement with the used measurement scheme. On the other hand, in order to obtain additional information, it is possible to increase the oxygen content in the medium contacting the solution, as it was done in the next experiment (Fig. 17) by replacing argon with air. With an increase in the oxygen content in the gaseous medium, the process of POM destruction accelerated in general, but the optical density fluctuations did not disappear, which indirectly confirms the hypothesized mechanism of the occurrence of oscillations 
of A. In addition, attention should be paid to the amount of oxygen required in accordance with the reaction scheme for the oxidation of $\mathrm{Mo}_{132}$ in the solution: it takes about $1.5 \cdot 10^{-6} \mathrm{~g}$ of oxygen per $1 \mathrm{ml}$ of a solution in the used concentration. The solubility of oxygen at room temperature in water and diluted solutions is about $6.6 \cdot 10^{-3} \mathrm{~g} / \mathrm{L}$. If $1 \mathrm{ml}$ of the initial solution could contain about $6.6 \cdot 10^{-6} \mathrm{~g}$ of dissolved oxygen, then its amount was about 4.4 times higher than that required for POM oxidation.

The photochemical nature of POM oxidative destruction can be confirmed by the stabilization of $\mathrm{Mo}_{132}$ upon formation of its associates with rhodamine-B, a dye of the xanthene series [303] (the main absorption maximum at a wavelength of $558 \mathrm{~nm}$, near one of the maxima of the used LED). Stabilization manifests itself, for instance, during irradiation of such solutions $\left(\mathrm{Mo}_{132}\right.$ - RhB molar ratio of 1:8) in contact with air (Fig. 19). In another case, when a substance that is more easily oxidized than POM is in contact with the above associates, the $\mathrm{Mo}_{132}$-rhodamine-B system is capable of playing the role of a photoactivated catalyst. The oxidation of compounds such as toluene and isopropyl alcohol proceeds under quite mild conditions. Toluene is selectively oxidized to benzyl alcohol and benzaldehyde [321], and isopropyl alcohol is oxidized to acetone. Photoactivated compounds of the nanocluster type, including d-metals in different oxidation states, can be practically useful as catalysts for the oxidation of organic compounds [322,323], for instance in processes of organic synthesis, and of alternative energetics (hydrogen production) for reducing the potential of electrochemical decomposition of aqueous solutions [324]. Examples of the use of molybdenum and tungsten compounds in the photolysis of water [316,325] are known from the literature.

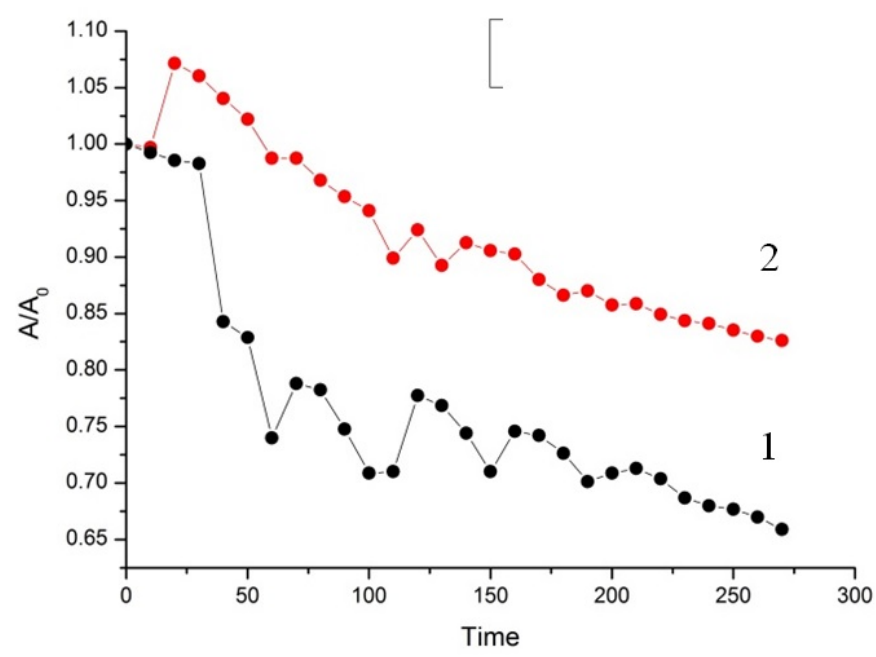

FIG. 19. Relative optical density of the irradiated solutions of $\mathbf{M o}_{132}$ (1) and $\mathbf{M o}_{132}$ - rhodamin-

B (2) in contact with air (as a function of time, in min)

So, it has been shown that diffusion processes can be the cause of the oscillatory phenomena occurrence, in particular, of oscillations of the measured optical density of $\mathrm{Mo}_{132}$ POM aqueous solutions under local exposure to light. In the studied system, the processes of POM oxidative photodestruction occurring in the surface part of the solution, are limited by the mobility of $\mathrm{Mo}_{132}$ polyanions, the speed of which periodically changes depending on the ratio of the values of the concentration and diffusion potentials arising between the surface of the solution and its deep part. Further studies of oscillatory phenomena involving POM are of interest, especially taking into account the possibility of using these compounds in catalysis. It should be assumed that similar phenomena can occur in the body's environment, and it should be taken into account, in particular, when monitoring drug release.

\section{Conclusion}

Thus, there are a number of factors that make it possible to consider molybdenum-based nanocluster POMs as compounds for use in biomedicine which show promise. These physical and biochemical properties include: the ability of POMs to undergo decomposition in vivo; the absence of accumulation of POM and their components in organs and tissues due to elimination in the course of natural metabolism; the possibility of obtaining conjugates of drugs and bioactive substances (including protein), biocompatible polymers, indicator dyes; targeted transport (for instance, ionophoresis) of POM and their conjugates into the body. $\mathrm{Mo}_{72} \mathrm{Fe}_{30}$ is able to penetrate into immuno-privileged organs (e.g., brain, eyes, thymus, spleen, etc.) and overcome blood-tissue barriers. At the same time, $\mathrm{Mo}_{72} \mathrm{Fe}_{30} \mathrm{has}$ low toxicity for warm-blooded organisms; its administration by various methods does not lead to disruption of organs 
and systems, being reflected only in small reversible changes at the metabolic level, e.g., in the aminotransferase activity. In addition, it was noted that the organism of animals (rats) is capable of adapting to the influence of POM, which, among other things, provides the normalization of the above-mentioned parameter. The effect of $\mathrm{Mo}_{72} \mathrm{Fe}_{30}$ at the molecular level revealed itself only in a change in the content of heat shock proteins, which are involved in the adaptation of the organism and maintenance of homeostasis. The single and multiple action of POM did not cause a decrease in the amount of histone proteins in blood lymphocytes, which makes a suggestion about the absence of autoimmune aggression of these cells against liver tissue. The effect of rapid recovery of the hemoglobin level and the number of erythrocytes was established upon administration of $\mathrm{Mo}_{72} \mathrm{Fe}_{30}$ preparations to animals in a state of post-hemorrhagic anemia. It indicates the possibility of therapeutic use for POMs, which have a positive effect on the processes of erythropoiesis.

$\mathrm{Mo}_{132}$, which contains $\mathrm{Mo}(\mathrm{V})$, is more toxic than $\mathrm{Mo}_{72} \mathrm{Fe}_{30}$, in general. A study of the effect of these two POMs on cell cultures of normal and transformed fibroblasts showed that $\mathrm{Mo}_{72} \mathrm{Fe}_{30}$ is practically non-toxic for normal fibroblasts, while $\mathrm{Mo}_{132}$ is toxic for both normal and transformed fibroblasts, and its damaging effect on transformed fibroblasts is stronger: a decrease in cell proliferative activity and an accelerated differentiation of transformed rat fibroblasts were recorded. The experimental results indicate the potential use of $\mathrm{Mo}_{132}$ in chemotherapy.

It is important to study the aspects related to the processes of POM destruction under various conditions in their free and conjugated states, as it allows predicting the lifetime of POM-based functional transport units and regulating their stability. The studies have shown possible mechanisms of POM destruction, including photoinitiated ones, and established that stabilizing factors can include self-aggregation of POM into hollow globular associates, the interaction of POM with such biogenic ions as calcium, and association with water-soluble nonionic biocompatible polymers. One of the most important stabilizing factors influencing POM upon entering normal alkaline environments of the body (e.g., blood) is the interaction with proteins, in particular, with albumins (protein corona appearance), while in the environment of a corresponding alkaline buffer solution, POMs decompose much more quckly.

Fundamental approaches for the creation of new POM-based controlled releasing systems with feedback have been proposed. In these systems, POM conjugates with a drug and an indicator luminescent dye are initially bound with a matrix of a biocompatible polymeric organic or inorganic carrier in the microgel composition. This should ensure prolonged release of drugs and simultaneous monitoring of their residual concentration indicated by the fluorescent signal of the dye molecules.

\section{Acknowledgements}

The paper was prepared in the framework of implementation of the State Assignment from the Ministry of Education and Science of the Russian Federation (Projects Nos. AAAA-A20-120061990010-7 (FEUZ-2020-0052) and AAAA-A18-118020590107-0), as well as of the Program for Increasing Competitiveness of UrFU (financially supported according to the Decree No. 211 of the Government of the Russian Federation, Contract No. 02.A03.21.0006). The research aimed at creating the long-time drug release systems with feedback was carried out within the framework of the project of the Russian Science Foundation No. 19-73-00177.

\section{References}

[1] Gregoriadis G., Swain C.P., Wills E.J., Tavill A.S. Drug-carrier potential of liposomes in cancer chemotherapy. Lancet, 1974, 1, P. $1313-1316$.

[2] Torchilin V.P. Recent advances with liposomes as pharmaceutical carriers. Nat. Rev. Drug Discov., 2005, 4, P. 145-160.

[3] Johnston M.J., Semple S.C., Klimuk S.K., Ansell S., Maurer N., Cullis P.R. Characterization of the drug retention and pharmacokinetic properties of liposomal nanoparticles containing dihydrosphingomyelin. Biochim. Biophys. Acta, 2007, 1768, P. 1121-1127.

[4] Fenske D.B., Cullis C.A. Liposomal Nanomedicines: An Emerging Field. Toxicologic Pathology, 2008, 36, P. $21-29$.

[5] Raney S.G., Wilson K.D., Sekirov L., Chikh G., de Jong S.D., Cullis P.R., Tam Y.K. The effect of circulation lifetime and drug-to-lipid ratio of intravenously administered lipid nanoparticles on the biodistribution and immunostimulatory activity of encapsulated CpG-ODN. J. Drug. Target, 2008, 16(7), P. 564-77.

[6] Fenske D.B., Cullis P.R. Liposomal Nanomedicines. Expert Opin. Drug. Deliv., 2008, 5(1), P. 25-44.

[7] Farokhzad O.C., Langer R. Impact of Nanotechnology on Drug Delivery. ACS Nano, 2009, 3(1), P. 16-20.

[8] Takahama H., Minamino T., Asanuma H. Fujita M., Asai T., Wakeno M., Sasaki H., Kikuchi H., Hashimoto K., Oku N., Asakura M., Kim J., Takashima S., Komamura K., Sugimachi M., Mochizuki N., Kitakaze M. Prolonged targeting of ischemic/reperfused myocardium by liposomal adenosine augments cardioprotection in rats. J. Amer. College of Cardiology, 2009, 53(8), P. 709-717.

[9] Chen Y., Bose A., Bothun G.D. Controlled Release from Bilayer-Decorated Magnetoliposomes via Electromagnetic Heating. ACS Nano, 2010, 4(6), P. 3215-3221.

[10] Parashar A.K., Kakde D., Chadhar V., Devaliya R, Shrivastav V., Jai U.K. A review on Solid Lipid Nanoparticles (SLN) for controlled and targeted delivery of medicinal agents. Curr. Res. Pharm. Sci., 2011, 1(2), P. 367-47.

[11] Anwekar H., Patel S., Singhai A.K. Liposomes as drug carriers. Int. J. Pharm. Life Sci. (IJPLS), 2011, 2(7), P. 945-951.

[12] Tam Y.C., Chen S., Cullis P.R. Advances in Lipid Nanoparticles for siRNA Delivery. Pharmaceutic, 2013, 5, P. 498-507.

[13] Akbarzadeh A., Rezaei-Sadabady R., Nejati K. Liposome: classification, preparation, and Applications. Nanoscale Research Letters, 2013, 8(1), P. 102-111. 
[14] Smyslov R.Yu., Ezdakova K.V., Kopitsa G.P., Khripunov A.K., Bugrov A.N., Tkachenko A.A., Angelov B., Pipich V., Szekely N.K., Baranchikov A.E., Latysheva E., Chetverikov Yu.O., Haramus V. Morphological structure of Gluconacetobacter xylinus cellulose and cellulose-based organic-inorganic composite materials. J. Phys.: Conf. Ser., 2017, 848(1), P. 012017.

[15] Almjasheva O.V., Garabadzhiu A.V., Kozina Yu.V., Litvinchuk L.F., Dobritsa V.P. Biological effect of zirconium dioxide-based nanoparticles. Nanosystems: Physics, Chemistry, Mathematics, 2017, 8(3), P. 391-396.

[16] Popov A.L., Shcherbakov A.B., Zholobak N.M., Baranchikov A.Ye., Ivanov V.K. Cerium dioxide nanoparticles as third-generation enzymes (nanozymes). Nanosystems: Physics, Chemistry, Mathematics, 2017, 8(6), P. 760-781.

[17] Shydlovska O., Kharchenko E., Zholobak N., Shcherbakov A., Marynin A., Ivanova O., Baranchikov A., Ivanov V. Cerium oxide nanoparticles increase the cytotoxicity of TNF alpha in vitro. Nanosystems: Physics, Chemistry, Mathematics, 2018, 9(4), P. 537-543.

[18] Almjasheva O.V., Smirnov A.V., Fedorov B.A., Tomkovich M.V., Gusarov V.V. Structural features of $\mathrm{ZrO}_{2}-\mathrm{Y}_{2} \mathrm{O}_{3}$ and $\mathrm{ZrO}_{2}-\mathrm{Gd}_{2} \mathrm{O}_{3}$ nanoparticles formed under hydrothermal conditions. Russ. J. Gen. Chem., 2014, 84(5), P. 804-809.

[19] Popov A.L., Savintseva I.V., Mysina E.A., Shcherbakov A.B., Popova N.R., Ivanova O.S., Kolmanovich D.D., Ivanov V.K. Cytotoxicity analysis of gadolinium doped cerium oxide nanoparticles on human mesenchymal stem cells. Nanosystems: Physics, Chemistry, Mathematics, 2018, 9(3), P. 430-438.

[20] Vardanyan Z., Gevorkyan V., Ananyan M., Vardapetyan H., Trchounian A. Effects of various heavy metal nanoparticles on Enterococcus hirae and Escherichia coli growth and proton coupled membrane transport. J. Nanobiotechnol, 2015, 13(69), P. 2-9.

[21] Popov A.L., Ermakov A.M., Shekunova T.O., Shcherbakov A.B., Ermakova O.N., Ivanova O.S., Popova N.R., Baranchikov A.Ye., Ivanov V.K. PVP-stabilized tungsten oxide nanoparticles inhibit proliferation of NCTC L929 mouse fibroblasts via induction of intracellular oxidative stress. Nanosystems: Physics, Chemistry, Mathematics, 2019, 10(1), P. 92-101.

[22] Sharker S.Md., Kim S.M., Lee J.E., Choi K.H., Shin G., Lee S., Lee D.K., Jeong J., Park S.Y. Functionalized biocompatible WO3 nanoparticles for triggered and targeted in vitro and in vivo photothermal therapy. J. Control. Release, 2015, 217, P. $211-220$.

[23] Zhou Z., Kong B., Yu C., Shi X., Wang M., Liu W., Sun Y., Zhang Y., Yang H., Yang S. Tungsten Oxide Nanorods: An Efficient Nanoplatform for Tumor CT Imaging and Photothermal Therapy. Sci. Rep., 2014, 4, P. 3653-3663.

[24] Xing Y., Li L., Ai X., Fu L. Polyaniline-coated upconversion nanoparticles with upconverting luminescent and photothermal conversion properties for photothermal cancer therapy. Intern. J. Nanomed., 2016, 11, P. 4327-4338.

[25] Slowing I.I. Mesoporous silica nanoparticles as controlled release drug delivery and gene transfection carriers. Adv. Drug Deliv. Rev., 2008, 60(11), P. 1278-1288.

[26] Kroto H.W., Heath J.R., O’Brien S.C., Curl, R.F. C 6 0: Buckminsterfullerene. Nature, 1985, 318, P. $162-163$.

[27] Mendes R.G., Bachmatiuk A., Buchner B., Cuniberti G., Rummeli M.H. Carbon nanostructures as multi-functional drug delivery platforms. J. Mater. Chem. B, 2013, 1(4), P. 401-428.

[28] Mo K., Jiang T., Sun W., Gu Z. ATP-responsive DNA-graphene hybrid nanoaggregates for anticancer drug delivery. Biomater, 2015, 50, P. 67-74.

[29] Thabitha P., Shareena D., McShan D., Dasmahapatra A.K., Tchounwou P.B. A Review on Graphene-Based Nanomaterials in Biomedical Applications and Risks in Environment and Health. Nano-Micro Lett., 2018, 10(53), P. 1-34.

[30] Ren L., Zhang Y., Cui C., Bi Y., Ge X. Functionalized graphene oxide for anti-VEGF siRNA delivery: preparation, characterization and evaluation in vitro and in vivo. RSC Adv., 2017, 7, P. 20553-20566.

[31] Jakubek L.M., Marangoudakis S., Raingo J., Liu X., Lipscombe D., Hurt R.H. The inhibition of neuronal calcium ion channels by trace levels of yttrium released from carbon nanotubes. Biomater., 2009, 30, P. 6351-6357.

[32] Bianco A., Kostarelos K., Partidos C.D., Prato M. Biomedical applications of functionalized carbon nanotubes. Chem. Commun. (Cambridge, UK), 2005, 5, P. 571-577.

[33] Singh R., Pantarotto D., McCarthy D. Binding and condensation of plasmid DNA onto functionalized carbon nano-tubes: toward the construction of nanotube-based gene delivery vectors. J. Am. Chem. Soc., 2005, 127, P. 4388-4396.

[34] Mahmood M., Karmakar A., Fejleh A., Mocan T., Iancu C., Mocan L., Iancu D.T., Xu Y., Dervishi E., Li Z., Biris A.R., Agarwal R., Ali N., Galanzha E.I., Biris A.S., Zharov V.P. Synergistic enhancement of cancer therapy using a combination of carbon nanotubes and antitumor drug. Nanomed., (London), 2009, 4, P. 883-893.

[35] Liu Z., Fan A.C., Rakhra K., Sherlock S., Goodwin A., Chen X., Yang Q., Felsher D.W., Dai H. Supramolecular stacking of doxorubicin on carbon nanotubes for in vivo cancer therapy. Angew. Chem. Int. Ed. Engl., 2009, 41(48), P. 7668-7672.

[36] Pastorin G., Wu W., Wieckwski S., Briand J.P., Kostarelos K., Prato M. Bianco A. Double functionalization of carbon nanotubes for multimodal drug delivery. Chem. Commun., 2006, 11, P. 1182-1184.

[37] Kateb B., Yamamoto V., Alizadeh D., Zhang L., Manohara H.M., Bronikowski M.J., Badie B. Multi-walled carbon nanotube (MWCNT) synthesis, preperetion, labeling, and functionalization. Immunotherapy of Cancer, Methods in Molecular Biology, 2010, 651, P. 307-317.

[38] Garcia B.O., Kharissova O.V., et al. Nanocomposites with antibacterial properties using CNTs with magnetic nanoparticles. Nanosystems: Physics, Chemistry, Mathematics, 2016, 7(1), P. 161-168.

[39] Foldvari M., Bagonluri M. Carbon nanotubes as functional excipients for nanomedicines: II. Drug delivery and biocompatibility issues. Nanomed., 2008, 4(3), P. 183-200.

[40] Cai D., Mataraza J.M., Qin Z.H., Huang Z., Huang J., Chiles T.C., Carnahan D., Kempa K., Ren Z. Highly efficient molecular delivery into mammalian cells using carbon nanotube spearing. Nat. Methods, 2005, 2, P. 449-454.

[41] Turcheniuk K., Mochalin V.N. Biomedical Applications of Nanodiamond (Review). Nanotechnology, 2017, 28, P. $252001-252027$.

[42] Rosenholm J.M., Vlasov I.I., Burikov S.A., Dolenko T.A., Shenderova O.A. Nanodiamond Based Composite Structures for Biomedical Imaging and Drug Delivery (Review). J. Nanosci. Nanotechnol., 2015, 15, P. 959-971.

[43] Kulvelis Y.V., Shvidchenko A.V., Aleksenskii A.E., Yudina E.B., Lebedev V.T., Shestakov M.S., Dideikin A.T., Khozyaeva L.O., Kuklin A.I., Gy T., Rulev M.I., Vul A.Y. Stabilization of detonation nanodiamonds hydrosol in physiological media with poly (vinylpyrrolidone). Diamond and Related Mater., 2018, 87, P. 78-89.

[44] Girard H., Pager V., Simic V., Arnault J.C. Peptide nucleic acid nanodiamonds: Covalent and stable conjugates for DNA targeting. RSC Adv., 2014, 4, P. 3566-3572.

[45] Bokarev A.N., Plastun I.L. Possibility of drug delivery due to hydrogen bonds formation in nanodiamonds and doxorubicin: molecular modeling. Nanosystems: Physics, Chemistry, Mathematics, 2018, 9(3), P. 370-377. 
[46] Giammarco J., Mochalin V.N., Haeckel J., Gogotsi Y. The adsorption of tetracycline and vancomycin onto nanodiamond with controlled release. J. Colloid Interface Sci., 2016, 468, P. 253-261.

[47] Schimke M., Steinmüller-Nethl D., Kern J., Krüger A., Lepperdinger G. Biofunctionalization of nano-scaled diamond particles for use in bone healing and tissue engineering. Experimental Gerontology, 2015, 68, P. 100.

[48] Chen M., Pierstorff E.D., Li Sh-Y., Robert Lam R., Huang H., Eiji Osawa E., Dean Ho D. Nanodiamond-mediated delivery of water-insoluble therapeutics. ASC Nano, 2009, 7(3), P. 2012-2022.

[49] Solomatin A.S., Yakovlev R.Yu., Efremenkova O.V., Sumarukova I.G., Kulakova I.I., Lisichkin G.V. Antibacterial activity of Amikacin immobilized detonation nanodiamond. Nanosystems: Physics, Chemistry, Mathematics, 2017, 8(4), P. 531-534.

[50] Vul A.Y., Dideikin A.T., Alexenskii A.E., Baidakova M.V. Detonation nanodiamonds: Synthesis, Properties and Applications. Chapter 2. In: Nanodiamond. Ed. Williams O.A. Published by the Royal Society of Chemistry, Cambridge, 2014, P. $27-48$.

[51] Bondar' V.S., Puzyr' A.P. Nanodiamonds for Biological Investigations. Physics of the Solid State, 2004, 46(4), P. 716-719.

[52] Krysanov E.Yu., Demidova T.B., Ivanova O.S., Ordzhonikidze K.G., Shcherbakov A.B., Ivanov V.K. Synergetic action of ceria nanoparticles and doxorubicin on the early development of two fish species, Danio rerio and Puntius tetrazona. Nanosystems: Physics, Chemistry, Mathematics, 2019, 10(3), P. 289-302.

[53] Semenov K.N., Andrusenko E.V., Charykov N.A., Litasova E.V., Panova G.G., Penkova A.V., Murin I.V., Piotrovskiy L.B. Carboxylated Fullerenes: Physico-Chemical Properties and Potential Applications. Prog. Solid State Chem., 2017, 47-48, P. 19-36.

[54] Tyurin D.P., Kolmogorov F.S., Cherepkova I.A., Charykov N.A., Semenov K.N., Keskinov V.A., Safyannikov N.M., Pukharenko Y.V., Letenko D.G., Segeda T.A., Shaimardanov Z. Antioxidant properties of fullerenol-d. Nanosystems: Physics, Chemistry, Mathematics, 2018, 9(6), P. 798-810.

[55] Safyannikov N.M., Charykov N.A., Garamova P.V., Semenov K.N., Keskinov V.A., Kurilenko A.V., Cherepcova I.A., Tyurin D.P., Klepikov V.V., Matuzenko M.Y., Kulenova N.A., Zolotarev A.A. Cryometry data in the binary systems bisadduct of $\mathrm{C}_{60}$ and indispensable aminoacids - lysine, threonine, oxyproline. Nanosystems: Physics, Chemistry, Mathematics, 2018, 9(1), P. 46-48.

[56] Dubinina I.A., Kuzmina E.M., Dudnik A.I., Vnukova N.G., Churilov G.N., Samoylova N.A. Study of antioxidant activity of fullerenols by inhibition of adrenaline autoxidation. Nanosystems: Physics, Chemistry, Mathematics, 2016, 7(1), P. 153-157.

[57] Shultz M.D., Duchamp J.C., Wilson J.D., Shu C.Y., Ge J., Zhang J., Gibson H.W., Fillmore H.L. Encapsulation of a radiolabeled cluster inside a fullerene cage, ${ }^{177} \mathrm{Lu}_{x} \mathrm{Lu}_{(3-x)} \mathrm{N} @ \mathrm{C}_{80}$ : an interleukin-13-conjugated radiolabeled metallofullerene platform. J. Amer. Chem. Soc., 2010, 132(14), P. 4980-4981.

[58] Bolskar R.D. Gadofullerene MRI contrast agents. Nanomedicine (Lond.), 2008, 3(2), P. 201-213.

[59] Lebedev V.T., Kulvelis Yu.V., Runov V.V., Szhogina A.A., Suyasova M.V. Biocompatible water-soluble endometallofullerenes: peculiarities of self-assembly in aqueous solutions and ordering under an applied magnetic field. Nanosystems: Physics, Chemistry, Mathematics, 2016, 7(1), P. 22-29.

[60] Kuchma E., Zolotukhin P., Belanova A., Soldatov M., Lastovina T., Kubrin S., Nikolsky A., Mirmikova L., Soldatov A. Low Toxic Maghemite Nanoparticles for Theranostic Applications. International Journal of Nanomedicine, 2017, 12, P. 6365-6371.

[61] Lojk J., Bregar V.B., Strojan K., Hudoklin S., Veranič P., Pavlin M., Kreft M.E. Increased Endocytosis of Magnetic Nanoparticles into Cancerous Urothelial Cells versus Normal Urothelial Cells. Histochemistry and Cell Biology, 2018, 149(1), P. 45-59.

[62] Firouzi M., Poursalehi R., Delavari H., Saba F., Oghabian M.A. Chitosan coated tungsten trioxide nanoparticles as a contrast agent for X-ray computed tomography. Int. J. Biol. Macromol., 2017, 98, P. 479-485.

[63] Gelperina S., Maksimenko O., Khalansky A., Vanchugova L., Shipulo E., Abbasova K., Berdiev R., Wohlfart S., Chepurnova N., Kreuter J. Drug delivery to the brain using surfactant-coated poly (lactideco-glycolide) nanoparticles: influence of the formulation parameters. Eur. $J$. Pharm. Biopharm., 2010, 74, P. 157-163.

[64] Popova N.R., Popov A.L., Shcherbakov A.B., Ivanov V.K. Layer-by-layer capsules as smart delivery systems of CeO 2 nanoparticlebasedtheranostic agents. Nanosyst. Phys. Chem. Math., 2017, 8(2), P. 282-289.

[65] Venkatesan H., Radhakrishnan S., Parthibavarman M., Kumar R.D., Sekar C. Synthesis of polyethylene glycol (PEG) assisted tungsten oxide $\left(\mathrm{WO}_{3}\right)$ nanoparticles for L-dopa bio-sensing applications. Talanta, 2011, 85(4), P. 2166-2174.

[66] Mornet S., Vasseur S., Grasset F., Duguet E. Magnetic Nanoparticle Design for Medical Diagnosis and Therapy. Journal of Materials Chemistry, 2004, 14(14), P. 2161-2175.

[67] Garanina A.S., Kireev I.I., Alieva I.B., Majouga A.G., Davydov V.A., Murugesan S., Khabashesku V.N., Agafonov V.N., Uzbekov R.E. New superparamagnetic fluorescent Fe@ $\mathrm{C}-\mathrm{C}_{5} \mathrm{ON}_{2} \mathrm{H}_{10}$-Alexa Fluor 647 nanoparticles for biological applications. Nanosystems: Physics, Chemistry, Mathematics, 2018, 9(1), P. 120-122

[68] Alieva I., Kireev I., Rakhmanina A., Garanina A., Strelkova O., Zhironkina O., Cherepaninets V., Davydov V., Khabashesku V., Agafonov V., Uzbekov R. Magnetinduced behavior of iron carbide $\left(\mathrm{Fe}_{7} \mathrm{C}_{3} @ \mathrm{C}\right)$ nanoparticles in the cytoplasm of living cells. Nanosystems: Physics, Chemistry, Mathematics, 2016, 7(1), P. 158-160.

[69] Koulikova M., Kochubey V.I. Synthesis and Optical Properties of Iron Oxide Nanoparticles for Photodynamic Therapy. Reports of Samara Scientific Center of Russian Academy of Sciences (RAS), 2012, 14(4), P. 206-209.

[70] Dykman L.A., Khlebtsov N.G. Gold Nanoparticles in Biology and Medicine: Recent Advances and Prospects. Acta Naturae, 2011, 3(2), P. 34-55.

[71] Preethika R.K., Ramya R., Ganesan M., Nagaraj S., Pandian K. Synthesis and characterization of neomycin functionalized chitosan stabilized silver nanoparticles and study its antimicrobial activity. Nanosystems: Physics, Chemistry, Mathematics, 2016, 7(4), P. 759-764.

[72] Akbarzadeh A., Mohammad Samiei M., Soodabeh Davaran S. Magnetic nanoparticles: preparation, physical properties, and applications in biomedicine. Nanoscale Res. Lett., 2012, 7, P. 144-157.

[73] Tartaj P., Morales M.D.D., Veintemillas-Verdaguer S., Gonzalez-Carreno T., Serna C.J. The preparation of magnetic nanoparticles for applications in biomedicine. J. Phys. D: Appl. Phys., 2003, 36, P. R182-R197.

[74] Ghadiri M., Vasheghani-Farahani E., Atyabi F., Kobarfard F., Mohamadyar-Toupkanlou F., Hosseinkhani H. Transferrin-conjugated magnetic dextran-spermine nanoparticles for targeted drug transport across blood-brain barrier. J. Biomed. Mater. Res. A, 2017, 105A(10), P. 28512864.

[75] MacBain S.C., Yiu H.H., Dobson J. Magnetic nanoparticles for gene and drug delivery. Int. J. Nanomed., 2008, 3(2), P. 169-180. 
[76] Akbarzadeh A., Zarghami N., Mikaeili H., Asgari D., Goganian A.M., Khiabani H.K., Samiei M., Davaran S. Synthesis, characterization, and in vitro evaluation of novel polymer-coated magnetic nanoparticles for controlled delivery of doxorubicin. Nanotechnol. Sci. Appl., 2012, 5, P. 13-25.

[77] Reddy L.H., Arias J.L., Nicolas J., Couvreur P. Magnetic nanoparticles: design and characterization, toxicity and biocompatibility, pharmaceutical and biomedical applications. Chem. Rev., 2012, 112, P. 5818-5878.

[78] Kayal S., Ramanujan R.V. Anti-cancer drug loaded iron - gold core - shell nanoparticles (Fe@ Au) for magnetic drug targeting. J. Nanosci. Nanotechnol., 2010, 10, P. 5527-5539.

[79] Popov A.L., Popova N.R., Selezneva I.I., Akkizov A.Y., Ivanov V.K. Cerium oxide nanoparticles stimulate proliferation of primary mouse embryonic fibroblasts in vitro. Materials Science and Engineering C, 2016, 68, P. 406-413.

[80] Goldt A.E., Polyakov A.Yu., Sorkina T.A., Dubov A.L., Davidova G.A., Selezneva I.I., Maximov Y.V., Presnyakov I.A., Polyakova N.Yu., Goodilin E.A., Perminova I.V. Humic acid-stabilized superparamagnetic maghemite nanoparticles: surface charge and embryotoxicity evaluation. Nanosystems: Physics, Chemistry, Mathematics, 2019, 11(3), P. 184-189.

[81] Popov A.L., Popova N., Gould D.J., Shcherbakov A.B., Sukhorukov G.B., Ivanov V.K. Ceria Nanoparticles-Decorated Microcapsules as a Smart Drug Delivery/Protective System: Protection of Encapsulated P. pyralis Luciferase. ACS Appl. Mater. Interfaces, 2018, 10, P. 1436714377.

[82] Popov A.L., Popova N.R., Tarakina N.V., Ivanova O.S., Ermakov A.M., Ivanov V.K., Sukhorukov G.B. Intracellular Delivery of Antioxidant $\mathrm{CeO}_{2}$ Nanoparticles via Polyelectrolyte Microcapsules. ACS Biomater. Sci. Eng., 2018, 4, P. 2453-2462.

[83] Popov A.L., Popova N., Gould D.J., Shcherbakov A.B., Sukhorukov G.B., Ivanov V.K. Ceria Nanoparticles-Decorated Microcapsules as a Smart Drug Delivery/Protective System: Protection of Encapsulated P. pyralis Luciferase. ACS Appl. Mater. Interfaces, 2018, 10, P. 1436714377.

[84] Pope M.T., Müller A. Polyoxometalate Chemistry: An Old Field with New Dimensions in Several Disciplines. Angew. Chem., Int. Ed. Engl., 1991, 30, P. 34-48.

[85] Pope M.T. Heteropoly and Isopoly Oxometalates. New York: Springer Verlag, 1983, 180 pp.

[86] Proust A. Functionalized Polyoxometalates. Polyoxometalate Molecular Science, 2003, 98, P. $233-252$.

[87] Gouzerh P., Che M. From Scheele and Berzelius to Müller Polyoxometalates (POMs) revisited and the "missing link" between the bottom up and top down approaches. L'actualité chimique. Recherche et développement, 2006, 298, P. 1-14.

[88] Müller A., Krickemeyer E., Meyer J., Bögge H., Peters F., Plass W., Diemann E., Dillinger S., Nonnenbruch F., Randerath M, Menke C. $\left[\mathrm{Mo}_{154}(\mathrm{NO})_{14} \mathrm{O}_{420}(\mathrm{OH})_{28}\left(\mathrm{H}_{2} \mathrm{O}\right)_{70}\right]^{(25 \pm 5)-}$ : A Water Soluble Big Wheel with More than 700 Atoms and a Relative Molecular Mass of About 24000. Angew. Chem. Int. Ed., 1995, 34(19), P. 2122-2124.

[89] Liu T., Diemann E., M?üller A. Hydrophilic Inorganic Macro-Ions in Solution: Unprecedented Self-Assembly Emerging from Historical "Blue Waters". J. Chemical Education, 2007, 84(3), P. 526-532.

[90] Müller A., Maiti R., Schmidtmann M., Bögge H., Samar K.D., Zhang W. Mimicking oxide surfaces: different types of defects and ligand coordination at well defined positions of a molybdenum oxide based nanocluster. Chem. Commun., 2001, P. $2126-2127$.

[91] Zhu Y., Cammers-Goodwin A., Zhao B., Dozier A., Dickey E.C. Kinetic precipitation of solution-phase polyoxomolybdate followed by transmission electron microscopy: A window to solution-phase nanostructure. Chem. Eur. J., 2004, 10, P. $2421-2427$.

[92] Müller A., Krickemeyer E., Bögge H., Schmidtmann M., Peters F. Organizational Forms of Matter: An Inorganic Super Fullerene and Keplerate Based on Molybdenum Oxide. Angewandte Chemie International Edition, 1998, 37(24), P. 3359-3363.

[93] Müller A., Gouzerh P. From Linking of Metal-Oxide Building Blocks in a Dynamic Library to Giant Clusters with Unique Properties and towards Adaptive Chemistry. Chemical Society Reviews, 2012, 41(22), P. 7431-7463.

[94] Ostroushko A.A., Korotaev V.Yu., Tonkushina M.O., Vazhenin V.A., Artemov M.Yu., Men'shikov S.Yu., Kutyashev I.B. Spectroscopic studies of molybdenum polyoxometallates with the buckyball structure and polymer-containing compositions based thereon. Russ. J. Inorg. Chem., 2011, 56(2), P. 276-281.

[95] Müller A., Diemann E., Shah S. Q. N., Kuhlmann C., Letzel M.C. Soccer-Playing Metal Oxide Giant Spheres: A First Step Towards Patterning Structurally Well Defined Nano-Object Collectives. Chem. Commun., 2002, P. 440-441.

[96] Müller A., Polarz S., Das S.K., Krickemeyer E., Bögge H., Schmidtmann M., Hauptfleisch B. "Open and shut” for guests in molybdenum oxide-based giant spheres, baskets, and rings containing the pentagon as a common structural element. Angew. Chem. Int. Ed., 1999, 38(21), P. 3241-3245.

[97] Müller A., Botar B., Das S.K., Bögge H., Schmidtmann M., Merca A. On the complex hedgehog-shaped cluster species containing 368 Mo atoms: simple preparation method, new spectral details and information about the unique formation. Polyhedron, 2004, 23(15), P. 2381-2385.

[98] Hall N. Bringing Inorganic Chemistry to Life. Chem. Commun. (The Royal Society of Chemistry), 2003, 7, P. 803-806.

[99] Müller A., Sarkar S., Shah S.Q.N., Bögge H., Schmidtmann M., Sarkar S., Kögerler P., Hauptfleisch B., Trautwein V.X., Schünemann V. Archimedean Synthesis and Magic Numbers: "Sizing" Giant Molybdenum-Oxide-Based Molecular Spheres of the Keplerate Type. Angew. Chem. Int. Ed. Engl., 1999, 38(21), P. 3238-3241.

[100] Liu T., Imber B., Diemann E., Liu G., Cokleski K., Li H., Chen Z., M?üller A. Deprotonations and Charges of Well-Defined Mo 72 Fe 30 Nanoacids Simply Stepwise Tuned by $\mathrm{pH}$ Allow Control/Variation of Related Self-Assembly Processes. Journal of the American Chemical Society, 2006, 128(49), P. 15914-15920.

[101] Besson C., Schmitz S., Capella K.M., Kopilevich S., Weinstock I.A., Kögerler P. A regioselective Huisgen reaction inside a Keplerate polyoxomolybdate nanoreactor. Dalton Trans., 2012, 41(33), P. 9852-9854.

[102] Henry M., Bögge H., Diemann E., Müller A. Chameleon water: assemblies confined in nanocapsules. J. Mol. Liq., 2005, 118(1-3), P. 155162.

[103] Müller A., Gouzerh P. From linking of metal-oxide building blocks in a dynamic library to giant clusters with unique properties and towards adaptive chemistry. Chem. Soc. Rev., 2012, 41(22), P. 7431-7463.

[104] Popa A.M., Hu L., Crespy D., Henry M., Rene M., Rossi R.M. Polyoxomolybdate-based selective membranes for chemical protection. J. Membrane Science, 2011, 373(1-2), P. 196-201.

[105] Ostroushko A.A., Sennikov M.Yu., Tonkushina M.O. Interaction of Polyoxometalate Mo132 with Poly(vinyl alcohol). Russ. J. Inorg. Chem., 2009, 54(4), P. 617-623. 
[106] Ostroushko A.A., Tonkushina M.O., Korotaev V.Yu., Prokof'eva A.V., Kutyashev I.B., Vazhenin V.A., Danilova I.G., Men'shikov S.Yu. Stability of the $\mathrm{Mo}_{72} \mathrm{Fe}_{30}$ Polyoxometalate Buckyball in Solution. Russ. J. Inorg. Chem., 2012, 57(9), P. $1210-1213$.

[107] Ostroushko A.A., Tonkushina M.O., Martynova N.A. Mass and charge transfer in systems containing nanocluster molybdenum polyoxometallates with a fullerene structure. Russ. J. Phys. Chem. A, 2010, 84(6), P. 1022-1027.

[108] Ostroushko A.A., Gagarin I.D., Tonkushina M.O., Grzhegorzhevskii K.V., Gette I.F., Medvedeva S.Yu., Mukhlynina E.A., Ulitko M.V., Danilova I.G. Promissing Means of Targeted Delivery of Medical Product on the Basis of Nanocluster Polyoxometalates // XX Mendeleev Congress on general and applied chemistry. Five volumes book. Vol. 4: abstracts. - Ekaterinburg: Ural Branch of the Russian Academy of Sciences, 2016. P. 511.

[109] Grzhegorzhevskii K., Ostroushko A., Koriakova O., Ovchinnikova I., Kim G. Photoinduced charge transfer in the supramolecular structure based on toroid polyoxomolibdate $\mathrm{Mo}_{138}$ and xanthene dye - Rhodamine-B. Inorganica Chim. Acta, 2015, 436, P. $205-213$.

[110] Grzhegorzhevskii K.V., Adamova L.V., Eremina E.V., Ostroushko A.A. On the Possibility of Controlling the Hydrophilic/Hydrophobic Characteristics of Toroid Mo 138 Nanocluster Polyoxometalates. Russ. J. Phys. Chem. A, 2017, 91(3), P. 561-568.

[111] Grzhegorzhevskii K.V., Ostroushko A.A. Supramolecular Structural Design in a System Based on Nanocluster Mo 138 and a Cationic Surfactant: Influence of Components Ratio and $\mathrm{pH}$ of the Solutions. Colloids and Surfaces A. Physicochemical and Engineering Aspects, 2015, 480, P. 130-137.

[112] Ostroushko A.A., Fedorova O.V., Titova Yu.A., Vigorov K.V., Grzhegorzhevskii K.V. Enantioselective Catalytic Effect of Soft Thermal Decomposition Products of Iron-Molybdenum Polyoxometalat. Proceedings of the 3rd All-Russian Conference with International Participation on Advances of Synthesis and Complex Formation, Moscow, Russia, April 21-25, 2014, (RUDN, Moscow, 2014$), 2$, P. 207.

[113] Ostroushko A.A., Fedorova O.V., Titova Yu.A., Grzhegorzhevskii K.V. Iron-Molybdenum Polyoxometalat: Enantioselective Catalytic Activity of Soft Thermal Decomposition Products. Proceedings of the 2nd Russian Congress on Catalysis ROSKATALIZ, Samara, October 2-5, 2014, Ed. by V.N. Parmon and A.S. Noskov, Inst. Kataliza Boreskova, Sib. Otdel. RAN, Novosibirsk, 2014, 2, P. 75.

[114] Michelis F.V., Delitheos A., Tiligada E. Molybdate modulates mitogen and cyclosporin responses of human peripheral blood lymphocytes. Journal of Trace Elements in Medicine and Biology, 2011, 25, P. 138-142.

[115] Yamase T. Polyoxometalates for Molecular Devices: Antitumor Activity and Luminescence. Molecular Engineering, 1993, 3(1-3), P. 241262.

[116] Yamase T., Fujita H., Fukushima K. Medical Chemistry of Polyoxometalates. Part 1. Potent Antitumor Activity of Polyoxomolybdates on Animal Transplantable Tumors and Human Cancer Xenograft. Inorganica Chimica Acta, 1988, 151(1), P. 15-18.

[117] Merca A., Haupt E.T.K., Mitra T., Bögge H., Rehder D., Müller A. Mimicking biological cation-transport based on sphere-surface supramolecular chemistry: Simultaneous interaction of porous capsules with molecular plugs and passing cations. Chemistry - a European Journal, 2007, 13(27), P. 7650-7658.

[118] Ziv A., Grego A., Kopilevich S., Zeiri L., Miro P., Bo C., Müller A., Weinstock I.A. Flexible Pores of a Metal Oxide-Based Capsule Permit Entry of Comparatively Larger Organic Guests. J. Am. Chem. Soc., 2009, 131(18), P. 6380-6382.

[119] Rubcic M., Korenev V.S., Toma L., Bögge H., Fedin V.P., Müller A. Molecular recognition of Ca ${ }^{2+}$ cations by internal and external receptors/interfaces in a spherical porous molybdenum-oxide capsule: unusual coordination scenarios Inorganic Chemistry Frontiers, 2014, 1(10), P. 740-744.

[120] Watfa N., Melgar D., Haouas M., Taulelle F., Hijazi A., Naoufal D., Avalos J.B., Floquet S., Bo C., Cadot E. Hydrophobic Effect as a Driving Force for Host-Guest Chemistry of a Multi-Receptor Keplerate-Type Capsule J. Am. Chem. Soc., 2015, 137(17), P. 5845-5851.

[121] Elistratova J., Akhmadeev B., Korenev V., Sokolov M.. Nizameev I., Gubaidullin A., Voloshina A., Mustafina A. Self-assembly of Gd ${ }^{3+}$. bound keplerate polyanions into nanoparticles as a route for the synthesis of positive MRI contrast agents. Impact of the structure on the magnetic relaxivity. Soft Matter., 2018, 14(38), P. 7916-7925.

[122] Elistratova J., Akhmadeev B., Korenev V., Sokolov M., Nizameev I., Ismaev I., Kadirov M., Sapunova A., Voloshina A., Amirov R., Mustafina A. Aqueous solutions of triblock copolymers used as the media affecting the magnetic relaxation properties of gadolinium ions trapped by metal-oxide nanostructures. Journal of Molecular Liquids, 2019, 296, P. 111821.

[123] Pizzanelli S., Zairov R., Sokolov M., Mascherpa M.C., Akhmadeev B., Mustafina A., Calucci L. Trapping of Gd(III) Ions by Keplerate Polyanionic Nanocapsules in Water: A 1H Fast Field Cycling NMR Relaxometry Study. J. Phys. Chem. C, 2019, 123(29), P. 18095-18102.

[124] Yin P., Li D., Liu T. Counterion Interaction and Association in Metal-Oxide. Cluster Macranionic Solutions and the Consequent SelfAssembly. Isr. J. Chem., 2011, 51, P. 191-204.

[125] Yang H.-K., Cheng Y.-X., Su M.-M., Xiao Y., Hu M.-B., Wang W., Wang Q. Polyoxometalate-biomolecule Conjugates: A New Approach to Create Hybrid Drugs for Cancer Therapeutics. Bioorganic \& Medicinal Chemistry Letters, 2013, 23(5), P. $1462-1466$.

[126] Awada M., Floquet S., Marrot J., Haouas M., Morcillo S.P., Bour Ch., Gandon V., Coeffard V., Greck Ch., Cadot E. Synthesis and Characterizations of Keplerate Nanocapsules Incorporating L- and D-Tartrate Ligands. J. Clust. Sci., 2017, 28(2), P. $799-812$.

[127] Ostroushko A.A., Adamova L.V., Eremina E.V., Grzhegorzhevskii K.V. Interaction between nanocluster polyoxometallates and lowmolecular-weight organic compounds. Russ. J. Phys. Chem. A, 2015, 89(8), P. 1439-1444.

[128] Tonkushina M.O., Gagarin I.D., Grzhegorzhevskii K.V., Ostroushko A.A. Electrophoretic Transfer of Nanocluster Polyoxometalate $\mathrm{Mo}_{72} \mathrm{Fe}_{30}$ Associates through the Skin Membrane. Bulletin of Ural Medical Academic Science, 2014, 3(49), P. 59-61.

[129] Ostroushko A.A., Grzhegorzhevskii K.V. Electric Conductivity of Nanocluster Polyoxomolybdates in the Solid State and Solutions. Russ. J. Phys. Chem. A, 2014, 88(6), P. 1008-1011.

[130] Ostroushko A.A., Gette I.F., Danilova I.G., Mukhlynina E.A., Tonkushina M.O., Grzhegorzhevskii K.V. Studies on the Possibility of Introducing Iron-Molybdenum Buckyballs into an Organism by Electrophoresis. Nanotechnologies in Russia, 2014, 9(9-10), P. 586-591.

[131] Ostroushko A.A., Danilova I.G., Gette I.F., Tonkushina M.O., Behavior of Associates of Keplerate-Type Porous Spherical Mo72 Fe 30 Clusters with Metal Cations in Electric Field-Driven Ion Transport. Russ. J. Inorg. Chem., 2015, 60(4), P. 500-504.

[132] Ostroushko A.A., Danilova I.G., Gette I.F., Medvedeva S.Yu., Tonkushina M.O., Prokofieva A.V., Morozova M.V. Study of Safety of Molybdenum and Iron-Molybdenum Nanocluster Polyoxometalates Intended for Targeted Delivery of Drugs. Journal of Biomaterials and Nanobiotechnology, 2011, 2(5), P. 557-560.

[133] Ostroushko A.A., Gette I.F., Medvedeva S.Y., Danilova I.G., Mukhlynina E.A., Tonkushina M.O., Morozova M.V. Study of Acute and Subacute Action of Iron-Molybdenum Nanocluster Polyoxometalates. Nanotechnologies in Russia, 2013, 8(9-10), P. 672-677. 
[134] Gette I.F., Medvedeva S.Yu., Ostroushko A.A. Condition of the Immune System Organs and Blood Leucocytes in Rats after the Exposition of Iron-Molybdenum Polyoxometalates. Russian J. of Immunology, 2017, 11(2), P. 280-282.

[135] Ostroushko A.A., Tonkushina M.O. Destruction of Molybdenum Nanocluster Polyoxometallates in Aqueous Solutions. Russ. J. Phys. Chem. $A, 2015,89(3)$, P. 443-446

[136] Ostroushko A.A., Danilova I.G., Medvedeva S.J., Gette I.F., Tonkushina M.O. Studying of safety of molybden nanocluster polyoxometalates indented for address delivery of medicinal substances. Ural Medical Journal, 2010, 9(74), P. 114-117.

[137] Ostroushko A.A., Gette I.F., Medvedeva S.J., Tonkushina M.O., Danilova I.G., Prokofyeva A.V., Morozova M.V. Estimation of safety of ferrum-molybdenum nanocluster polyoxometallates indented for address delivery of medicines. Bulletin of Ural Medical Academic Science, 2011, 2(34), P. 107-110.

[138] Sodemann W.A., Sodemann Th.M. Pathologic physiology. Philadelphia: W.B.Saunders Co., 1985, 1154 pp.

[139] Ostroushko A.A., Adamova L.V., Grzhegorzhevskii K.V., Gagarin I.D., Koveza E.V., Danilova I.G., Gette I.F., Ulitko M.V., Vlasov D.A., Belozerova K.A., Men'shikov S. Yu. Studies of the Functional Properties of Nanocluster Polyoxomolybdates and Materials on Their Basis. XXI Mendeleev Congress on General and Applied Chemistry. Saint Petersburg, 2019. Book 2a: Abstracts. - Saint Petersburg, 2019 , P. 86.

[140] Zurabyan S.E. Fundamentals of Bioorganic Chemistry. GEOTAR-Media, 2012. 304 pp.

[141] Ostroushko A.A., Gette I.F., Brilliant S.A., Danilova I.G. Application of Nanocluster Iron-Molybdene Polyoxometalates for Correction of Experimental Posthemorrhagic Anemia. Nanotechnol. Russia, 2019, 14(3-4), P. 159-164.

[142] Ostroushko A.A., Tonkushina M.O., Gagarin I.D., Grzhegorzhevskii K.V., Danilova I.G., Gette I.F. Method of post-hemorragic anemia correction. Patent RU 2671077 (C1) RU, 2018.

[143] Danilova I.G., Gette I.F., Medvedeva S.Y., Mukhlynina E.A., Tonkushina M.O., Ostroushko A.A. Changing the Content of Histone Proteins and Heat-Shock Proteins in the Blood and Liver of Rats after the Single and Repeated Administration of Nanocluster Iron-Molybdenum Polyoxometalates. Nanotechnologies in Russia, 2015, 10(9-10), P. 820-826.

[144] Mecke A., Uppuluri S., Sassanella T.M., Lee D.K., Ramamoorthy A., Baker J.R. Jr., Orr B.G., Banaszak Holl M.M. Direct observation of lipid bilayer disruption by poly (amidoamine) dendrimers. Chem. Phys. Lipids, 2004, 132(1), P. 3-14.

[145] Sayes C.M., Wahi R., Kurian P.A., Liu Y., West J.L., Ausman K.D., Warheit D.B., Colvin V.L. Correlating nanoscale titania structure with toxicity: A cytotoxicity and inflammatory response study with human dermal fibroblasts and human lung epithelial cells. Toxicol Sci., 2006, 92(1), P. 174-185.

[146] Zager R.A., Johnson A.C. Progressive histone alterations and proinflammatory gene activation: consequences of heme protein/iron-mediated proximal tubule injury. Am. J. Physiol. Renal Physiol., 2010, 298(3), P. 827-837.

[147] Gette I.F. Content of histone proteins in lymphocytes of rats with alloxanic diabetes in the conditions of modulation activity of macrophages. Bulletin of Ural Medical Academic Science, 2014, 3(49), P. 19-20.

[148] Villeneuve L.M., Reddy M.A., Lanting L.L., Wang M., Meng L., Natarajan R. Epigenetic histone H3 lysine 9 methylation in metabolic memory and inflammatoryphenotype of vascular smooth muscle cells in diabetes. Proc. Natl. Acad. Sci. USA, 2008, 105(26), P. 9047-9052.

[149] Kampinga H.H., Hageman J., Vos M.J., Kubota H., Tanguay R.M., Bruford E.A., Cheetham M.E., Chen B., Hightower L.E. Guidelines for the nomenclature of the human heat shock proteins. Cell Stress Chaperones, 2009, 14(1), P. 105-111.

[150] Stacchiotti A., Rodella L.F., Ricci F., Rezzani R., Lavazza A., Bianchi R. Stress proteins expression in rat kidney and liver chronically exposed to aluminium sulphate. Histol Histopathol., 2006, 21(2), P. 131-140.

[151] Walter S., Buchner J. Molecular chaperones-cellular machines for protein folding. Angew. Chem. Int. Ed. Engl., 2002, 41(7), P. 1098-1113.

[152] Bonardi M.A., Giovanetti E., Legname G., Fossati G., Porro G., Gromo G., Modena D., Marcucci F. Cochaperonins are histone-binding proteins. Biochem. Biophys. Res. Commun., 1995, 206(1), P. 260-265.

[153] Wuillemin N., Terracciano L., Beltraminelli H., Schlapbach C., Fontana S., Krähenbühl S., Pichler W.J., Yerly D. T cells infiltrate the liver and kill hepatocytes in HLA-B(*)57:01-associated floxacillin-induced liver injury. Am. J. Pathol., 2014, 184(6), P. 1677-1682.

[154] Ghedira I., Landolsi H., Mankai A., Fabien N., Jeddi M. Antihistones antibodies in systemic lupus erythematosus, comparison of three assays: Elisa, dot blot and immunoblot. Pathol. Biol. (Paris), 2006, 54(3), P. 148-154.

[155] Westerheide S.D., Kawahara T.L., Orton K., Morimoto R.I. Triptolide, an inhibitor of the human heat shock response that enhances stressinduced cell death. J. Biol. Chem., 2006, 281(14), P. 9616-1922.

[156] Wickner S., Maurizi M.R., Gottesman S. Posttranslational quality control: folding, refolding, and degrading proteins. Science, 1999, 286(5446), P. 1888-1893.

[157] Reference book on laboratory methods of a research (Sprawochnik po laboratornym metodam issledowaniya). Ed. Danilova L.A. SPb: Piter, 2003, 736 pp. (In Russian).

[158] Chshieva F.T., Tsirihov O.T., Chsieva M.O., Muzaeva R.V., Timoshenko V.Yu. Studying the Influence of Nanocrystal Silicon on Maintenance of Aminotransferases, Alkaline Phospatase, Bilirubin and Cholesterol in Rats Blood. Reports of Samara Scientific Center of Russian Academy of Sciences (RAS), 2011, 13, 1(7), P. 1764-1766.

[159] Danilova I.G., Gette I.F., Medvedeva S.Yu., Belousova A.V., Tonkushina M.O., Ostroushko A.A. Influence of Iron-Molybdenum Nanocluster Polyoxometalates on the Apoptosis of Blood Leukocytes and the Level of Heat-Shock Proteins in the Cells of Thymus and Spleen in Rats. Nanotechnologies in Russia, 2016, 11(9-10), P. 653-662.

[160] Gette I., Ostroushko A., Danilova I., Medvedeva S., Pozdina V. Impact of iron-molybdenum polyoxometalates on the thymus and blood leukocytes in rats. Virchovs Archiv. European Journal of Pathology, 2018, 473(Suppl. 1), P. 325-326.

[161] Ostroushko A.A., Gagarin I.D., Grzhegorzhevskii K.V., Gette I.F., Vlasov D.A., Ermoshin A.A., Antosyuk O.N., Shikhova S.V., Danilova I.G. The Physicochemical Properties and Influence on Living Organisms of Nanocluster Polyoxomolybdates as Prospective Bioinspired Substances (Based on Materials from the Plenary Lecture). J. Molec. Liq., 2019, 301, P. 110910.

[162] Popov A.L., Ermakov A.M., Shekunova T.O., Shcherbakov A.B., Ermakova O.N., Ivanova O.S., Popova N.R., Baranchikov A.Ye., Ivanov V.K. PVP stabilized tungsten oxide nanoparticles inhibit proliferation of NCTC L929 mouse fibroblasts via induction of intracellular oxidative stress. Nanosystems: Physics, Chemistry, Mathematics, 2019, 10(1), P. 92-101.

[163] Ostroushko A.A., Ulitko M.V., Tonkushina M.O., Zubarev I.V., Medvedeva S.Yu., Danilova I.G., Gubaeva O.V., Gagarin I.D., Gette I.F. Influence of nanocluster molybdenum-containing polyoxometalates on the morpho-functional condition of fibroblastes in culture. Nanotechnologies in Russia, 2018, 13(1-2), P. 3-11. 
[164] Volkmer, D., Du Chesne A., Kurth D.G., Schnablegger H., Lehmann P., Koop M.J., Müller A. Toward nanodevices: Synthesis and characterization of the nanoporous surfactant-encapsuested Keplerate $(\mathrm{DODA})_{(40)}\left(\mathrm{NH}_{4}\right)_{(2)}\left[\left(\mathrm{H}_{2} \mathrm{O}\right)_{(n)}\right.$ subset of $\left.\mathrm{Mo}_{132} \mathrm{O}_{372}\left(\mathrm{CH}_{3} \mathrm{COO}\right)_{(30)}\left(\mathrm{H}_{2} \mathrm{O}\right)_{(72)}\right]$. J. Am. Chem. Soc., 2000, 122(9), P. 1995-1998.

[165] Clemente-Leon M., Ito T., Yashiro H., Yamase T. Two-Dimensional Array of Polyoxomolybdate Nanoball Constructed by Langmuir-Blodgett Semiamphiphilic Method. Chem. Mater., 2007, 19, P. 2589-2594.

[166] Fan D., Hao J. Phase stability of Keplerate-type polyoxomolybdates controlled by added cationic surfactant. J. Colloid Interface Sci., 2009, 333, P. 757-763.

[167] Car P.-E., Patzke G.R. The Fascination of Polyoxometalate Chemistry. Inorganics, 2015, 3(2), P. 511-515.

[168] Watfa N., Floquet S., Terazzi E., Salomon W., Guénée L., Buchwalder K.L., Hijazi A., Naoufal D., Piguet C., Cadot E. Synthesis, Characterization and Study of Liquid Crystals Based on the Ionic Association of the Keplerate Anion $\left[\mathrm{Mo}_{132} \mathrm{O}_{372}\left(\mathrm{CH}_{3} \mathrm{COO}\right)_{30}\left(\mathrm{H}_{2} \mathrm{O}\right)_{72}\right]^{42-}$ and Imidazolium Cations. Inorganics, 2015, 3(2), P. 246-266.

[169] Floquet, S., Terazzi E., Korenev V.S., Hijazi A., Guénée L., Cadot E. Layered ionic liquid-crystalline organisations built from nano - capsules $\left[\mathrm{Mo}_{132} \mathrm{O}_{312} \mathrm{~S}_{60}\left(\mathrm{SO}_{4}\right)_{x}\left(\mathrm{H}_{2} \mathrm{O}\right)_{132-2 x}\right]^{(12+2 x)-}$ and DODA+ cations. Liq. Cryst., 2014, 41(6), P. $1000-1007$.

[170] Kurth D.G., Lehmann P., Volkmer D., Müller A., Schwahn D. Biologically inspired polyoxometalate-surfactant composite materials. Investigations on the structures of discrete, surfactant-encapsulated clusters, monolayers, and Langmuir-Blodgett films of $(\text { DODA })_{40}\left(\mathrm{NH}_{4}\right)_{2}\left[\left(\mathrm{H}_{2} \mathrm{O}\right)_{n} \subset \mathrm{Mo}_{132} \mathrm{O}_{372}\left(\mathrm{CH}_{3} \mathrm{CO}_{2}\right)_{30} \times\left(\mathrm{H}_{2} \mathrm{O}\right)_{72}\right]$. J. Chem. Soc. Dalton Trans., 2000, 21, P. $3989-3998$.

[171] Floquet S., Terazzi E., Hijazi A., Guénée L., Piguet, C., Cadot E. Evidence of Ionic Liquid Crystal Properties for a DODA+ Salt of the Keplerate $\left[\mathrm{Mo}_{132} \mathrm{O}_{372}\left(\mathrm{CH}_{3} \mathrm{COO}\right)_{30}\left(\mathrm{H}_{2} \mathrm{O}\right)_{72}\right]^{42-}$. New J. Chem., 2012, 36, P. 865-868.

[172] Panagiotopoulos A., Douvas A.M., Argitis P., Coutsolelos A.G. Porphyrin-Sensitized Evolution of Hydrogen using Dawson and Keplerate Polyoxometalate Photocatalysts. ChemSusChem, 2016, 9, P. 3213-3219.

[173] Liu S., Tang Z. Polyoxometalate-based functional nanostructured films: Current progress and future prospects. Nano Today, 2010, 5, P. 267281.

[174] Fan D., Hao J. Fabrication and Electrocatalytic Properties of Chitosan and Keplerate-Type Polyoxometalate $\left\{\mathrm{Mo}_{72} \mathrm{Fe}_{30}\right\} \mathrm{Hybrid}$ Films. $J$. Phys. Chem. B, 2009, 113, P. 7513-7516.

[175] Tonkushina M.O., Alekseeva O.V., Agafonov A.V., Ostroushko A.A. Viscosity and Electrophysical Characteristics of Solutions Containing Nanocluster Polyoxometalates and Polyvinylpyrrolidone. Russ. J. Phys. Chem. A, 2016, 90(4), P. 838-842.

[176] Tonkushina M.O., Kraev A.S., Alekseeva O.V., Ostroushko A.A., Agafonov A.V. Effect of Polyoxomolybdate Nanocluster Doping on the Dielectric Characteristics of Polyvinyl Alcohol Nanocomposite Films. Russ. J. Inorg. Chem., 2016, 61(4), P. 477-481.

[177] Ostroushko A.A., Safronov A.P., Tonkushina M.O. Thermochemical Study of Interaction between Nanocluster Polyoxomolybdates and Polymers in Film Compositions. Russ. J. Phys. Chem. A, 2014, 88(2), P. 295-300.

[178] Ostroushko A.A., Sennikov M.Yu., Tonkushina M.O. Interaction of Polyoxometalate Mo132 with Poly(vinyl alcohol). Russ. J. Inorg. Chem., 2009, 54(4), P. 617-623.

[179] Ostroushko A.A., Gagarin I.D., Danilova I.G., Gette I.F. The use of nanocluster polyoxometalates in the bioactive substance delivery systems. Nanosystems: Physics, Chemistry, Mathematics, 2019, 10(3), P. 318-349.

[180] Cui J., Fan D., Hao J. Magnetic $\mathrm{Mo}_{72} \mathrm{Fe}_{30}$-embedded hybrid nanocapsules. J. Coll. Interface Sci., $2009,330(2)$, P. $488-492$.

[181] Zhao W., Cui J., Hao J., Van Horn J.D. Co-assemblies of polyoxometalate $\left\{\mathrm{Mo}_{72} \mathrm{Fe}_{30}\right\} /$ double-tailed magnetic surfactant for magneticdriven anchorage and enrichment of protein. J. Coll. Interface Sci., 2019, 536, P. 88-97.

[182] Ostroushko A.A., Adamova L.V., Eremina E.V., Gzhegorzhevskii K.V., Velichko E.V., Bogdanov S.G., Pirogov A.N. Thermodynamics of Acetone Sorption from Vapor Phase by Keplerate and Toroid Polyoxomolybdate Nanoclusters. Russ. J. Phys. Chem. A, 2017, 91(7), P. 13131318.

[183] Tonkushina M.O., Ostroushko A.A. Enthalpy of Mixing of Porous Nanocluster Polyoxometalates of Keplerate-Type Mo ${ }_{72} \mathrm{Fe}_{30}$ with Polyvinyl Alcohol and Polyethylene Glycol. Russ. J. Phys. Chem. A, 2017, 91(6), P. 1076-1079.

[184] Ostroushko A.A., Tonkushina M.O., Safronov A.P. New Data for Molybdenum Polyoxometallate with the Buckyball Structure Containing Acetate Groups and Compositions Based Thereon. Russ. J. Inorg. Chem., 2010, 55(5), P. 808-813.

[185] Ostroushko A.A., Gagarin I.D., Tonkushina M.O., Grzhegorzhevskii K.V., Adamova L.V., Eremina E.V., Russkikh O.V., Gette I.F., Danilova I.G., Kim G.A. The Functionalization of Nannocluster Polyoxomolybdates by Various Molecules. VIIIth Intern. Symp. "Design and Synthesis of Supramolecular Architectures", IInd Yoyuth School on Supramolecular and Coordination Chemistry. Apr. 25-29, 2016. Kazan, Russia. P. 136.

[186] Barsukov L.I. Liposomes. Soros Education J., 1998, 10, P. 2-9.

[187] Taboada P., Velasquez G., Barbosa S., Castelletto V., Nixon S.K., Yang Z., Heatley F., Hamley I.W., Mosquera V., Ashford M., Attwoodand D., Booth C. Block copolymers of ethylene oxide and phenyl glycidyl ether: Micellization, gelation and drug solubilization. Langmuir, 2005, 21, P. 5263-5271.

[188] Hamley I.W., Castelletto V., Fundin J., Crothers M., Attwoodand D., Talmon Y. Close-packing of Diblock Copolymer Micelles. Colloid Polym. Sci., 2004, 282, P. 514-517.

[189] Hamley I.W. Nanoshells and Nanotubes from Block Copolymers. Soft Matter, 2005, 1, P. 36-43.

[190] De Geest B.G., De Koker S., Sukhorukov G.B., Kreft O., Parak W.J., Skirtach A.G., Demeester J., De Smedt S.C., Hennink W.E. Polyelectrolyte microcapsules for biomedical applications. Soft Matter., 2009, 5, P. 282-291.

[191] Hernández R.M., Orive G., Murua A., Pedraz J.L. Microcapsules and microcarriers for in situ cell delivery. Adv. Drug Delivery Rev., 2010, 62, P. 711-730.

[192] Jämsä S., Mahlberg R., Holopainen U., Ropponen J., Savolainen A., Ritschkoff A.-C. Slow release of a biocidal agent from polymeric microcapsules for preventing biodeterioration. Progress in Organic Coatings, 2013, 76, P. 269-276.

[193] Zhang Y., Chan H.F., Leong K.W. Advanced materials and processing for drug delivery: the past and the future. Adv. Drug Delivery Rev., 2013, 65, P. 104-120.

[194] Kaur I.P., Singh H. Nanostructured drug delivery for better management of tuberculosis. J. Controlled Release, 2014, 184, P. 36-50.

[195] Elistratova J., Akhmadeev B., Gubaidullin A., Korenev V., Sokolov M., Nizameev I., Stepanov A., Ismaev I., Kadirov M., Voloshina A., Mustafina A. Nanoscale hydrophilic colloids with high relaxivity and low cytotoxicity based on Gd(III) complexes with Keplerate polyanions. New J. Chem., 2017, 41(13), P. 5271-5275. 
[196] Ostroushko A.A., Danilova I.G., Gette I.F., Tonkushina M.O. Behavior of Associates of Keplerate Type Porous Spherical Mo72Fe-30 Clusters with Metal Cations in Electric Field Driven Ion Transport. Russ. J. Inorg. Chem., 2015, 60(4), P. $500-504$.

[197] Ostroushko A., Gagarin I., Tonkushina M., Grzhegorzhevskii K., Russkikh O. Association of spherical porous nanocluster Keplerate-type polyoxometalate $\mathrm{Mo}_{72} \mathrm{Fe}_{30}$ with biologically active substances. Journal of Cluster Science, 2018, 29(1), P. 111-120.

[198] Ostroushko A.A., Tonkushina M.O. Destruction of Porous Spherical Mo 132 Nanocluster Polyoxometallate of Keplerate Type in Aqueous Solutions. Russ. J. Phys. Chem. A, 2016, 90(2), P. 436-442.

[199] Verhoeff A.A., Kistler M.L., Bhatt A., Pigga J., Groenewold J., Klokkenburg M., Veen S., Roy S., Liu T., Kegel W.K. Charge Regulation as a Stabilization Mechanism for Shell-Like Assemblies of Polyoxometalates. Physical Review Letters, 2007, 99(6), P. 066104.

[200] Ostroushko A.A., Zubarev A.Yu., Bublik I.V., Sennikov M.Yu., Iskakova L.Yu., Safronov A.P. Modeling and calculation of the association processes between oxygen-containing polyanions and nonionic polymers. Russ. J. Inorg. Chem., 2004, 49(7), P. 1028-1033.

[201] Ostroushko A.A. Interaction of Keplerate-Type Molybdenum-Based Porous Spherical Nanoclusters with Polymer Macromolecules. Russ. J. Inorg. Chem., 2015, 60(3), P. 387-391.

[202] Ostroushko A.A., Danilova I.G., Tonkushina M.O., Medvedeva S.Yu., Gette I.F., Mukhlynina E.A., Prokofieva A.V., Morozova M.V., Russkikh O.V. Toxicity Studying of Polyoxometalat $\mathrm{Mo}_{72} \mathrm{Fe}_{30}$, Possibilities of Its Transport in Organism and Interactions with other Substances. Congress and Exhibition on Advanced Materials and Processes. 25.-27. Sept. 2012, Darmstadt, Germany. F2-1098.

[203] Cedervall T., Lynch I., Lindman S., Berggard T., Thulin E., Nilsson H., Dawson K.A., Linse S. Understanding the nanoparticle-protein corona using methods to quantify exchange rates and affinities of proteins for nanoparticles. Proc. Natl Acad. Sci. USA, 2007, 104, P. $2050-2055$.

[204] Lundqvist M., Stigler J., Elia G., Lynch I., Cedervall T., Dawson K.A. Nanoparticle size and surface properties determine the protein corona with possible implications for biological impacts Proc. Natl Acad. Sci. USA, 2008, 105, P. 14265-14270.

[205] Casals E., Pfaller T., Duschl A., Oostingh G.J., Puntes V. Quantitative study of protein coronas on gold nanoparticles with different surface modifications. ACS Nano, 2010, 4, P. 3623-3632.

[206] Docter D., Westmeier D., Markiewicz M., Stolte S., Knauer S.K., Stauber R.H. The nanoparticle biomolecule corona: lessons learned challenge accepted? Chem. Soc. Rev., 2015, 44, P. 6094-6121.

[207] Walkey C.D., Olsen J.B., Song F., Liu R., Guo H., Olsen D.W.,Cohen Y., Emili A., Chan W.C. Protein corona fingerprinting predicts the cellular interaction of gold and silver nanoparticles. ACS Nano, 2014, 8, P. 2439-2455.

[208] Arcamone F., Cassinelli G., Franceschi G., Penco S., Pol C., Redaelli S., Selva A. Structure and Physicochemical Properties of Adriamycin (Doxorubicin). Int. Symp. Adriamycin, 1972, P. 9-22.

[209] Arcamone F., Discovery and Development of Doxorubicin. Med. Chem. (Los. Angeles), Academic Press, New York, 1981 , P. 1-47.

[210] Arcamone F. Antitumor anthracyclines: Recent developments. Med. Res. Rev., 1984, 4, P. $153-188$.

[211] Cagel M., Grotz E., Bernabeu E., Moretton M.A., Chiappetta D.A. Doxorubicin: nanotechnological overviews from bench to bedside. Drug Discov. Today, 2017, 22, P. 270-281.

[212] Borišev I., Mrdanovic J., Petrovic D., Seke M., Jović D., Srdenović B., Latinovic N., Djordjevic A. Nanoformulations of doxorubicin: How far have we come and where do we go from here? Nanotechnology, 2018, 29, P. 33202(1-21).

[213] Gewirtz D. A critical evaluation of the mechanisms of action proposed for the antitumor effects of the anthracycline antibiotics adriamycin and daunorubicin. Biochemical pharmacology, 1999, 57(7), P. 727-741.

[214] Tacar O., Sriamornsak P., Dass C.R. Doxorubicin: An update on anticancer molecular action, toxicity and novel drug delivery systems. $J$. Pharm. Pharmacol., 2013, 65, P. 157-170.

[215] Fojtu M., Gumulec J., Stracina T., Raudenska M., Skotakova A., Vaculovicova M., Masarik M. Reduction of doxorubicin-induced cardiotoxicity using nanocarriers: a review. Current drug metabolism, 2017, 18(3), P. 237-263.

[216] Hatakeyama H., Akita H., Ishida E., Hashimoto K., Kobayashi H., Aoki T., Yasuda J., Obata K., Kikuchi H., Ishida T., Kiwada H., Harashima H. Tumor targeting of doxorubicin by anti -MT1-MMP antibody-modified PEG liposomes. Int. J. Pharm., 2007, 342, P. 194-200.

[217] Peller M., Willerding L., Limmer S., Hossann M., Dietrich O., Ingrisch M., Sroka R., Lindner L.H. Surrogate MRI markers for hyperthermiainduced release of doxorubicin from thermosensitive liposomes in tumors. J. Control. Release, 2016, 237, P. $138-146$.

[218] Haeri A., Zalba S., ten Hagen T.L.M., Dadashzadeh S., Koning G.A. EGFR targeted thermosensitive liposomes: A novel multifunctional platform for simultaneous tumor targeted and stimulus responsive drug delivery. Colloids Surfaces B Biointerfaces, 2016,146, P. 657-669.

[219] Sesarman A., Tefas L., Sylvester B., Licarete E., Rauca V., Luput L., Patras L., Banciu M., Porfire A. Anti-angiogenic and anti-inflammatory effects of long-circulating liposomes co-encapsulating curcumin and doxorubicin on $\mathrm{C}_{26}$ murine colon cancer cells, Pharmacol. Reports, 2017, 70, P. 331-339.

[220] Li Q., Tang Q., Zhang P., Wang Z., Zhao T., Zhou J., Li H., Ding Q., Li W., Hu F., Du Y., Yuan H., Chen S., Gao J., Zhan J., You J. Human epidermal growth factor receptor-2 antibodies enhance the specificity and anticancer activity of light-sensitive doxorubicin-labeled liposomes. Biomaterials, 2015, 57, P. 1-11.

[221] Xie Q., Deng W., Yuan X., Wang H., Ma Z., Wu B., Zhang X. Selenium-functionalized liposomes for systemic delivery of doxorubicin with enhanced pharmacokinetics and anticancer effect. Eur. J. Pharm. Biopharm., 2018, 122, P. 87-95.

[222] Plourde K., Derbali R.M., Desrosiers A., Dubath C., Vallée-Bélisle A., Leblond J., Aptamer-based liposomes improve specific drug loading and release. J. Control. Release, 2017, 251, P. 82-91.

[223] Park J.W. Liposome-based drug delivery in breast cancer treatment. Breast Cancer Res., 2002, 4, P. 93-97.

[224] Immordino M.L., Dosio F., Cattel L. Stealth liposomes: Review of the basic science, rationale, and clinical applications, existing and potential. Int. J. Nanomedicine, 2006, 1, P. 297-315.

[225] Gonçalves M., Mignani S., Rodrigues J., Tomás H. A glance over doxorubicin based-nanotherapeutics: From proof-of-concept studies to solutions in the market. J. Control. Release, 2020, 317, P. 347-374.

[226] Benesch M., Urban C. Liposomal cytarabine for leukemic and lymphomatous meningitis: recent developments. Expert Opin. Pharmacother., 2008, 9, P. 301-309.

[227] Yu M.K., Park J., Jon S. Targeting Strategies for Multifunctional Nanoparticles in Cancer Imaging and Therapy. Theranostics, 2012, 2(1), P. 3-44.

[228] Qu X., Yang C., Zhang J., Ding N., Lu Y., Huang L., Xiang G. In vitro evaluation of a Folate-bovine serum albumin-doxorubicin conjugate. J. Drug Targeting, 2010, 18(5), P. 351-361. 
[229] Sun J., Zhang L., Zhang Y., Yue C. W., Lin J., Wang H., Fang Z.-J., Wu J. Smart albumin-loaded Rose Bengal and doxorubicin nanoparticles for breast cancer therapy. J. microencapsulation, 2019, 36(8), P. 728-737.

[230] Park C., Meghani N., Amin H., Tran P. H. L., Tran T. T. D., Nguyen V. H., Lee B. J. The roles of short and long chain fatty acids on physicochemical properties and improved cancer targeting of albumin-based fattigation-platform nanoparticles containing doxorubicin. Int. J. Pharmaceutics, 2019, 564, P. 124-135.

[231] Kimura K., Yamasaki K., Nishi K., Taguchi K., Otagiri M. Investigation of anti-tumor effect of doxorubicin-loaded human serum albumin nanoparticles prepared by a desolvation technique. Cancer chemotherapy and pharmacology, 2019, 83(6), P. 1113-1120.

[232] Lee J.H., Moon H., Han H., Lee I.J., Kim D., Lee H.J., Ha Sh.-W., Kim H., Chung J.W. Antitumor Effects of Intra-Arterial Delivery of Albumin-Doxorubicin Nanoparticle Conjugated Microbubbles Combined with Ultrasound-Targeted Microbubble Activation on VX2 Rabbit Liver Tumors. Cancers, 2019, 11(4), P. 581.

[233] Muniswamy V.J., Raval N., Gondaliya P., Tambe V., Kalia K., Tekade R.K. 'Dendrimer-Cationized-Albumin'encrusted polymeric nanoparticle improves BBB penetration and anticancer activity of doxorubicin. Int. J. Pharmaceutics, 2019, 555, P. 77-99.

[234] Delorme V., Lichon L., Mahindad H., Hunger S., Laroui N., Daurat M., Godefroy A., Coudane J., Gary-Bobo M., Van Den Berghe H. Reverse Poly ( $\varepsilon$-caprolactone)-g-Dextran Graft Copolymers. Nano-carriers for Intracellular Uptake of Anticancer Drugs. Carbohydrate Polymers, 2019, P. 115764.

[235] Wang H., Li Z., Lu S., Li C., Zhao W., Zhao Y., Yu Sh., Wang T., Sun T. Nano micelles of cellulose-graft-poly (1-lactic acid) anchored with epithelial cell adhesion antibody for enhanced drug loading and anti-tumor effect. Materials Today Communications, 2020,22, P. 100764.

[236] Wang M., Yan J., Li C., Wang X., Xiong J., Pan D., Wang L., Xu Yu., Xiaotian Li Yang M. Cationic Poly (amide-imide)-Conjugated Camptothecin Prodrug with Variable Nanomorphology for Efficient Reductive-Responsive Drug Delivery. European Polymer Journal, 2019, P. 109462.

[237] Li Y., Gao F., Guo J., Ren P., Tian Z., Bai J., Hua J. Polymeric micelles with aggregation-induced emission based on microbial $\varepsilon$-polylysine for doxorubicin delivery. European Polymer Journal, 2020, 122, P. 109355.

[238] Fang J.Y., Lin Y.K., Wang S.W., Lee R.S. Synthesis, and characterization folate-conjugated photocleavable poly (4-substituted- $\varepsilon$ caprolactone) polymers for drug delivery. Int. J. Polymeric Materials and Polymeric Biomaterials, 2020, 69(1), P. 53-63.

[239] Ni G., Yang G., He Y., Li X., Du T., Xu L., Zhou S. Uniformly sized hollow microspheres loaded with polydopamine nanoparticles and doxorubicin for local chemo-photothermal combination therapy. Chemical Engineering Journal, 2020, 379, P. 122317.

[240] Liu P., Zhang R. Polymer microspheres with high drug-loading capacity via dual-modal drug-loading for modulating controlled release property in $\mathrm{pH} /$ reduction dual-responsive tumor-specific intracellular triggered doxorubicin release. Colloids and Surfaces A: Physicochemical and Engineering Aspects, 2019, 577, P. 291-295.

[241] Jiang J., Li J., Zhou B., Niu C., Wang W., Wu W., Liang J. Fabrication of Polymer Micelles with Zwitterionic Shell and Biodegradable Core for Reductively Responsive Release of Doxorubicin. Polymers, 2019, 11(6), P. 1019.

[242] Banerjee D., Bose S. Effects of polymer chemistry, concentration, and pH on doxorubicin release kinetics from hydroxyapatite-PCL-PLGA composite. Journal of Materials Research, 2019, 34(10), P. 1692-1703.

[243] Tan Y., Yang X., Dai S., Lian K., Wen L., Zhu Y., Meng T., Liu X., Yuan H., Hu F. In vivo programming of tumor mitochondria-specific doxorubicin delivery by a cationic glycolipid polymer for enhanced antitumor activity. Polymer Chemistry, 2019, 10(4), P. 512-525.

[244] Butowska K., Kozak W., Zdrowowicz M., Makurat S., Rychłowski M., Hać A., Anna Herman-Antosiewicz A., Piosik J., Rak J. Cytotoxicity of doxorubicin conjugated with $\mathrm{C}_{60}$ fullerene. Structural and in vitro studies. Structural Chemistry, 2019, 30(6), P. $2327-2338$.

[245] Grebinyk A., Prylutska S., Grebinyk S., Prylutskyy Y., Ritter U., Matyshevska O., Dandekar T., Frohme M. Complexation with C60 Fullerene Increases Doxorubicin Efficiency against Leukemic Cells In Vitro. Nanoscale research letters, 2019, 14(1), P. 61.

[246] Kepinska M., Kizek R., Milnerowicz H. Fullerene as a doxorubicin nanotransporter for targeted breast cancer therapy: Capillary electrophoresis analysis. Electrophoresis, 2018, 39(18), P. 2370-2379.

[247] Petrovic D., Seke M., Borovic M. L., Jovic D., Borisev I., Srdjenovic B., Rakocevic Z., Pavlovic V., Djordjevic A. Hepatoprotective effect of fullerenol/doxorubicin nanocomposite in acute treatment of healthy rats. Experimental and molecular pathology, 2018, 104(3), P. 199-211.

[248] Zhou Y., Li J., Ma H., Zhen M., Guo J., Wang L., Jiang L., Shu C., Wang C. Biocompatible [60]/[70] Fullerenols: Potent Defense against Oxidative Injury Induced by Reduplicative Chemotherapy. ACS applied materials \& interfaces, 2018, 9(41), P. 35539-35547.

[249] Grebinyk A., Prylutska S., Chepurna O., Grebinyk S., Prylutskyy Y., Ritter U., Ohulchanskyy T. Y., Matyshevska O., Dandekar T., Frohme M. Synergy of chemo-and photodynamic therapies with $\mathrm{C}_{60}$ fullerene-doxorubicin nanocomplex. Nanomaterials, 2019, 9(11), P. 1540.

[250] Ramalingam V., Varunkumar K., Ravikumar V., Rajaram R. Target delivery of doxorubicin tethered with PVP stabilized gold nanoparticles for effective treatment of lung cancer. Sci. Rep., 2018, 8, P. 1-12.

[251] Chen W.-H., Xu X.-D., Jia H.-Z., Lei Q., Luo G.-F., Cheng S.-X., Zhuo R.-X., Zhang X.-Z. Therapeutic nanomedicine based on dualintelligent functionalized gold nanoparticles for cancer imaging and therapy in vivo. Biomaterials, 2013, 34, P. 8798-8807.

[252] Prabaharan M., Grailer J.J., Pilla S., Steeber D.A., Gong S. Gold nanoparticles with a monolayer of doxorubicin-conjugated amphiphilic block copolymer for tumor-targeted drug delivery. Biomaterials, 2009, 30, P. 6065-6075.

[253] Elbialy N.S., Fathy M.M., Khalil W.M. Doxorubicin loaded magnetic gold nanoparticles for in vivo targeted drug delivery. Int. J. Pharm., 2015, 490, P. 190-199.

[254] Jeon S., Ko H., Vijayakameswara Rao N., Yoon H.Y., You D.G., Han H.S., Um W., Saravanakumar G., Park J.H. A versatile gold cross-linked nanoparticle based on triblock copolymer as the carrier of doxorubicin. R. Soc. Chem. Adv., 2015, 5, P. 70352-70360.

[255] Benyettou F., Rezgui R., Ravaux F., Jaber T., Blumer K., Jouiad M., Motte L., Olsen J.-C., Platas-Iglesias C., Magzoub M., Trabolsi A. Synthesis of silver nanoparticles for the dual delivery of doxorubicin and alendronate to cancer cells. J. Mater. Chem., 2015, B. 3, P. 72377245.

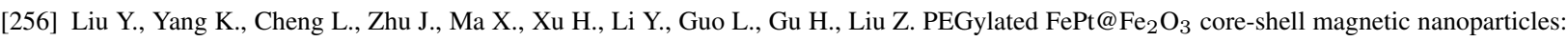
Potential theranostic applications and in vivo toxicity studies. Nanomedicine Nanotechnology, Biol. Med., 2013, 9, P. 1077-1088.

[257] Gaihre B., Khil M.S., Lee D.R., Kim H.Y. Gelatin-coated magnetic iron oxide nanoparticles as carrier system: Drug loading and in vitro drug release study. Int. J. Pharm., 2009, 365, P. 180-189.

[258] Hałupka-Bryl M., Asai K., Thangavel S., Bednarowicz M., Krzyminiewski R., Nagasaki Y. Synthesis and in vitro and in vivo evaluations of poly(ethylene glycol)-block-poly(4-vinylbenzylphosphonate) magnetic nanoparticles containing doxorubicin as a potential targeted drug delivery system. Colloids Surfaces B Biointerfaces, 2014, 118, P. 140-147. 
[259] Nadeem M., Ahmad M., Akhtar M.S., Shaari A., Riaz S., Naseem S., Masood M., Saeed M.A. Magnetic properties of polyvinyl alcohol and doxorubicine loaded iron oxide nanoparticles for anticancer drug delivery applications. PLoS One, 2016, 11, P. 1-12.

[260] Kayal S., Ramanujan R.V. Doxorubicin loaded PVA coated iron oxide nanoparticles for targeted drug delivery. Mater. Sci. Eng., 2010, 30, P. 484-490.

[261] Grzhegorzhevskii K.V., Tonkushina M.O., Fokin A.V., Belova K.G., Ostroushko A.A. Coordinative interaction between nitrogen oxides and ironmolybdenum POM Mo72 $\mathrm{Fe}_{30}$. Dalton Transactions, 2019, 48(20), P. 6984-6996.

[262] McCleverty J.A., Chemistry of nitric oxide relevant to biology. Chem. Rev., 2004, 104(2), P. $403-418$.

[263] Akaike T., Maeda H. Nitric oxide and virus infection. Immunology, 2000, 101(3), P. 300-308.

[264] Ignarro LJ. Preface to this special journal issue on nitric oxide chemistry and biology. Arch. Pharm. Res., 2009, 32(8), P. 1099-1101.

[265] Cattaneo D., Warrender S.J., Duncan M.J., Castledine R., Parkinson N., Haley I., Morris R.E. Water based scale-up of CPO-27 synthesis for nitric oxide delivery. Dalt. Trans., 2016, 45(2), P. 618-629.

[266] Lakomkin V.L., Abramov A.A., Ruuge E.K., Kapel'ko V.I., Chazov E.I., Vanin A.F. The hypotensive effect of the nitric monoxide donor Oxacom at different routs of its administration to experimental animals. Eur. J. Pharm., 2015, 765, P. 525-532.

[267] McCleverty J.A. Chemistry of Nitric Oxide Relevant to Biology. Chem. Rev., 2004, 104, P. 403-418.

[268] Aldoshin S.M., Lysenko K.A., Antipin M.Yu., Sanina N.A., Gritsenko V.V. Precision X-ray study of mononuclear dinitrosyl iron complex $\left[\mathrm{Fe}\left(\mathrm{SC}_{2} \mathrm{H}_{3} \mathrm{~N}_{3}\right)\left(\mathrm{SC}_{2} \mathrm{H}_{2} \mathrm{~N}_{3}\right)(\mathrm{NO})_{2}\right] \cdot 0.5 \mathrm{H}_{2} \mathrm{O}$ at low temperatures. J. Molec. Struct., 2008, 875, P. 309-315.

[269] Roudneva T.N., Syrtsova L.A., Sanina N.A., Shkondina N.I., Kotel'nikov A.I., Aldoshin S.M. Formation of iron nitrosyl complexes of ferriand ferrocytochrome $\mathrm{C}$ at its interaction with nitrosyl iron complex cysaconite. Nitric Oxide: Biology and Chemistry, $2010,22, \mathrm{P} .546$.

[270] Timoshin A.A., Lakomkin V.L., Abramov A.A., Ruuge E.K., Vanin A.F. Effect of dinitrosyl iron complexes on NO level in rat organs during endotoxin shock. Doklady Biochemistry and Biophysics, 2015, 462(1), P. 166-168.

[271] Andreyev-Andriyevsky A.A., Mikoyan V.D., Serezhenkov V.A., Vanin A.F. Penile erectile activity of dinitrosyl iron complexes with thiolcontaining ligands. Nitric Oxide - Biology and Chemistry, 2011, 24(4), P. 217-223.

[272] Shumaev K.B., Kosmachevskaya O.V., Timoshin A.A., Vanin A.F., Topunov A.F. Globins and other nitric oxide-reactive proteins. Dinitrosyl iron complexes bound with haemoglobin as markers of oxidative stress. Methods in Enzymology, 2008, 436, P. 441-457.

[273] Vanin A.F., Sanina N.A., Serezhenkov V.A., Burbaev D.Sh., Lozinsky V.I., Aldoshin S.M. Dinitrosyl-iron complexes with thiol-containing ligands: Spatial and electronic structures. Nitric Oxide - Biology and Chemistry, 2007, 16(1), P. 82-93.

[274] Kurtikyan T.S., Martirosyan G.G., Lorkovic I.M., Ford P.C. Comparative IR Study of Nitric Oxide Reactions with Sublimed Layers of Iron(II)- and Ruthenium(II)-meso-Tetraphenylporphyrinates. J. Am. Chem. Soc., 2002, 124, P. 10124-10129.

[275] Atsutoshi Y., Han J.E., Karlin K.D., Nam W. An isoelectronic NO dioxygenase reaction using a nonheme iron(III)-peroxo complex and nitrosonium ion. Chem. Commun., 2014, 50, P. 1742-1744.

[276] Müller A., Plass W., Krickemeyer E., Dillinger S., Bögge H., Armatage A., Proust A., Beugholt Ch., Bergmann U. $\left[\mathrm{Mo}_{57} \mathrm{Fe}_{6}(\mathrm{NO})_{6} \mathrm{O}_{174}(\mathrm{OH})_{3}(\mathrm{H} 2 \mathrm{O})_{41}\right]^{15-}$ : A Highly Symmetrical Giant Cluster with an Unusual Cavity and the Possibility of Positioning Paramagnetic Centers on Extremely Large Cluster Surfaces. Angew. Chem. Int. Ed. Engl., 1994, 33(8), P. 849-851.

[277] Müller A., Krickemeyer E., Dillinger S., Bögge H., Plass W., Proust A., Dloczik L., Menke C., Meyer J., Rohlfing R. New Perspectives in Polyoxometalate Chemistry by Isolation of Compound Containing Very Large Moieties as Transferable Building Blocks: $\left(\mathrm{NMe}_{4}\right)_{5}\left[\mathrm{As}_{2} \mathrm{Mo}_{8} \mathrm{~V}_{4} \mathrm{AsO}_{40}\right] \cdot 3 \mathrm{H}_{2} \mathrm{O}, \quad\left(\mathrm{NH}_{4}\right)_{21}\left[\mathrm{H}_{3} \mathrm{Mo}_{57} \mathrm{~V}_{6}\left(\mathrm{NO}_{6} \mathrm{O}_{183}\left(\mathrm{H}_{2} \mathrm{O}\right)_{18}\right] \cdot 65 \mathrm{H}_{2} \mathrm{O}\right.$, $\left(\mathrm{NH}_{2} \mathrm{Me}_{2}\right)_{18}\left(\mathrm{NH}_{4}\right) 6\left[\mathrm{Mo}_{5} \mathrm{~V}_{6}(\mathrm{NO})_{6} \mathrm{O}_{183}\left(\mathrm{H}_{2} \mathrm{O}\right)_{18}\right] \cdot 14 \mathrm{H}_{2} \mathrm{O}$ and $\left(\mathrm{NH}_{4}\right)_{12}\left[\mathrm{Mo}_{36}\left(\mathrm{NO}_{4} \mathrm{O}_{108}\left(\mathrm{H}_{2} \mathrm{O}\right)_{16}\right] \cdot 33 \mathrm{H}_{2} \mathrm{O}\right.$. Z. anorg. allg. Chem., 1994, 620, P. 599-619.

[278] Müller A., Krickemeyer E., et al. [Mo-154(NO) $\left.{ }_{14} \mathrm{O}_{420}(\mathrm{OH})_{28}\left(\mathrm{H}_{2} \mathrm{O}\right)_{70}\right]^{(25 \pm 5)-}$ : A Water-Soluble Big Wheel with More than 700 Atoms and a Relative Molecular Mass of About 24 000. Angew. Chem. Int. Ed. Engl., 1995, 34(19), P. 2122-2124.

[279] Matsumoto T., Nakamura I., Ishiguro K., Tsunashima R. Concentration Dependent Stability of Fullerene-Shaped Metal-Oxide Nanocluster $\left\{\mathrm{Mo}_{132}\right\}$ in Aqueous Solution. Sci. Adv. Mat., 2014, 6, P. 1-5.

[280] Grzhegorzhevskii K.V., Zelenovskiy P.S., Koryakova O.V., Ostroushko A.A. Thermal destruction of giant polyoxometalate nanoclusters: a vibrational spectroscopy study. Inorg. Chim. Acta, 2019, 489, P. 287-300.

[281] Ostroushko A.A., Tonkushina M.O., et al. Study of the stability of solid polyoxometalate Mo72 $\mathrm{Fe}_{30}$ with a buckyball structure. Russ. J. Inorg. Chem., 2012, 57(6), P. 858-863.

[282] Ostroushko A.A., Tonkushina M.O., Safronov A.P., Men'shikov S.Yu., Korotaev V.Yu. Thermal Behavior of Polyoxometalate Mo 132 . Russ. J. Inorg. Chem., 2009, 54(2), P. 172-179.

[283] Ostroushko A.A., Sennikov M.Yu. Polythermal Study of Electrophysical Characteristics of Poly(vinyl alcohol) Polymer-Salt Films. Russ. J. Inorg. Chem., 2009, 54(1), P. 115-120.

[284] Bielan'ski A., Małecka-Luban'ska A., Micek-Ilnicka A., Müller A., Diemann E. Thermal properties of $\left(\mathrm{NH}_{4}\right)_{32}\left[\mathrm{Mo}_{138} \mathrm{O}_{416} \mathrm{H}_{6}\left(\mathrm{H}_{2} \mathrm{O}\right)_{58}\left(\mathrm{CH}_{3} \mathrm{COO}\right)_{6}\right] \cdot$ approximately $250 \mathrm{H}_{2} \mathrm{O}$ : on the route to prove the complexity of a nanostructured landscape-especially with different type of $\mathrm{H}_{2} \mathrm{O}$ ligands-embedded in an 'ocean' of water molecules. Inorg. Chim. Acta, $2002,338, \mathrm{P}$. 7-12.

[285] Bielan'ski A., Małecka-Luban'ska A., Micek-Ilnicka A., Diemann E. Thermal stability of giant wheel type polyoxomolybdates and their derivatives. J. Molec. Struct., 2006, 365, P. 55-65.

[286] Ostroushko A.A., Korotayev V.Yu., Tonkushina M.O., Grzhegorzhevskii K., Vazhenin V.A., Kutyashev I.B., Martynova N.A., Men'shikov S.Yu., Selezneva N.V. Electrotransport, Sorption, and Photochemical Properties of Nanocluster Polyoxomolibdates with a Toroidal Structure. Russ. J. Phys. Chem. A, 2012, 86(8), P. 1268-1273.

[287] Müller A., Diemann E., Kuhlmann Ch., Eimer W., Serain C., Tak T., Knochel A., Pranzas P.K. Hierarchic patterning: architectures beyond 'giant molecular wheels'. Chem. Commun., 2001, 19, P. 1928-1929.

[288] Kistler M.L., Liu T., Gouzerh P., Todea A.-M., Müller A. Molybdenum-oxide based unique polyprotic nanoacids showing different deprotonations and related assembly processes in solution. Dalton Trans., 2009, 26, P. 5094-5100.

[289] Liu T. An Unusually Slow Self-Assembly of Giant Inorganic Ions in Aqueous Solution, J. Am. Chem. Soc., 2003, 125, P. $312-313$.

[290] Liu T. Surfactant-Induced Trans-Interface Transportation and Complex Formation of Giant Polyoxomolybdate Clusters, J. Clust. Sci. (Achim Müller Issue), 2003, 14, P. 215-226.

[291] Liu, G., Liu T. Thermodynamic properties of the unique self-assembly of $\mathrm{Mo}_{72} \mathrm{Fe}_{30}$ inorganic macro-ions in salt-free and salt-containing aqueous solutions. Langmuir, 2005, 21(7), P. 2713-2720. 


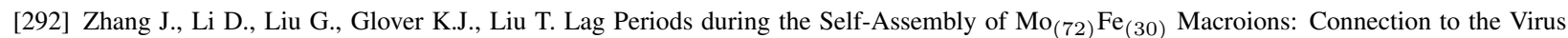
Capsid Formation Process. J. Am. Chem. Soc., 2009, 131, P. 15152-15159.

[293] Steinfeld J.I., Francisco J.S., Hase W.L. Chemical Kinetics and Dynamics, 2nd Edition., Prentice Hall. 1998,409 pp.

[294] Stanciu I. Mechanism of autocatalytic reactions. Publisher Lap Lambert Academic Publishing. 2014, 64 pp.

[295] Ramirez W.F. Computational Methods in Process Simulation. 2nd edit. Butterworth-Heinemann. Oxford. 1997,512 pp.

[296] Müller A., Das S.K., Talismanov S., Roy S., Beckmann E., Bögge H., Schmidtmann M., Merca A., Berkle A., Allouche L., Zhou Y., Zhang L. Trapping Cations in Specific Positions in Tuneable "Artificial Cell" Channels: New Nanochemistry Perspectives. Angew. Chem. Int. Ed. Engl., 2003, 42, P. 5039-5044.

[297] Ostroushko A.A., Sennikov M.Yu., Sycheva N.S. Features of Photochemical Reactions in Polymer-Salt Compositions Containing Ammonium Heptamolybdate and Polyvinyl Alcohol. Russ. J. Inorg. Chem., 2005, 50(7), P. 1050-1054.

[298] Ostroushko A.A., Vazhenin V.A., Tonkushina M.O. Features of Thermophotoinitiated Degradation of Nanocluster Polyoxomolybdate Mo132 and Its Polymer-Containing Composites. Russ. J. Inorg. Chem., 2017, 62(4), P. 483-488.

[299] Ostroushko A.A., Tonkushina M.O., Safronov A.P., Vazhenin V.A., Artemov M.Yu. Mutual Stabilization of Components in Composites of Polyoxomolybdates of Buckyball Structure and Water-Soluble Nonionic Polymers. Russ. J. Appl. Chem., 2010, 83(2), P. 332-336.

[300] Gagarin I., Tonkushina M., Ostroushko A. Stabilization of Keplerate-type Spheric Porous Nanocluster Polyoxometalate Mo 72 Fe 30.2018 Ural Symposium on Biomedical Engineering, Radioelectronics and Information Technology (USBEREIT). IEEE sponsors: Russia (Siberia) Section. 7-8 May 2018 Yekaterinburg, Russia. P. 41-44.

[301] Ostroushko A., Grzhegorzhevskii K., Gagarin I., Danilova I., Gette I., Ulitko M., Antosyuk O., Shikhova S., Vlasov D., Belozerova K. On some opportunities of using Keplerate-type polyoxomolybdates in biomedicine // 4th Russ. Conf. on Medicinal Chemistry with intern. Participants. MedChem 2019. Abstract book. Ekaterinburg: Ural Branch of the Russian Academy of Sciences, 2019,448 p. P. 96.

[302] Grzhegorzhevskii K., Ostroushko A. The concept of novel drug relising system with feedback function based on inorganic-organic hybrid material. 4th Russ. Conf. on Medicinal Chemistry with intern. participants. MedChem 2019. Abstract book. Ekaterinburg: Ural Branch of the Russian Academy of Sciences, 2019, 448 p. P. 200.

[303] Grzhegorzhevskii K.V., Shevtsev N.S., et al. Prerequisites and prospects for the development of novel systems based on the Keplerate type polyoxomolybdates for the controlled release. Russian Chemical Bulletin, International Edition, 2020, 69(4), P. 804-814.

[304] Fazylova V., Shevtsev N., Mikhailov S., Kim G., Ostroushko A., Grzhegorzhevskii K. Fundamental aspects of xanthene dye aggregation on the surfaces of nanocluster polyoxometalates: H to J aggregate switching. Chemistry Eur. J., 2020, P. 05781.

[305] Sasaki S., Drummen G.P.C., Konishi G.C. Recent advances in twisted intramolecular charge transfer (TICT) fluorescence and related phenomena in materials chemistry. J. Mater. Chem. C, 2016, 4, P. 2731-2743.

[306] Merkushev D.A., Usoltsev S.D., Marfin Y.S., Pushkarev A.P., Volyniuk D., Grazulevicius J.V., Rumyantsev E.V. BODYPY associates in organic matrices: spectral properties, photostability and evaluation as OLED emitters. Mater. Chem. Phys., 2017, 187, P. 104-111.

[307] Arbeloa F.L., Ojeda P.R., Arbeloa I.L. Fluorescence self-quenching of the molecular forms of rhodamine B in aqueous and ethanolic solutions. J. Lumin., 1989, 44, P. 105-112.

[308] Austin J.M., Harrison I.R., Quickenden T.I. Electrochemical and photoelectrochemical properties of rhodamine B. J. Phys. Chem., 1986, 90, P. $1839-1843$.

[309] Xu S., Wang Y., Zhao Y., Chen W., Wang J., He L., Su Z., Wang E., Kang Z.J. Keplerate-type polyoxometalate/semiconductor composite electrodes with light-enhanced conductivity towards highly efficient photoelectronic devices. Mater. Chem. A, 2016, 4, P. 14025-14032.

[310] Grzhegorzhevskii K., Ostroushko A., Koriakova O., Ovchinnikova I., Kim G. Photoinduced charge transfer in the supramolecular structure based on toroid polyoxomolibdate $\mathrm{Mo}_{138}$ and xanthene dye - Rhodamine-B. Inorganica Chim. Acta, 2015, 436, P. $205-213$.

[311] Noble G.T., Stefanick J.F., et al. Ligand-targeted liposome design: challenges and fundamental considerations. Trends Biotechnol., 2014, 32, P. 32-45.

[312] Gao W., Wang J. Synthetic micro/nanomotors in drug delivery. Nanoscale, 2014, 6, P. 10486-10494.

[313] Bordat A., Boissenot T., Nicolas J., Tsapis N. Thermoresponsive polymer nanocarriers for biomedical applications. Adv. Drug Deliv. Rev., 2019, 138, P. 167-192.

[314] Patel S.G., Patel M.D., Patel A.J., Chougule M.B., Choudhury H. Solid lipid nanoparticles for targeted brain drug delivery. NanotechnologyBased Targeted Drug Delivery Systems for Brain Tumors, Elsevier, 2018, P. 191-244.

[315] Gao Y., Chen J., Zhang T., Szymanowski J.E.S., Burns P.C., Liu T. Inhomogeneous Distribution of Cationic Surfactants around Anionic Molecular Clusters. Chem. Eur. J., 2019, 25, P. 15741-15745.

[316] Niu J.-Y., You X.-Z., Chun-ying Duan C.-Y., Fun H.-K., Zhong-yuan Zhou Z.-Y.A Novel Optical Complex between an Organic Substrate and a Polyoxometalate. Crystal and Molecular Structure of $\alpha-\mathrm{H}_{4} \mathrm{SiW}_{12} \mathrm{O}_{40} \cdot 4 \mathrm{HMPA} \cdot 2 \mathrm{H}_{2} \mathrm{O}(\mathrm{HMPA}=\mathrm{Hexamethylphosphoramide})$. Inorg. Chem., 1996, 35(14), P. 4211-4217.

[317] Andreev V.N., Chudnovskii F.A., Nikitin S.E., Kozyrev S.V. Photochromic effect in MoO Clusters - Citronic acid - H ${ }_{2} \mathrm{O}$ system. Mol. Mat., 1998, 11, P. 139-142.

[318] Ostroushko A.A., Sennikov M.Yu. The Kinetics of Photochemical Processes in Polymer-Salt Systems. Russian Journal of Physical Chemistry $A, 2009, \mathbf{8 3}(1)$, P. 111-115.

[319] Yamase T. Photo- and Electrochromism of Polyoxometalates and Related Materials. Chem. Rev., 1998, 98, P. $307-325$.

[320] Bogomolova T.G. Diffusion of atmospheric oxygen into resting and moving mass of liquid (Diffuzia atmosphernogo kisloroda w pokoyashuusa i dwigushuusa massu gidkosti). Wesynik MGSU, 2009, 3, P. 205-210, (in Russian).

[321] Ostroushko A.A., Adamova L.V., et al. Studies of the Functional Properties of Nanocluster Polyoxomolybdates and Materials on Their Basis. XXI Mendeleev Congress on General and Applied Chemistry. Saint Petersburg, 2019. Abstracts. Book 2a. P. 86.

[322] Yamase T., Kurozumi T. Photoreduction of Polymolybdates in Aqueous Solutions containing Acetic Acid. J. Chem. Soc. Dalton Trans., 1983, P. 2205-2209.

[323] Boggs B.K., King R.L., Botte G.G. Urea electrolysis: direct hydrogen production from urine. Chem. Commun., 2009 , P. 4859-4861.

[324] Yamase T., Ikawa T. Photogalvanic effect in alkylammonium molybdate solutions and production of hydrogen. Inorganica Chimica Acta, 1979, 37, P. 529-531.

[325] Yamase T. Hydrogen production by ultraviolet irradiation of alkylammonium polytungstate in neutral aqueous solutions. Inorganica Chimica Acta, 1982, 64, P. 155-156. 